\title{
Lossen Rearrangement Reaction of Aromatic and Aliphatic Hydroxamates
}

\author{
By \\ Mirvat Sanaallah

\begin{abstract}
A thesis submitted to
the Faculty of Graduate Studies and Postdoctoral Affairs

in Partial Fulfillment of the Requirements for the Degree of

Master in Science
\end{abstract}

Department of Chemistry

Carleton University

Ottawa, Ontario, Canada

August 2016

${ }^{\circledR}$ Copyright 2016, Mirvat Sanaallah 


\begin{abstract}
The main goal of this research is to explore a potential of the most green and non-toxic possible route to the synthesis of industrially important chemicals, such as isocyanates and amines, based on the bio-based starting materials.

In this work, we demonstrated the synthesis of 1,4-diisocyanatobenzene and 1,4diisocyanatobutane in three steps. First step is the synthesis of hydroxamic acid, second step involves a conversion of the hydroxamic acid to its corresponding hydroxamate, and the final step is the transformation of the hydroxamate into the corresponding isocyanate by Lossen rearrangement reaction. The starting materials for PPDI and BDI are diethyl terephthalate and dimethyl adipate, respectively.
\end{abstract}

Both esters are derivatives of acids that are now available from biomass. The final products were characterized IR, NMR, MS, TGA, and DSC. 


\section{Acknowledgements}

I would like to express my greatest and deepest gratitude to my supervisor Dr. Zhi Yuan (Wayne) Wang for his support, endless guidance and continuous encouragement throughout my research work. He was at all times available for any needed help and explanation of any question in my study.

I would also like to thank Dr. Jane Gao for her endless direction and advice to overcome any obstacle in laboratory and research. In addition, to her loving and caring attitude towards me and my colleagues.

My sincere thanks also goes to my colleagues: Sukanta Kumar Saha, Khama Rani Ghosh, Saif Mia, Di Zhang and Songqiu Zhou for their great support.

In the end, I would like to express my gratitude to my beloved husband and family for the love, support, patience they gave me during my study. 


\section{List of Schemes}

Scheme I.1. Mechanism of NCO/OH reaction: a) and b) using organometallic catalysis; c) and d)

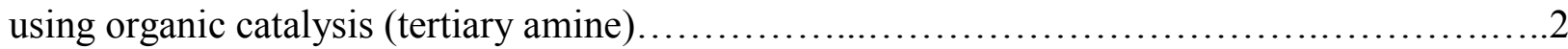

Scheme I.2. Synthesis of a) polyether polyol, b) polyester polyol PEPO, c) acrylic polyol

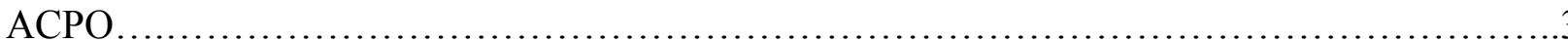

Scheme I.3. Reactions of isocyanates..............................................

Scheme I.4. Phosgenation of primary amines...........................................

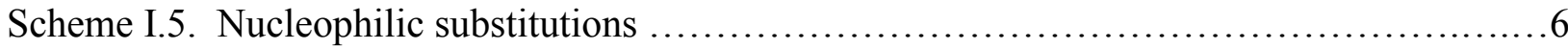

Scheme I.6. Curtius rearrangement................................................... 8

Scheme I.7. Synthesis of acyl azides............................................. 8

Scheme I.8. Curtius rearrangement in alcohol.......................................

Scheme I.9. Curtius rearrangement in water........................................ 9

Scheme I.10. Hofmann rearrangement............................................. 10

Scheme I.11. Hofmann rearrangement of succinimide................................ 10

Scheme I.12. Synthesis of methylstyrylcarbamate via Hofmann rearrangement................11

Scheme I.13. Decomposition of potassium anisoyl benzohydroxamante by Lossen

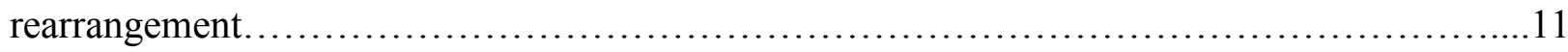

Scheme I.14. General Mechanism for Curtius, Hofmann and Lossen rearrangement...........12 
Scheme I.15. Lossen rearrangement of O-acylated hydroxamic acid 13

Scheme I.16. Conventional synthesis of hydroxamic acid using N/O-protected hydroxylamine.14

Scheme I.17. Possible routes of hydroxamic acids to the corresponding anions....

Scheme II.1. Phosgenation of p-phenylene diamine .20

Scheme II.2. Decomposition of carbamate into isocyanate

Scheme II.3. Isocyanate through synthesis of carbamate anion.

Scheme II.4. Reaction scheme for the transformation of furfural into terephthalic acid.

Scheme II.5. Overall synthesis reaction for PPDI

Scheme II.6. Proposed mechanism for PPDI formation by Lossen rearrangement reaction......24

Scheme III.1. BDI by phosgenation of tetramtheylene diamine.

Scheme III.2. Thermal decomposition of diurethanes into BDI.

Scheme III.3. Synthesis of diurethanes .45

Scheme III.4. Transforming biomass into adipic acid.

Scheme III.5. Transforming benzoate into muconic acid for synthesis of adipic acid.

Scheme III.6. Adipic acid from D-glucose.

Scheme III.7. Overall synthesis reaction for BDI. .48

Scheme III.8. Proposed reaction mechanism for BDI formation by Lossen rearrangement reaction. 


\section{List of Figures}

Figure II.1. IR spectrum of compound $\mathbf{1}$ .28

Figure II.2. IR spectrum of compound 2 .28

Figure II.3. ${ }^{1} \mathrm{H}$ NMR spectrum of compound 1 .29

Figure II.4. ${ }^{1} \mathrm{H}$ NMR spectrum of compound 2 .30

Figure II.5. Mass spectrum of compound 2 31

Figure II.6. Thermogravimetric analysis of compound 2. .31

Figure II.7. DSC of compound 2 up to $250{ }^{\circ} \mathrm{C}$ .32

Figure II.8. DSC of compound 2 up to $220^{\circ} \mathrm{C}$ .33

Figure II.9. IR spectrum of compound 3 (Method 1)... 34

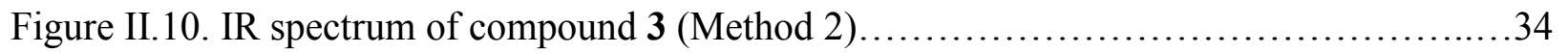

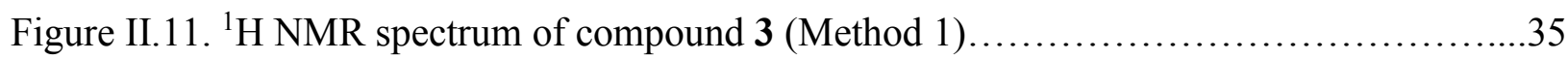

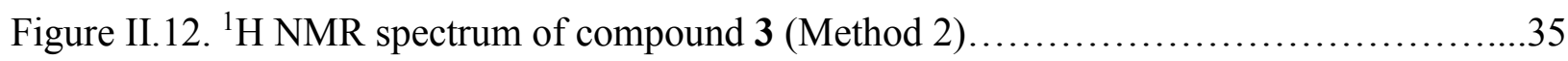

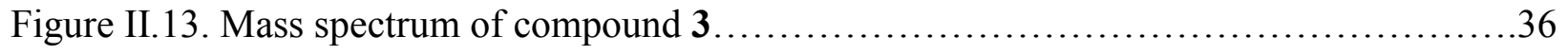

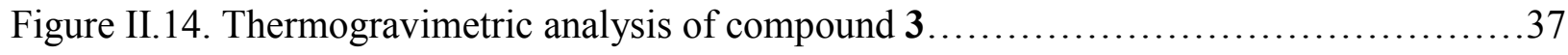

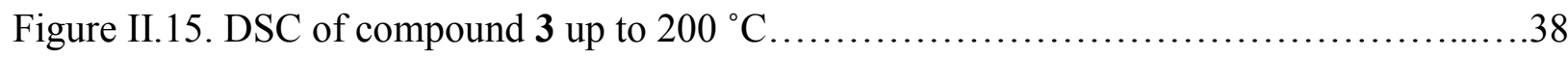

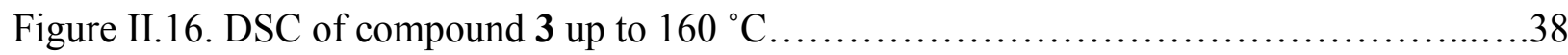

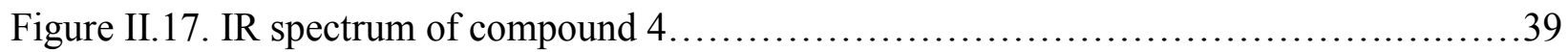


Figure II.18. ${ }^{1} \mathrm{H}$ NMR spectrum of compound 4

Figure III.1. IR spectrum of compound $\mathbf{5}$ 52

Figure III.2. IR spectrum of compound $\mathbf{6}$ 52

Figure III.3. ${ }^{1} \mathrm{H}$ NMR spectrum of compound $\mathbf{5}$. .53

Figure III.4. ${ }^{1} \mathrm{HNMR}$ spectrum of compound $\mathbf{6}$. .54

Figure III.5. Mass spectrum of compound 6 . .55

Figure III.6. Thermogravimetric analysis of compound $\mathbf{6}$ .56

Figure III.7. DSC of compound 6 up to $200{ }^{\circ} \mathrm{C}$. .57

Figure III.8. DSC of compound 6 up to $160{ }^{\circ} \mathrm{C}$. .57

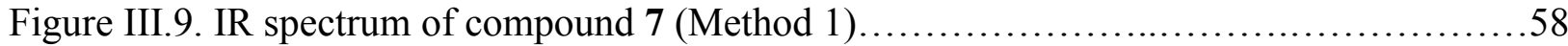

Figure III.10. IR spectrum of Compound 7 (Method 2).................................59

Figure III.11. ${ }^{1}$ HNMR spectrum of compound 7 (Method 1) .............................60

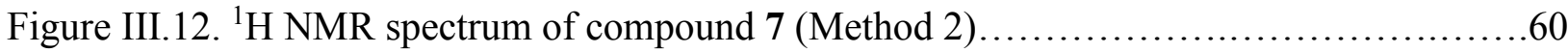

Figure III.13. Mass spectrum of compound 7..........................................61

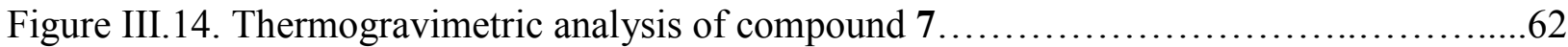

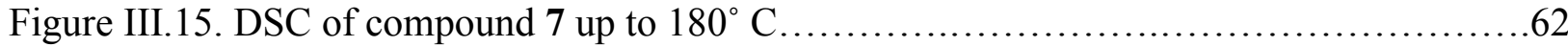

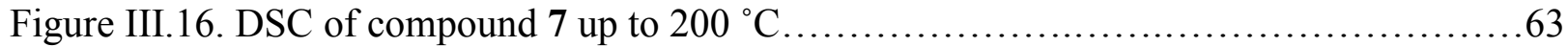




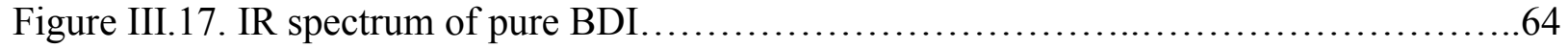

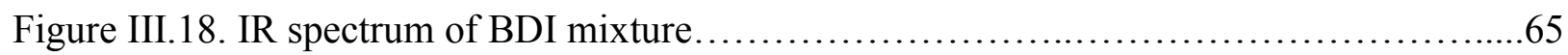

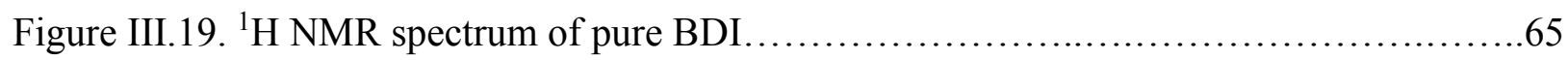

Figure III.20. ${ }^{1} \mathrm{H}$ NMR spectrum of BDI mixture......................................66 


\section{List of Abbreviations}

PU

TDI

MDI

PPDI

BDI

PPDA

TPA

AAN

DME

TMS

TGA

DSC

HA

$\mathrm{HCl}$

DMSO

IR

NMR

PPM

THF
Polyurethanes

Toluene-2,4-Diisocyanate

Methylene Diphenyl Diisocyanate

p-Phenylene Diisocyanate

1,4-Butylene Diisocyanate

p-Phenylene Diamine

Terephthalic Acid

Acetic Anhydride

Dimethoxyethane

Tetramethylsilane

Thermogravemtric Analysis

Differential Scanning Calorimetry

Hydroxamic Acid

Hydrochloric Acid

Dimethyl Sulfoxide

Infrared

Nuclear Magnetic Resonance

Part Per Million

Tetrahydrofuran 


\section{Table of Contents}

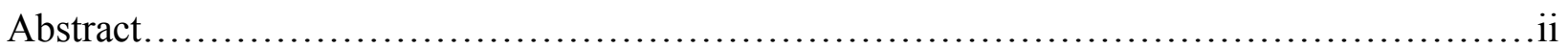

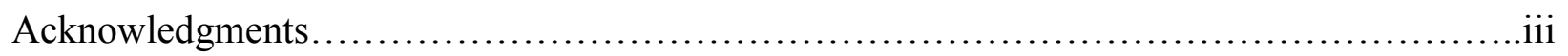

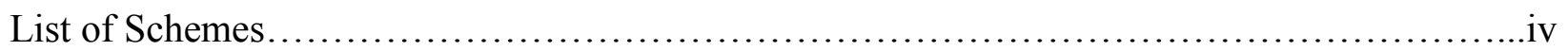

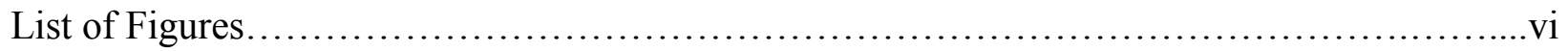

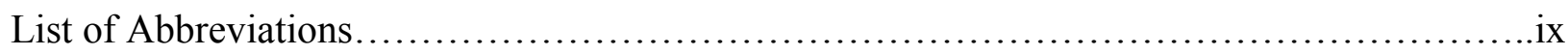

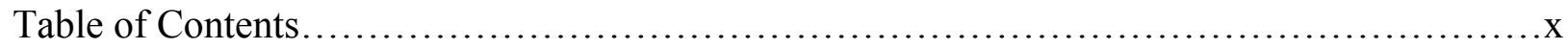

Chapter I Introduction

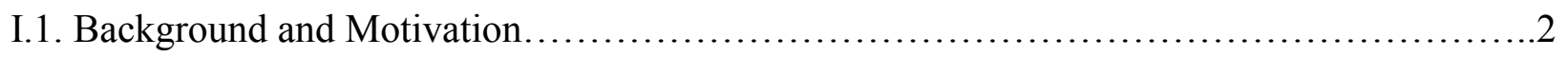

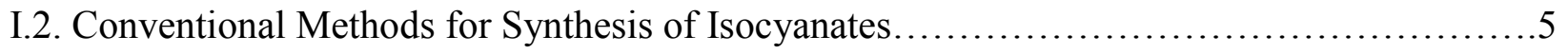

I.2.1. Phosgenation of Amines.........................................................

I.2.2. Non-Phosgenation Route.............................................. 6

i- Nucleophilic Substitutions .............................................6

ii- Rearrangement Reactions.............................................. 7

a. Curtis Rearrangement............................................... 7

b. Hoffmann Rearrangement.............................................. 9

c. Lossen Rearrangement.....................................................11

I.3. Hydroxamic Acids for Lossen Rearrangement: Synthesis and Properties....................13

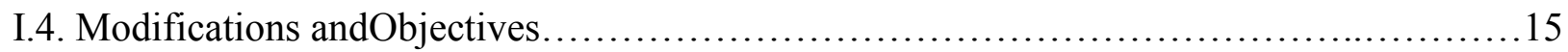

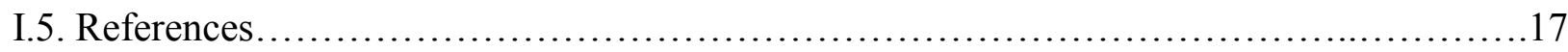

Chapter II Synthesis and Characterization of 1,4-Diisocyanatobenzene PPDI

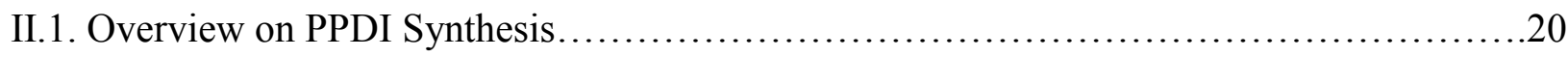

II.2. Synthesis of Bio-Based Terephthalic Acid............................................ 21

II.3. Synthesis of PPDI by Lossen Rearrangement Reaction................................23

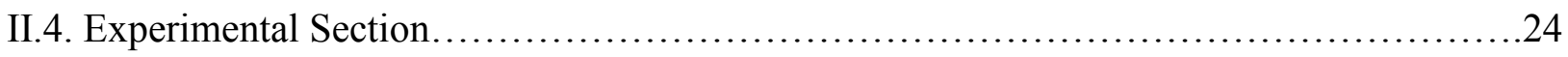


II.4.1. Materials............................................................. 24

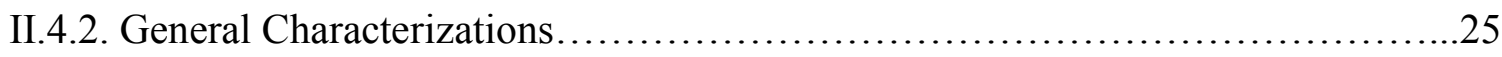

II.4.3. Syntheses......................................................... 26

II.4.4. Discussion........................................................ 28

II.5. Conclusion.............................................................41

II.6. References...........................................................42

Chapter III Synthesis and Characterization of 1,4-Diisocyanatobutane BDI

III.1. Overview on BDI Synthesis................................................ 44

III.2. Synthesis of Bio-Based Adipic Acid........................................45

III.3. Synthesis of BDI by Lossen Rearrangement Reaction...............................48

III.4. Experimental Section.................................................. 49

III.4.1. Materials ...................................................... 49

III.4.2. General Characterizations...........................................50

III.4.3. Syntheses.....................................................50

III.4.4. Discussion.......................................................52

III.5. Conclusion ..........................................................67

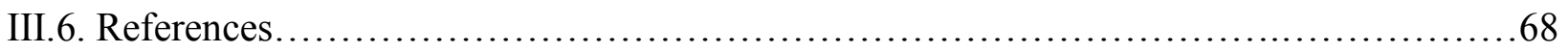




\title{
CHAPTER I
}

\author{
Introduction
}




\section{I.1. Background and Motivation}

Polyurethanes (PU), are used in various applications ranging from foams, sealants, coatings and adhesives. As any other polymer, polyurethanes are derived from petrochemical derivatives, and the main building blocks for polyurethanes are polyols and di/polyisocyanates. ${ }^{1}$ The reaction can be catalyzed using a metal catalyst or amine base.

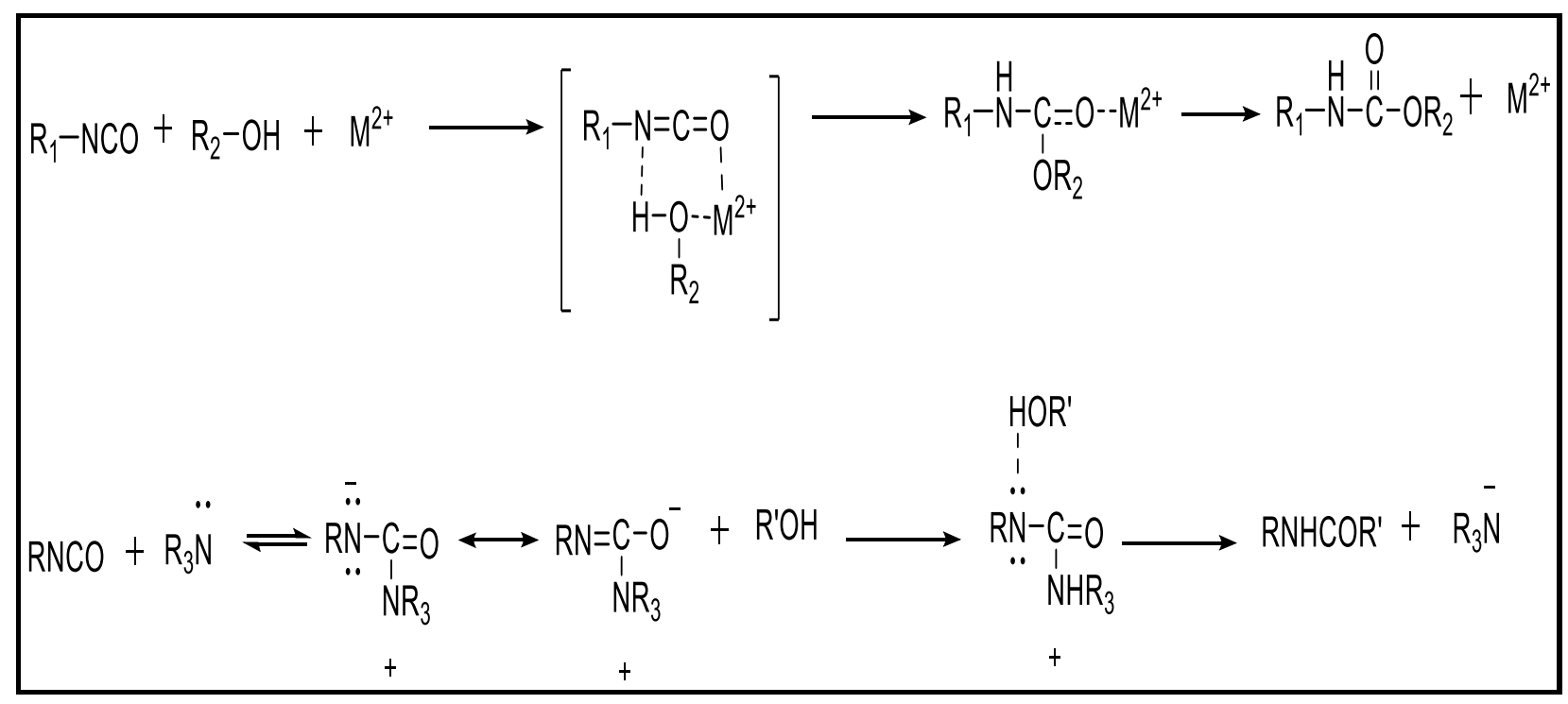

Scheme I.1. Mechanism of $\mathrm{NCO} / \mathrm{OH}$ reaction: a) and b) using organometallic catalysis; c) and d) using organic catalysis (tertiary amine). ${ }^{2}$ 
The first monomer of the polymer is the polyol, which could be a polyfunctional polyether, polyester polyol, polycarbonate polyol, etc. The simplest form of polyols that can be used in PU synthesis are 1,4-butane diol or ethylene glycol.

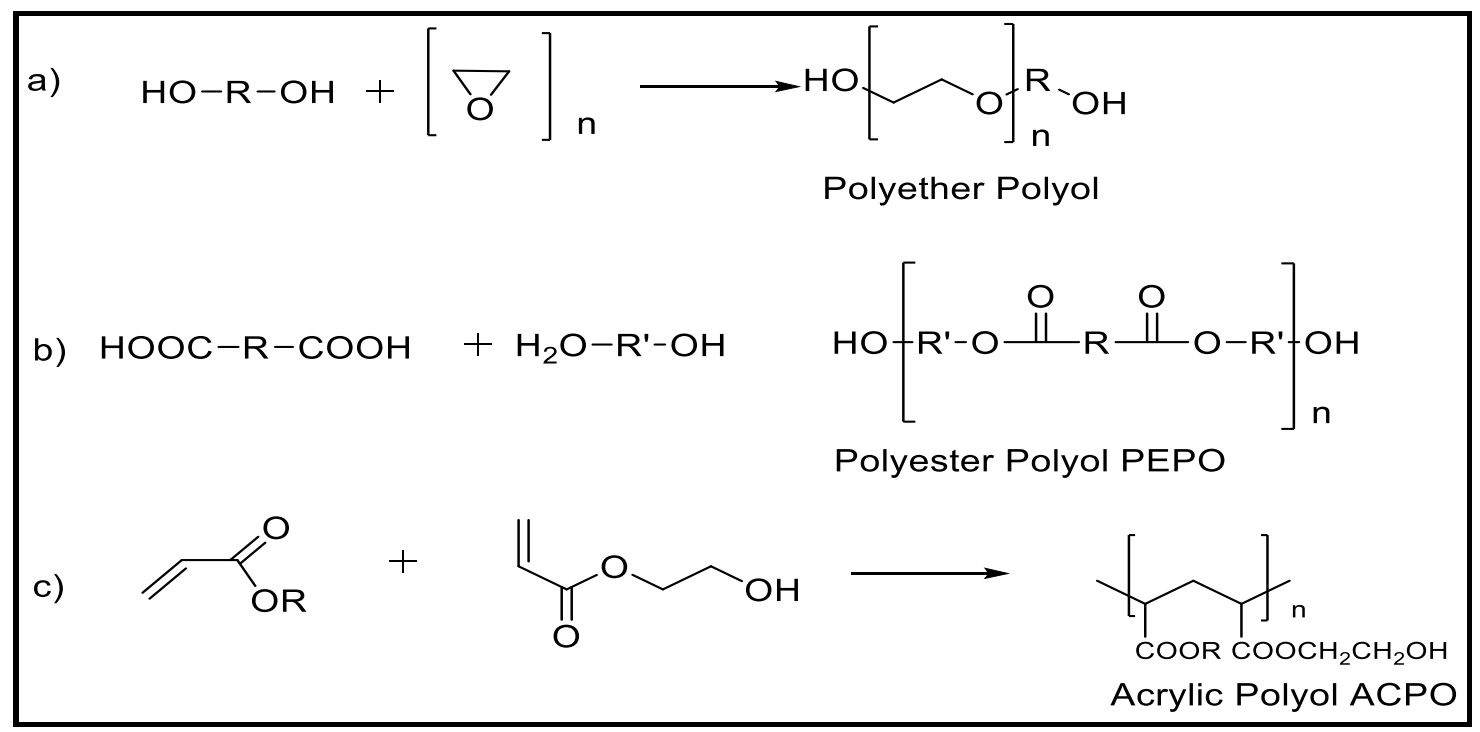

Scheme I.2. Synthesis of a) polyether polyol, b) polyester polyol PEPO, c) acrylic polyol ACPO ${ }^{2}$

Polyols with longs chain and low functionality are the soft and elastic segment of the polyurethane chain. However, polyols with shorter chains and greater functionality give more rigid and crosslinked form of the polyurethane chain.

The other building block used for the polyurethane, in which we are interested in our research, is the polyfunctional isocyanate, it can be aromatic, aliphatic or even cyclic. Examples of polyisocyanates that can be used for the synthesis of PU like toluene-2,4-diisocyanate (TDI), methylene diphenyl diisocyanate (MDI). 
Isocyanates are very reactive towards compounds having active hydrogen, such as compounds with $\mathrm{NH}$ or $\mathrm{OH}$ functional group. The reactions of isocyanates can be summarized in Scheme I.3. ${ }^{2}$

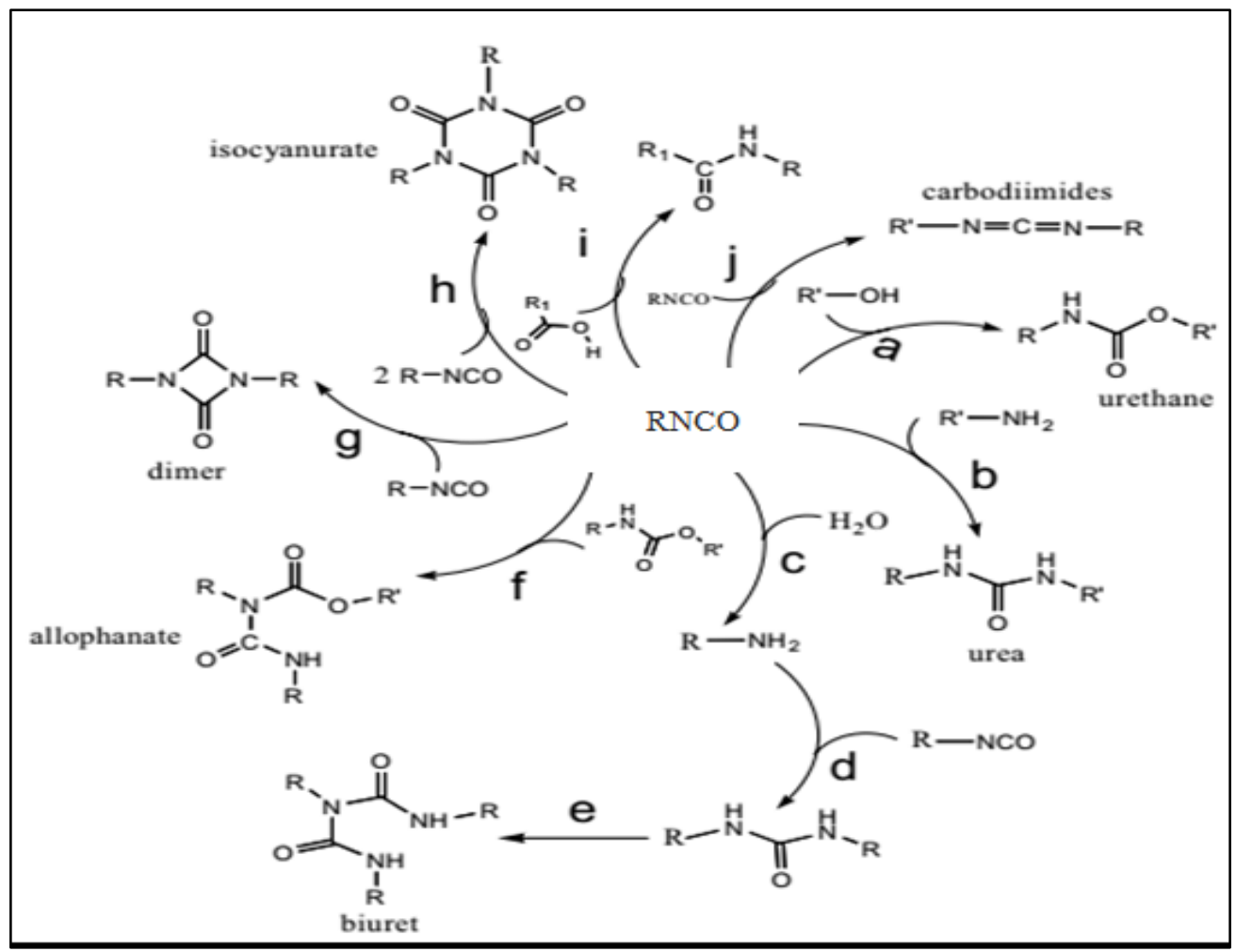

Scheme I.3. Reactions of isocyanates ${ }^{2}$

With the rise of environmental concerns, and due to the non-renewability of crude oil stock, in addition to the rise in the cost of petroleum, attention is being directed towards biomass and renewable sources such as vegetable oils and plant resources like corn and starch. ${ }^{1}$ 
Many publications were done about making bio-based polyols from vegetable oils such as castor oil. ${ }^{3}$ On the other side, very few routes were published on the synthesis of isocyanates from bio-based origin.

Therefore, in our research we are focusing on the synthesis of two types of diisocyanates, aliphatic and aromatic, in the most eco-friendly possible way and from renewable source.

\section{I.2. Conventional Methods for Synthesis of Isocyanates}

The routes for synthesizing isocyanates can be classified into two major groups, first one, which is the most industrially applied is the phosgenation route (use of phosgene $\mathrm{COCl}_{2}$ ), and the second group is composed of many different ways of synthesis, and it is called the nonphosgenation route (No use of phosgene).

\section{I.2.1. Phosgenation of Amines}

There are many routes for the synthesis of isocyanates. However, the most used in industry is the phosgenation of primary amines.

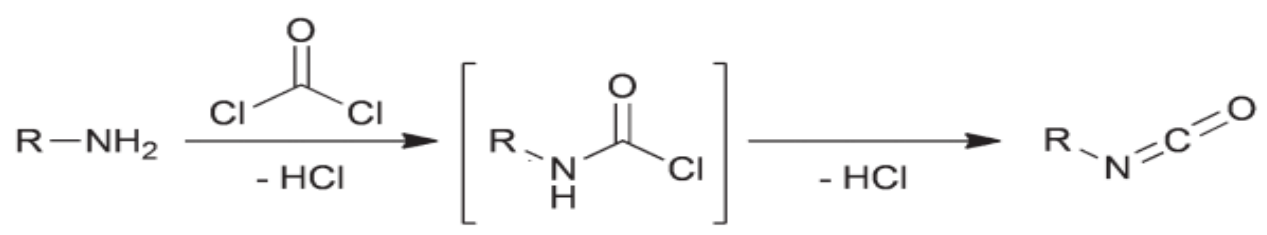

Scheme I.4. Phosgenation of primary amines ${ }^{4}$

This route was done first in 1884 by Hentschel. The reaction is done by dissolving the primary amine in a solvent, an inert solvent is used, and then the solution is treated with phosgene. ${ }^{4}$ 
In other cases, the amine is converted to a salt first by treating it with dry hydrogen chloride prior to mixing with phosgene. Many isocyanates are synthesized via phosgenation such as TDI and MDI. ${ }^{5}$

The phosgenation route has many drawbacks, such as being highly toxic due to the use of phosgene. In addition, to the yield of great amount of hydrogen chloride which is a corrosive chemical, and the reaction runs at elevated temperatures in a range greater than $200{ }^{\circ} \mathrm{C}$. Thus, it makes it inefficient for synthesizing low molecular weight products. ${ }^{6}$

\section{I.2.2. Non- Phosgenation Route}

\section{i. Nucleophilic Substitutions}

Another method for the synthesis of isocyanates is the nucleophilic substitution of halogenated organic compounds, tosylated and mesylated with metal cyanates as sodium cyanate and potassium cyanate. ${ }^{5}$

$$
\mathrm{R}-\mathrm{X}+\mathrm{M}^{+} \mathrm{NCO}^{-} \stackrel{\mathrm{S}^{2}}{\longrightarrow} \mathrm{R}_{\mathrm{N}} \mathrm{C}=\mathrm{O}
$$

Scheme I.5. Nucleophilic substitutions ${ }^{5}$

Metal cyanates were widely investigated and used for the nucleophilic substitution reactions, such as, the use of potassium cyanate KNCO to synthesize aryl carbamates in the presence of alcohol. 
However, such reaction needs a metal catalyst such as nickel, copper, or even palladium. In one published work, done by Ekaterina V. Vinogradova, Brett P. Fors and Stephen L. Buchwald, they used a palladium catalyst to transform aryl chlorides or triflates into their corresponding aryl isocyanates. $^{7}$

Another study was published in a patent by Nobuyuki Nagato and Taketoshi Naito, where it stated that tertiary alkyl isocyanates can be produced by means of nucleophilic substitution, ${ }^{8}$ which is an alternative route for phosgenation since tertiary alkyl amine are difficult to be synthesized. The isocyanates are produced upon heating tertiary alkyl halides with the metal cyanate in the presence of mineral acid salt such as zinc chloride or organic salt such as carboxylic acid salts. In this patent, zinc chloride was the chosen catalyst. The reaction was done in aprotic solvent such as chlorobenzene, dioxane, diethylene glycol diethyl ether and many other solvents.

The conversion of tertiary butyl chloride into tertiary butyl isocyanate was $97.9 \%$ and yield was $74.4 \%$. However, it was less efficient for secondary and primary alkyl halides because of their lower reactivity. ${ }^{8}$

\section{ii. Rearrangement Reactions}

\section{a. Curtius Rearrangement}

In Curtius rearrangement, an acyl azide is decomposed by pyrolysis and rearranges into an isocyanate by giving out a nitrogen molecule. ${ }^{9}$ 


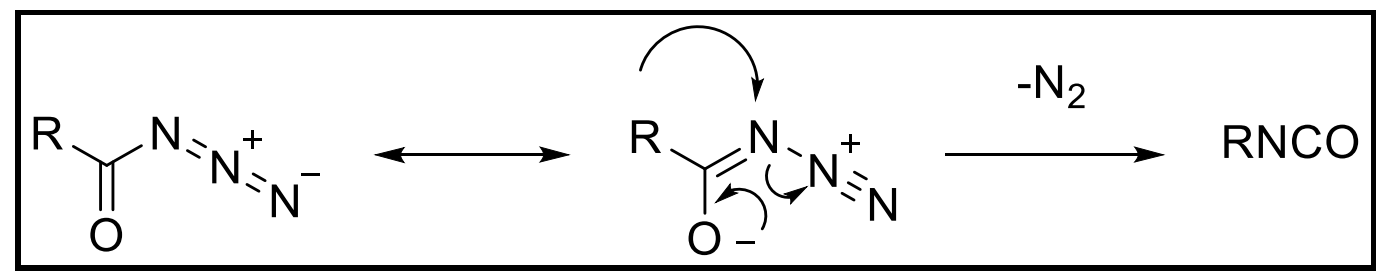

Scheme I.6. Curtius rearrangement ${ }^{9}$

Acyl azides are considered as important intermediates for the synthesis of many organic compounds such as isocyanates, amines, ureas and carbamates. They are prepared by the reaction of acyl chlorides, or any carboxylic acid derivative, with azides. A reaction was done to synthesize acyl azides with high yield, in which carboxylic acids are mixed with Trichloroacetonitrile $\mathrm{Cl}_{3} \mathrm{CCN}$, Triphenylphosphate $\mathrm{PPh}_{3}$ and reacted with sodium azide to give acyl azides. ${ }^{10}$

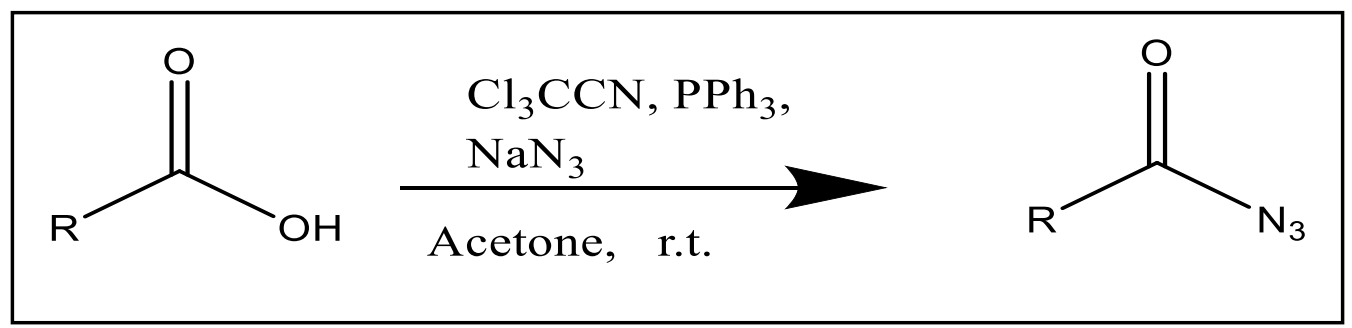

Scheme I.7. Synthesis of acyl azides ${ }^{10}$

Thus, the resulting acyl azide is decomposed in aprotic solvent, such as chloroform, in order to isolate isocyanate. However, if chloroform is substituted with alcohol, the later will react with the resulting isocyanate and give the corresponding urethane. 


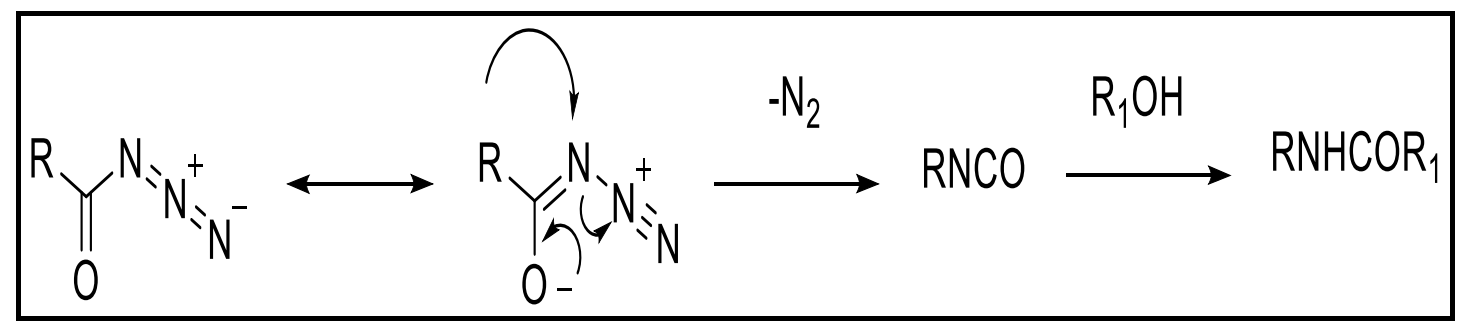

Scheme I.8. Curtius rearrangement in alcohol $^{9}$

On the other hand, if water is used as solvent, the product will be carbamic acid, that will decarboxylate, due to its instability, to give amine.

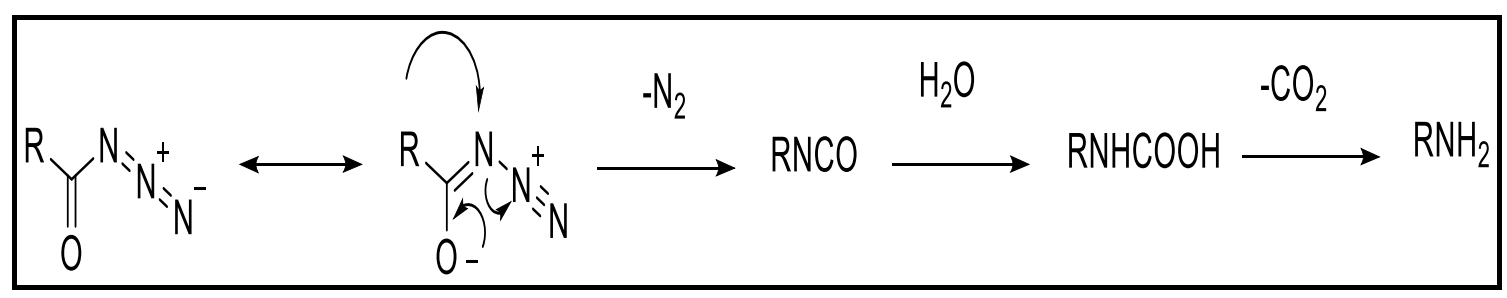

Scheme I.9. Curtius rearrangement in water. ${ }^{9}$

Although this reaction gives high yield of isocyanates, but it has a major limitation which is the explosive properties and the toxicity of azides. ${ }^{9}$

\section{b. Hofmann Rearrangement}

Hofmann Rearrangement was named after its discoverer August Wilhelm Von Hofmann. The paper was first published by Hofmann in $1881 .^{11}$

This rearrangement reaction is also a degradation reaction since the chain of the resulting amine or isocyanate intermediate is short by one carbon from the starting material which is a carboxylic acid amide. The reaction proceed by transforming the carboxylic amide into the 
corresponding amine by the action of aqueous sodium hypobromite. Sodium hypobromite is obtained by the mixing sodium hydroxide and bromine. There are two main steps in the Hofmann rearrangement. The first step involves the formation of N-bromoamide, in which it gets deprotonated. Then in the second step, the deprotonated compound loses the bromide ion to give nitrene. Thus, the obtained nitrene rearranges into an isocyanate.

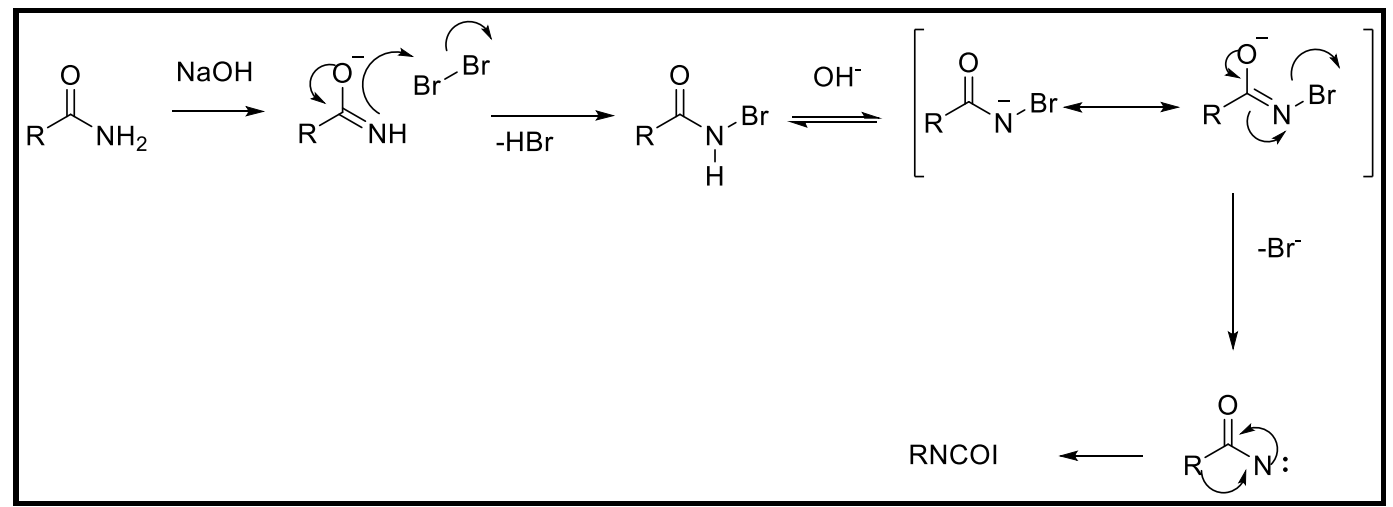

Scheme I.10. Hofmann rearrangement ${ }^{9}$

The resulting isocyanate can be obtained in anhydrous conditions, or transformed into amine by treating with water, and to urethane by treating with alcohol. Many aromatic and aliphatic amides can be transformed by the Hofmann rearrangement into their corresponding amines such as succinimide can yield $45 \% \beta$-aniline, by treating it with $\mathrm{Br}_{2}$ and aqueous potassium hydroxide.

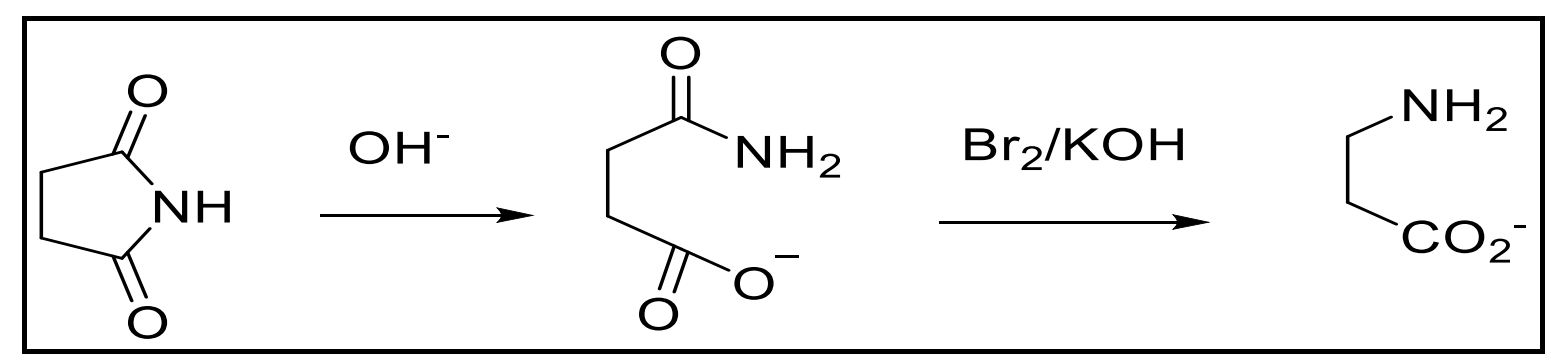

Scheme I.11. Hofmann rearrangement of succinimide ${ }^{9}$ 
Another example, unsaturated amide can give the corresponding urethane upon reacting with sodium hypochlorite in presence of methanol. ${ }^{9}$

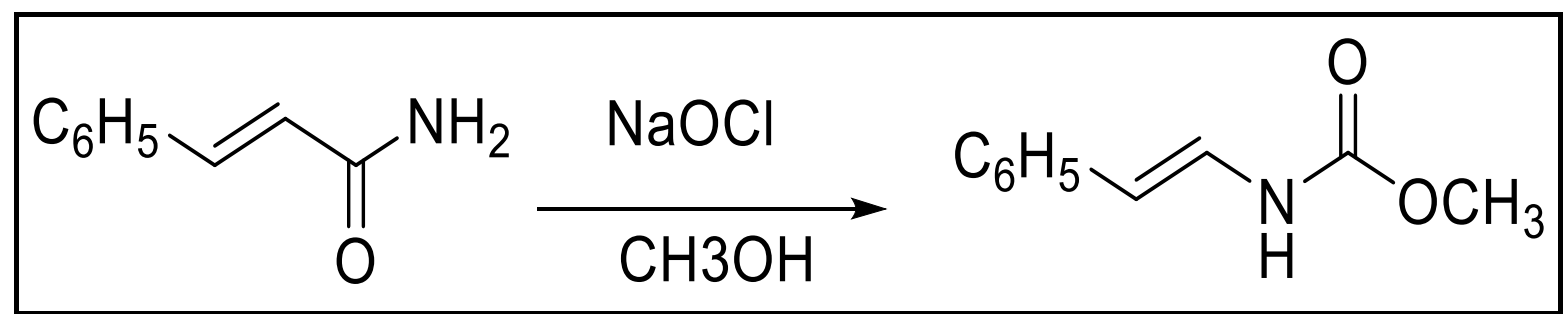

Scheme I.12. Synthesis of methylstyrylcarbamate via Hofmann rearrangement. ${ }^{9}$

However, the toxicity of bromine used in this reactions is considered as main limitations, in addition to the easy degradation of the isocyanates into amine in the presence of water. ${ }^{4}$

\section{c. Lossen Rearrangement}

Lossen rearrangement was discovered by Wilhelm Lossen in 1872, while he was heating benzoyl benzohydroxamate on its own, at a temperature higher than its melting point. He obtained a new substance which was phenyl isocyanate.

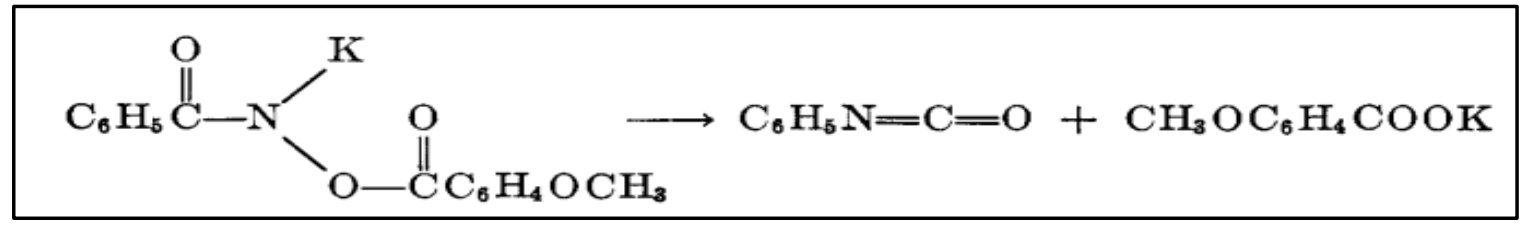

Scheme I.13. Decomposition of potassium anisoyl benzohydroxamate by Lossen rearrangement ${ }^{12}$

Afterwards, Lossen mentioned that heating potassium anisoyl benzohydroxamate in water yielded diphenylurea in addition to carbon dioxide and potassium anisoate. ${ }^{12}$ 
Curtius, Hofmann, and Lossen rearrangements can be summarized in a general reaction as follows:

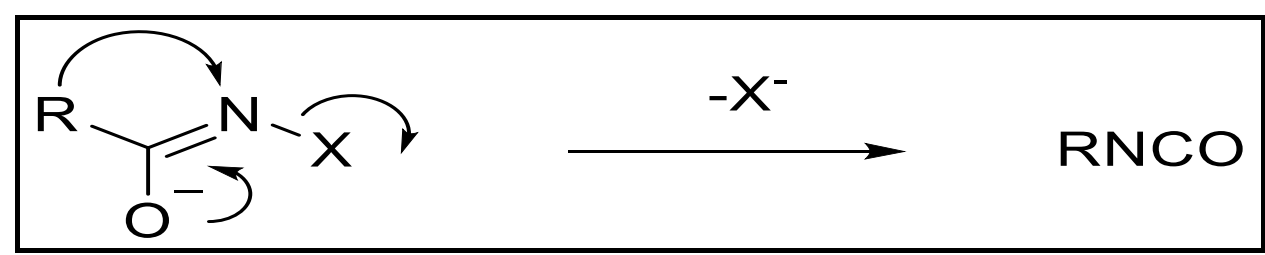

Scheme I.14. General mechanism for Curtius, Hofmann and Lossen rearrangement ${ }^{9}$

Where X, the leaving group, can be bromide ion in Hofmann, $\mathrm{N}_{2}{ }^{+}$in Curtius, and carboxylate ion in Lossen, and $\mathrm{R}$ is the alkyl group. ${ }^{9}$

Lossen rearrangement usually occurs with mixed anhydrides or hydroxamic acid derivatives and salts. However, it doesn't occur with hydroxamic acid on its own. Hence, Oacylation of hydroxamic acid is required to facilitate its rearrangement into isocyanates, ureas, or carbamates.

In the rearrangement, the carboxylate group departs and the $\mathrm{R}$ group is dislocated from carbon atom to nitrogen group. ${ }^{13}$

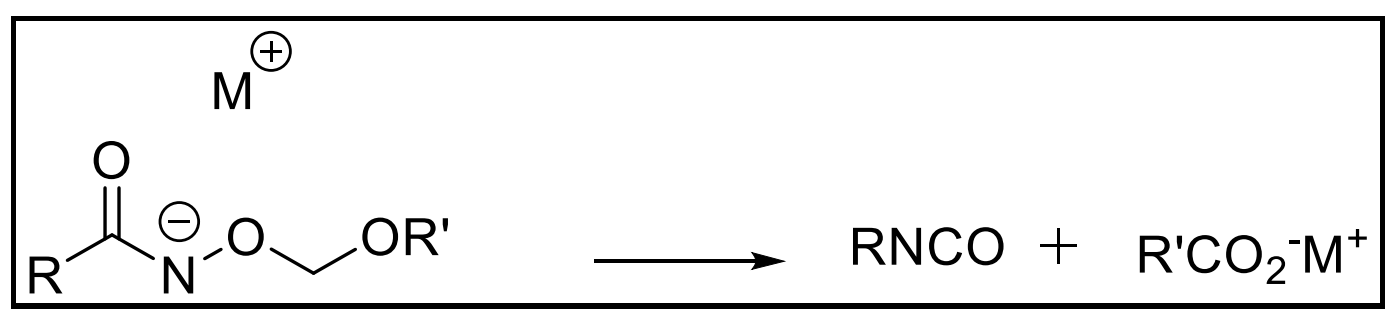

Scheme I.15. Lossen Rearrangement of O-Acylated Hydroxamic acid ${ }^{17}$ 
The activation of O-position of hydroxamic acid not only occurs by acetylation, it can occur using sulfonyl chloride derivatives. However, the by products are more harsh such as sulfonic acids and sulfur dioxide gas. Hence, O-acetylation will give less acidic product and less harmful. ${ }^{17}$

Thus, we considered to study the Lossen rearrangement and modify it, in addition to the use of hydroxamic acids in the rearrangement, in which they are non-toxic and used in the medical field as well.

\section{I.3. Hydroxamic Acids for Lossen Rearrangement: Synthesis and Properties}

Hydroxamic acids were first introduced in 1869 by H. Lossen, where he isolated oxalohydroxamic acid as a product from the reaction of hydroxylamine and ethyl oxalate. ${ }^{13}$

Hydroxamic acids are widely used in the biological field. They form complexes with metals such as iron, in which these complexes possess antibacterial and antifungal properties. For example, many hydroxamic acid complexes, siderphores, are used to treat iron metabolism disorders, such as desferrioxamine, that is used as a drug to treat Cooley's anemia. ${ }^{14}$

Conventionally, hydroxamic acids are obtained by the reaction of carboxylic acids with N/O- protected hydroxylamines. ${ }^{15}$ Such as, the reaction of N/O-bisprotected hydroxylamine, N-

BOC-O-THF hydroxylamine, with carboxylic acid chloride at $0^{\circ} \mathrm{C}$ in acetonitrile under basic conditions such as use of triethylamine as a base. 


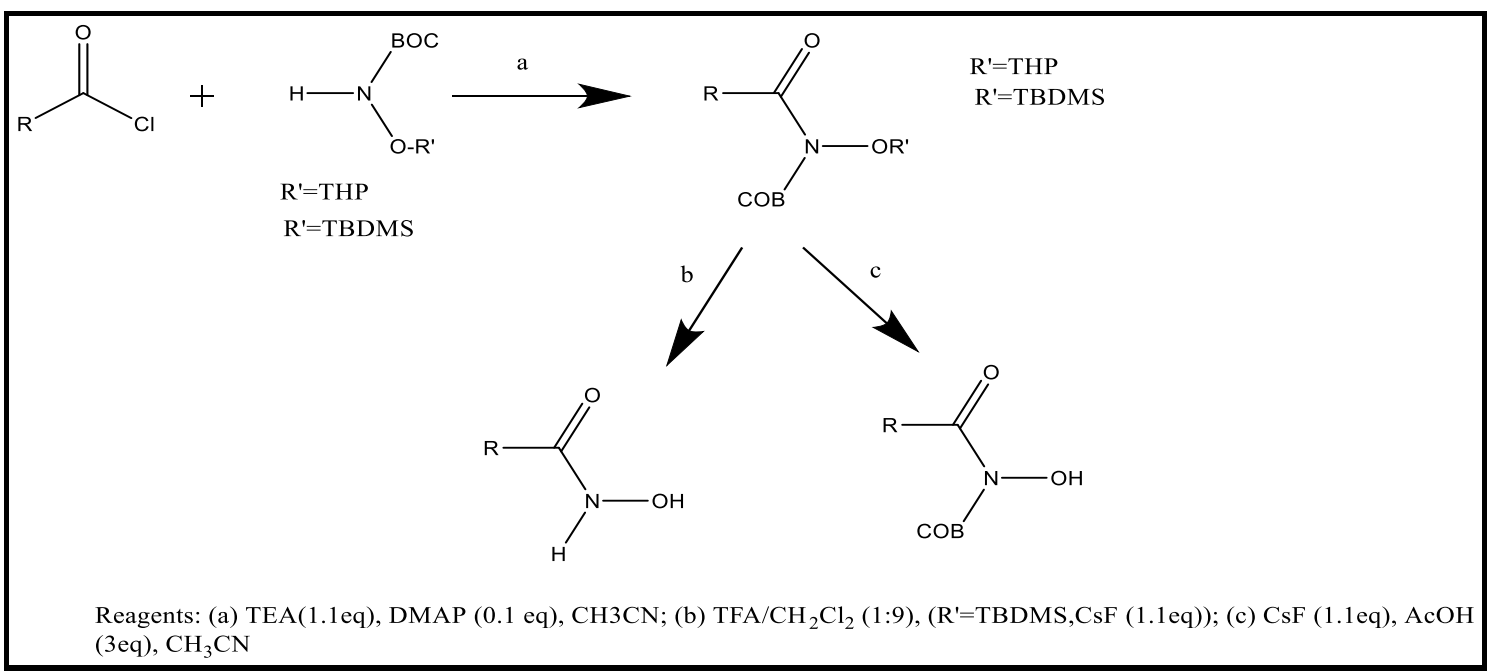

Scheme I.16. Conventional synthesis of hydroxamic acid using N/O-protected hydroxylamine. ${ }^{16}$

However, the main limitation of such process is the treatment of the final product with trifluoric acid for 6 hours in order to remove the protecting groups. Thus, the work up of this reaction requires many steps in order to isolate pure hydroxamic acid. ${ }^{16}$

Another route was mentioned for the synthesis of hydroxamic acid, was the transformation of carboxylic acid such as isobutyric acid into anhydride form in ether. Then, treating the anhydride with hydroxylamine in methanol to get hydroxamic acid. The limitation of this route was the use of ether which is a toxic substance and in addition to the complicated work up such as the use of column chromatography in order to purify the hydroxamic acid. ${ }^{15}$

Hydroxamic acids have high acidity which is of order $9 \mathrm{pk}$ units that is $6 \mathrm{pk}$ units greater than amides. There is still controversy about the anion of the hydroxamic acid, which can occur in three different forms. 


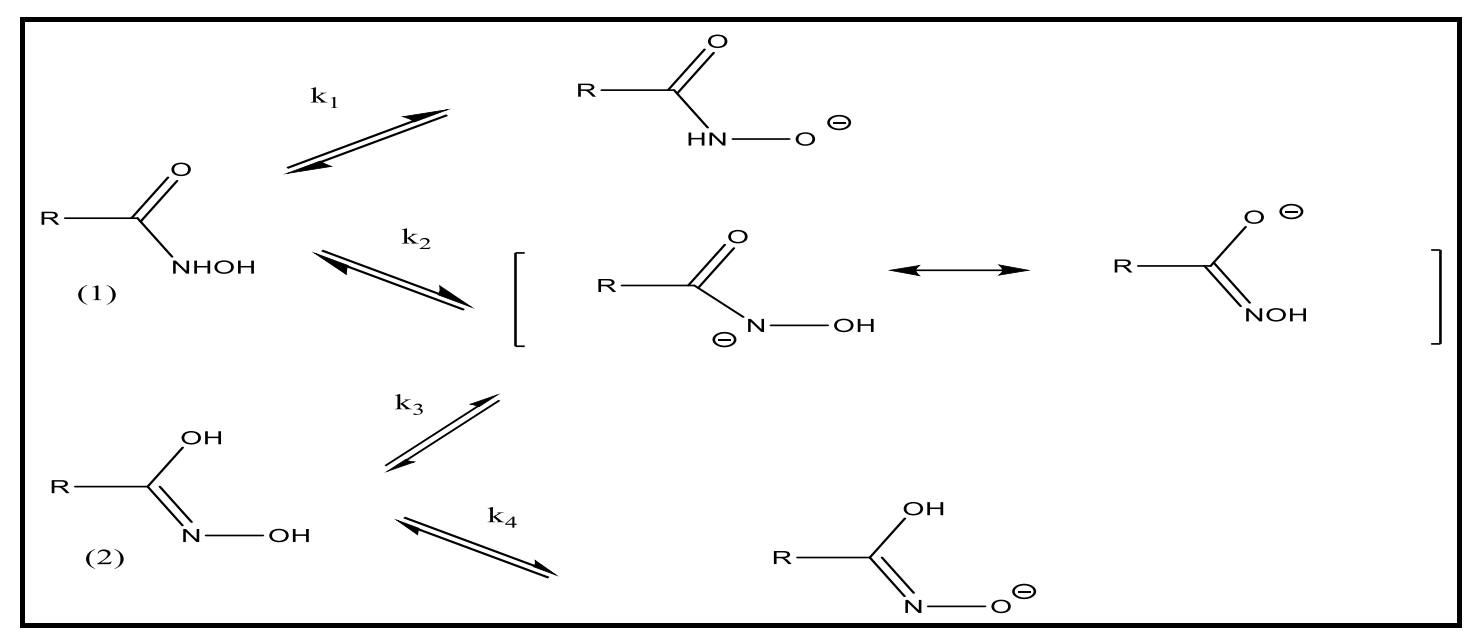

Scheme I.17. Possible routes of hydroxamic acids to the corresponding anions ${ }^{13}$

In early discovery, hydroxamic acid was thought to be present in two possible tautomeristic forms (1) and (2) (Scheme I.17). It was very difficult to confirm the structure with the absence of spectrum technology. However, with the evolution of this technology one it is possible now to confirm the structure of the hydroxamic acid which is 1 , the keto form, specially using IR spectra which will show the $\mathrm{C}=\mathrm{O}$ stretching in the range $1670-1640 \mathrm{~cm}^{-1} .{ }^{13}$

Accordingly, due to the importance of such compound we will study further more about its synthesis and its transformation into isocyanates via Lossen rearrangement.

\section{I.4. Modifications and Objectives}

Upon studying the synthetic routes of isocyanates, we noticed that the Lossen rearrangement received less attention than the other routes. In addition, to the importance of hydroxamic acids in many fields and can be derived from bio-renewable source, plus they are a less toxic source for isocyanates, we were encouraged to study and modify this route and synthesize hydroxamic acids to be starting materials for isocyanates. 
Moreover, the starting materials used in our research are now being synthesized from biobased substances which make them eligible to be applied in our work.

In this research, we synthesized two diisocyanates, one aromatic 1,4-diisocyanatobenzene or commonly known as p-phenylene diisocyanate (PPDI) and one aliphatic 1,4diisocyanatobutane or 1,4-butylene diisocyanate (BDI). The overall synthetic process is deemed as green as possible and in the most efficient and economical way possible.

For PPDI, diethyl terephthalate was used in order to be converted to the corresponding hydroxamic acid, then hydroxamic acid was transformed to its acetate from in order to allow its rearrangement into PPDI. For BDI, dimethyl adipate was converted into the corresponding hydroxamic acid, then the hydroxamic acid was transformed into its acetate formed to be converted into BDI.

For converting both aromatic and aliphatic hydroxamic acids into their corresponding Oacetate hydroxamic acids or generally termed as hydroxamates, we used two different methods. The first method uses acetic anhydride and amine base in solution, and the second method uses acetic anhydride as a reagent and solvent.

For monitoring the reactions and characterization, infrared spectrometry and nuclear magnetic resonance were used and for further information, thermogravimetric analysis in addition to mass spectrometry was also done. 


\section{I.5. References}

1- Zhang, C.; Madbouly, S.; Kessler, M. ACS Appl. Mater. Interfaces, 2015, 7, 1226-1233.

2- Chattopadhyay, D.Raju, K. Progress in Polymer Science, 2007, 32, 352-418.

3- Çaylı, G.Küsefoğlu, S. J. Appl. Polym. Sci. 2008, 109, 2948-2955.

4- Kreye, O.; Mutlu, H.; Meier, M. Green Chemistry, 2013, 15, 1431.

5- Twitchett, H. Chem. Soc. Rev. 1974, 3, 209.

6- Carnaroglio, D.; Martina, K.; Palmisano, G.; Penoni, A.; Domini, C.; Cravotto, G. Beil. J. Org. Chem. 2013, 9, 2378-2386.

7- Vinogradova, E.; Fors, B.; Buchwald, S. J. Am. Chem. Soc. 2012, 134, 11132-11135.

8- Nagato, N.Naito, T. US4224238 A, 2016.

9- Singh, M. Advanced Organic Chemistry. 2004.

10- Jang, D.Kim, J. Synlett, 2008.

11- Hofmann, A. Berichte der deutschen chemischen Gesellschaft, 1881, 14, 2725-2736.

12- Yale, H. L. Chem. Rev. 1943, 33, 209-256.

13- Bauer, L.Exner, O. Angewandte Chemie International Edition in English, 1974, 13, 376384.

14- Miller, M. Chem. Rev. 1989, 89, 1563-1579.

15- Reddy, A.; Kumar, M.; Reddy, G. Tetrahedron Lett. 2000, 41, 6285-6288. 
16- Altenburger, J.; Mioskowski, C.; d'Orchymont, H.; Schirlin, D.; Schalk, C.; Tarnus, C.

Tetrahedron Lett. 1992, 33, 5055-5058.

17- Yoganathan, S.Miller, S. Org. Lett. 2013, 15, 602-605. 


\section{CHAPTER II}

Synthesis and Characterization of 1,4-Diisocyanatobenzene PPDI 


\section{II.1. Overview on PPDI synthesis}

P-phenylene diisocyanate (PPDI) is a double sided isocyanate where the NCO group is in the para position. PPDI is mainly used for the synthesis of polyurethanes upon its reaction with a diol and thus it acts as the hard segment of the polymeric chain.

Originally, as any isocyanate, PPDI was synthesized by the phosgenation route by adding triphosgene to p-phenylene diamine. ${ }^{1}$

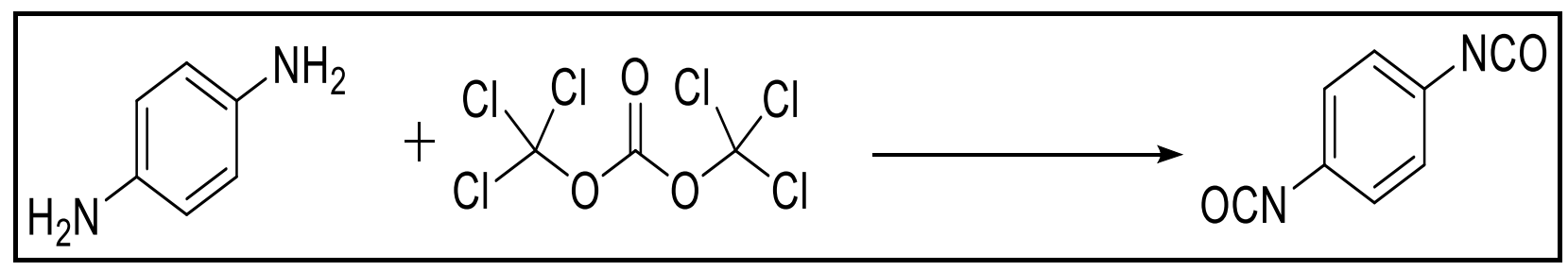

Scheme II.1. Triphosgenation of p-phenylene diamine ${ }^{1}$

Another route was taken for the synthesis of PPDI, by the decomposition of carbamate ester by using boron halides such as boron trichloride $\mathrm{BCl}_{3}$ in the presence of triethylamine $\mathrm{Et}_{3} \mathrm{~N}^{2}$<smiles>[R]O[R14](=O)O[Na]</smiles>

Scheme II.2. Decomposition of carbamate into isocyanate ${ }^{2}$ 
PPDI was also successfully obtained by generating a carbamate anion $\mathrm{RNHCO}_{2}{ }^{-} \mathrm{BaseH}^{+}$, and treating it with a dehydrating agent as phosphoryl chloride $\mathrm{POCl}_{3}$. This work was done by Thomas E. Waldman and William D. McGhee in 1994. In the reaction, carbon dioxide $\mathrm{CO}_{2}$ was added to a primary amine $\mathrm{RNH}_{2}$ solution, then it was mixed with an organic base to generate the carbamate ion. Then, one equivalent of $\mathrm{POCl}_{3}$ was added to the carbamate ion solution and isocyanate was obtained with good yield. PPDI was obtained through this route from $p$ phenylene diamine (PPDA) with $69 \%$ yield. $^{3}$

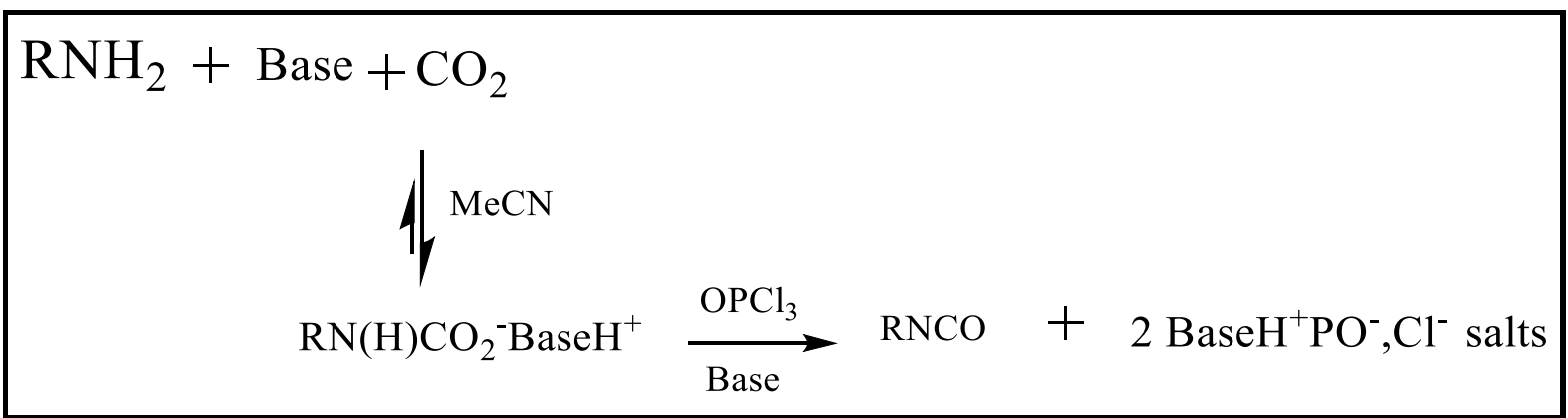

Scheme II.3. Isocyanate through synthesis of carbamate anion ${ }^{3}$

Although these routes were successful in giving high yields of PPDI reaching 90 and $100 \%$, they have limitations due to using toxic chemical such as phosgene and amine base. Hence we found a better modified route in order to synthesize PPDI, which is the use of terephthalate ester and transform it to hydroxamic acid, followed by converting it to its acetate form that will rearrange to PPDI upon heating.

\section{II.2. Synthesis of Bio-Based Terephthalic Acid (TPA)}

Originally, terephthalic acid is derived from para-xylene through the oxidation of the latter. Para-xylene is a petroleum derivative is also obtained by catalytic reforming of petrochemicals thus that will lead to the production of many greenhouse gases. ${ }^{4}$ 
However, with the increase of social demand of bio-based materials, routes to p-xylene were developed, where two routes were done using bio-based materials: glyceride and 5hydroxymethyl-2-furfural. Glyceride is a by-product of bio-derived chemicals and 5hydroxymethyl-2-furfural is obtained from cellulosic inedible sources.

In one published paper, TPA was successfully synthesized using furfural according to the following scheme.

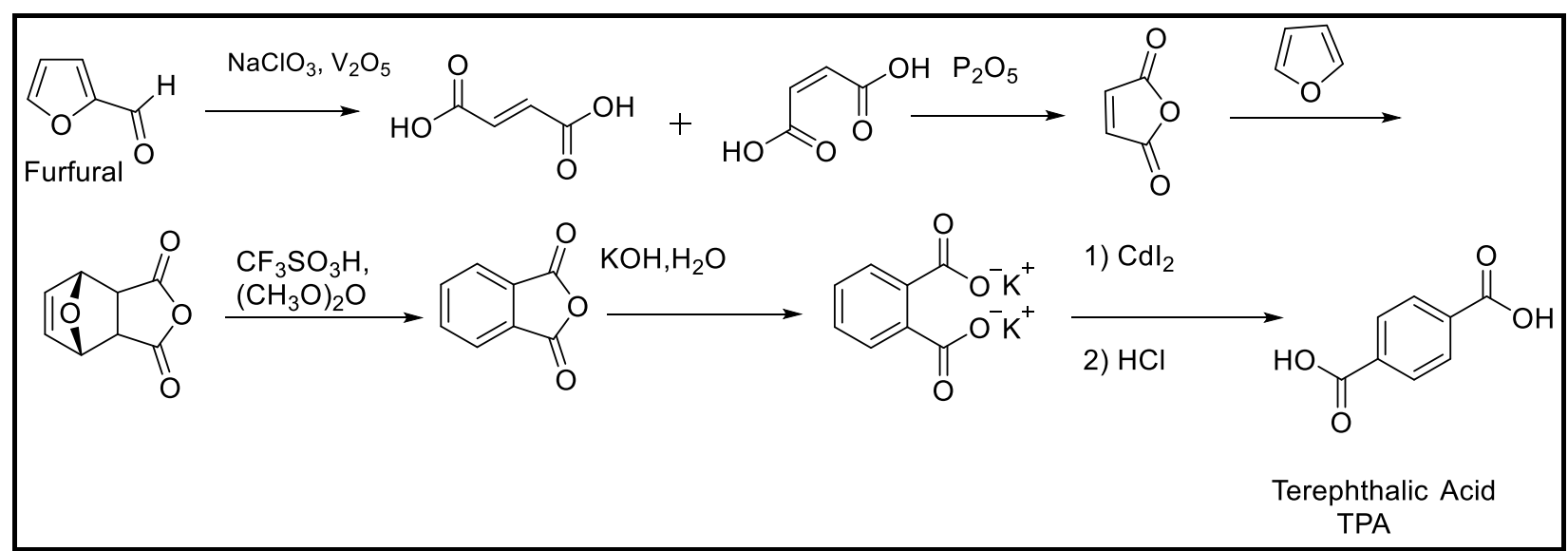

Scheme II.4. Reaction Scheme for the transformation of Furfural into Terephthalic Acid ${ }^{5}$

As shown in Scheme II.4, the synthetic route has six steps. The reaction starts first with the transformation of the furfural into a mixture of fumaric acid and maleic acid through oxidation. Then, dehydration of both acids into their corresponding anhydride form. The anhydrides are subjected to Diels-Alder reaction, followed by dehydration to obtain phthalic anhydride. The phthalic anhydride is hydrolyzed into its potassium salts, and in the last step the salt is acidified to give terephthalic acid.

This route has many steps that will make it limited to be applied in the industrial field, in addition to its performance under harsh conditions such as high temperature. ${ }^{5}$ 
More routes were also developed for the synthesis of terephthalic acid using limonene and acrylic acid, but these also have high cost which make them economically inefficient for industrial applications. However, they are showing great promises for the substitution of petrochemicals with biomass materials, thus improving quality of life. ${ }^{6}$

\section{II.3. Synthesis of PPDI by Lossen Rearrangement Reaction}

Lossen rearrangement reaction is a better alternative than the traditional phosgenation route to obtain PPDI, since we avoid using phosgenation and we rely on bio-based materials. To synthesize PPDI, we took many steps from converting the ester (starting material) to hydroxamic acid, then transforming it into its corresponding hydroxamate which will rearrange into PPDI. The reaction can be summarized by the following overall scheme II.5.

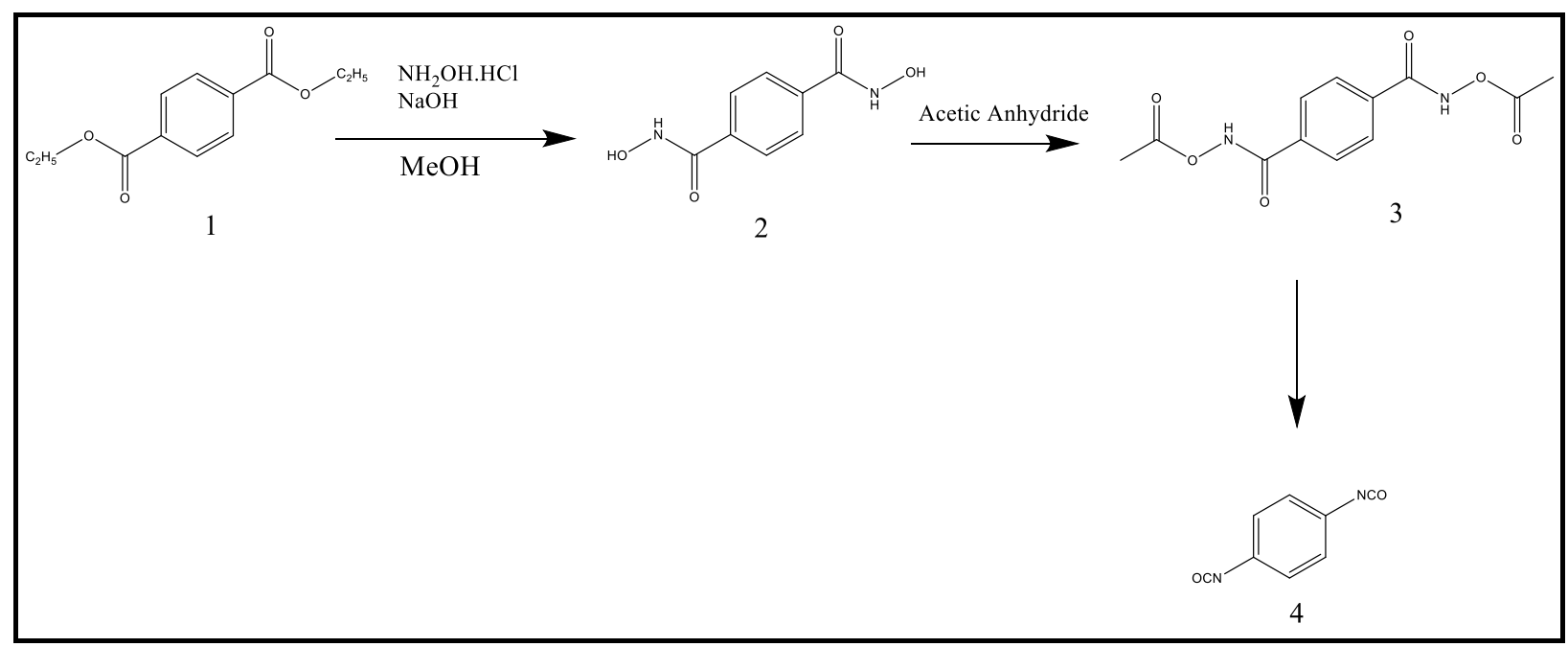

Scheme II.5. Overall reaction for the synthesis of PPDI

The proposed mechanism of the Lossen rearrangement reaction for PPDI formation is represented by Scheme II.6. 


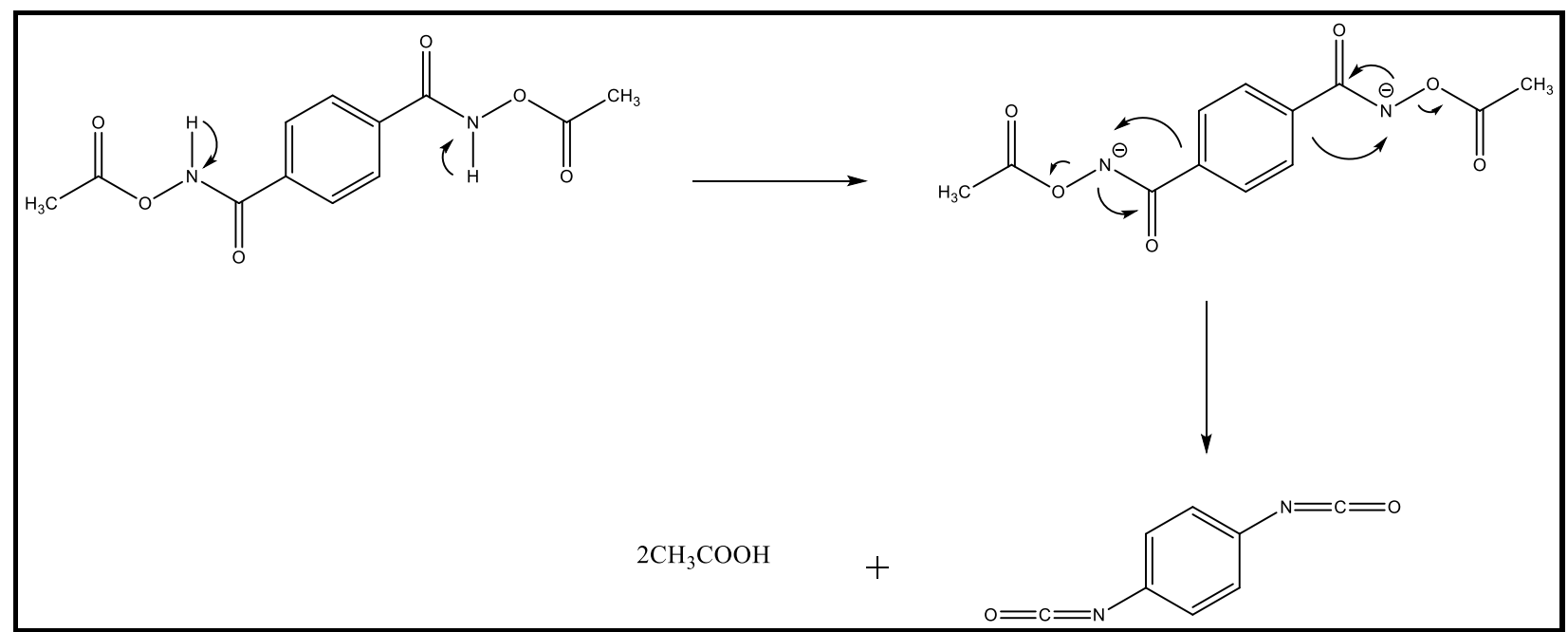

Scheme II.6. Proposed mechanism for PPDI formation by Lossen rearrangement reaction

\section{II.4. Experimental Section}

\section{II.4.1. Materials}

Diethyl terephthalate was purchased from TCI American, hydroxylamine hydrochloride, acetic anhydride (AAN), and N,N-diisopropylethylamine were purchased from Sigma Aldrich, sodium hydroxide was purchased from Riedel-de Haën, hydrochloric acid was purchased from Anachemia, methanol was purchased from BDH, and dimethoxyethane (DME) was purchased from ACP chemicals.

All chemicals were used as received, except for AAN and DME were distilled and dried. Molecular sieve 4A were purchased from Sigma Aldrich and were oven dried over night before using.

\section{Distilling and Drying of Solvents}


Each of Acetic Anhydride and Dimethoxyethane were dried by stirring with dry magnesium sulfate $\mathrm{MgSO}_{4}$ overnight. Then they were distilled over oven-dried 4A molecular sieves under dry nitrogen.

\section{II.4.2. General Characterization}

Proton NMR ( ${ }^{1} \mathrm{H}$ NMR) spectra were done by Bruker Avance Digital 300 MHz. Chemical shifts were measured in ppm relative to tetramethylsilane (TMS, $\delta=0$ ). Abbreviations used for description of spectra are: $\mathrm{s}=$ singlet, $\mathrm{d}=$ doublet, $\mathrm{t}=$ triplet, $\mathrm{q}=$ quartet, $\mathrm{m}=$ multiplate.

Infrared spectra were done using Varian 1000 FT-IR Scrinitar spectrophotometer. Transmittance was the measuring mode $\% \mathrm{~T}$, and the bands were in $\mathrm{cm}^{-1}$. Abbreviations used for bands description are: $\mathrm{s}=$ strong, $\mathrm{m}=$ medium, $\mathrm{w}=$ weak, $\mathrm{b}=$ broad, $\mathrm{sh} .=$ sharp. Mass spectra were done using Qstar via direct ESI-MS. Thermogravimetric analysis TGA was done using HiRes TGA 2950 instrument with a heating rate $10{ }^{\circ} \mathrm{C}$ per min under nitrogen. Differential Scanning Calorimetry DSC was done using TA DSC Q100 with heating rate $10{ }^{\circ} \mathrm{C}$ per min under nitrogen.

\section{II.4.3. Synthesis}

\section{Synthesis of 1,4-Dihydroxyterephthalamide (Aromatic HA)}

Diethyl terephthalate $(30.0 \mathrm{~g}, 0.10 \mathrm{~mol})$ (compound 1) was dissolved in $400 \mathrm{~mL}$ of methanol in a 2L three-neck-round-bottom flask at room temperature. In a $200 \mathrm{~mL}$ conical flask, sodium hydroxide (32.4 g, $0.80 \mathrm{~mol})$ was dissolved in $90 \mathrm{~mL}$ of distilled water, and in another $200 \mathrm{~mL}$ conical flask, hydroxylamine hydrochloride (28.5 g, $0.40 \mathrm{~mol})$ were dissolved in $60 \mathrm{~mL}$ of distilled water. The two solutions were mixed together, then poured in a dropping funnel connected to the flask containing the terephthalate solution. The basic hydroxylamine solution 
was added drop-wise to the terephthalate solution at $0{ }^{\circ} \mathrm{C}$. Then the mixture was allowed to stir at $55{ }^{\circ} \mathrm{C}$ for 72 hours.

Afterwards, the mixture was neutralized with $(5 \% \mathrm{HCl})$ acidified water until $\mathrm{pH}$ reached 67. Then, solid was collected by filtration, and was stirred in boiling methanol $(1000 \mathrm{~mL})$ for 5 minutes. The solid product (dihydroxamic acid, compound 2) was obtained $(16.1 \mathrm{~g})$ with $60.6 \%$ yield and pure enough to be used in the next reaction. It was soluble in DMSO, and partially soluble in methanol.

${ }^{1} \mathrm{H}-\mathrm{NMR}\left(300 \mathrm{MHz}, \mathrm{DMSO}-\mathrm{d}_{6}, \mathrm{ppm}\right): \delta 11.32$ (2H s), 9.15 (2H s), 7.95 (4H s)

IR (Nujol, $\left.\mathrm{cm}^{-1}\right)$ 1560.2 N-C, 1613.4 HN-C=O, 1650.0 HN-C=O

\section{Synthesis of 1,4-Terephthalohydroxamic Diacetate(HA Acetate)}

Method 1: Hydroxamic acid (compound 2) (16.1 g, $0.10 \mathrm{~mol}$ ) was mixed with dried acetic anhydride (17.6 g, $0.20 \mathrm{~mol})$ and N,N-diisopropylethylamine $(31.8 \mathrm{~g}, 0.30 \mathrm{~mol})$ in $80 \mathrm{~mL}$ of dry DME in a $250 \mathrm{~mL}$ three-neck-round-bottom flask, and was stirred and refluxed at $70{ }^{\circ} \mathrm{C}$. Then the mixture was filtered and the solid obtained as residue was stirred and washed in chloroform. Then, the chloroform was filtered and the product (compound 3) (19.2 g, 83.7\% yield), was obtained as a creamy white solid as the residue.

The diacetate is soluble in DMSO, and insoluble in chloroform, water, and methanol.

${ }^{1} \mathrm{H}-\mathrm{NMR}\left(300 \mathrm{MHz}, \mathrm{DMSO}-\mathrm{d}_{6}, \mathrm{ppm}\right): \delta 7.87(2 \mathrm{H}, \mathrm{s}), 2.19(6 \mathrm{H}, \mathrm{s}) ; \mathrm{IR}\left(\mathrm{Nujol}, \mathrm{cm}^{-1}\right) 1789.1$ $(\mathrm{OC}=\mathrm{O})$ 
Method 2: Compound 2 (0.5 g, $0.002 \mathrm{~mol})$ was mixed with acetic anhydride $(3.3 \mathrm{~g}, 0.03$ $\mathrm{mol}$ ) in $50 \mathrm{~mL}$ three neck round bottom flask and stirred at room temperature for two days under nitrogen. Afterwards, the reaction mixture was filtered and the product (compound 3), was obtained as a creamy solid $(0.5 \mathrm{~g}, 80.9 \%$ yield $)$

${ }^{1} \mathrm{H}-\mathrm{NMR}\left(300 \mathrm{MHz}, \mathrm{DMSO}-\mathrm{d}_{6}, \mathrm{ppm}\right): \delta 7.93(2 \mathrm{H}, \mathrm{s}), 2.25(6 \mathrm{H}, \mathrm{s})$; IR (Nujol, $\left.\mathrm{cm}^{-1}\right) 1789.1$ $(\mathrm{OC}=\mathrm{O})$

\section{Synthesis of PPDI}

Compound 3 ( $0.1 \mathrm{~g}, 0.20 \mathrm{~mol})$ was heated in $10 \mathrm{~mL}$ round-bottom-flask with a stirring bar. The flask was connected by a pre-weighed bridge to another receiving $10 \mathrm{~mL}$ flask. The heating was done at $180{ }^{\circ} \mathrm{C}$ under vacuum. At $180{ }^{\circ} \mathrm{C}$, compound 3 started converting into PPDI (compound 4) and acetic acid. The PPDI sublimed as white solid, inside the bridge due to the continuous cooling. PPDI (0.03 g, 77.7\% yield) was found to be soluble in chloroform.

${ }^{1} \mathrm{H}-\mathrm{NMR}\left(300 \mathrm{MHz}, \mathrm{CDCl}_{3}, \mathrm{ppm}\right): 7.30(4 \mathrm{H}, \mathrm{s})$; IR (Nujol, $\left.\mathrm{cm}^{-1}\right): 2288.4$-NCO

\section{II.4.4. Discussion}

\section{1,4-Dihydroxyterephthalamide (Aromatic HA)}

For the synthesis of the aromatic hydroxamic acid, compound $\mathbf{2}$, the reaction was monitored through taking IR samples, where the ester peak of the starting material, compound $\mathbf{1}$, was decreasing at $1272.3 \mathrm{~cm}^{-1}$ (Figure II.1), and the two ester peaks $\mathrm{C}=\mathrm{O}$ stretch at 1650.0 and $1613.4 \mathrm{~cm}^{-1}$ starts appearing, in addition to $\mathrm{C}-\mathrm{N}$ stretch at $1561.8 \mathrm{~cm}^{-1}$ (Figure II.2). These three peaks are considered as the characteristic peaks of dihydroxamic acid. 


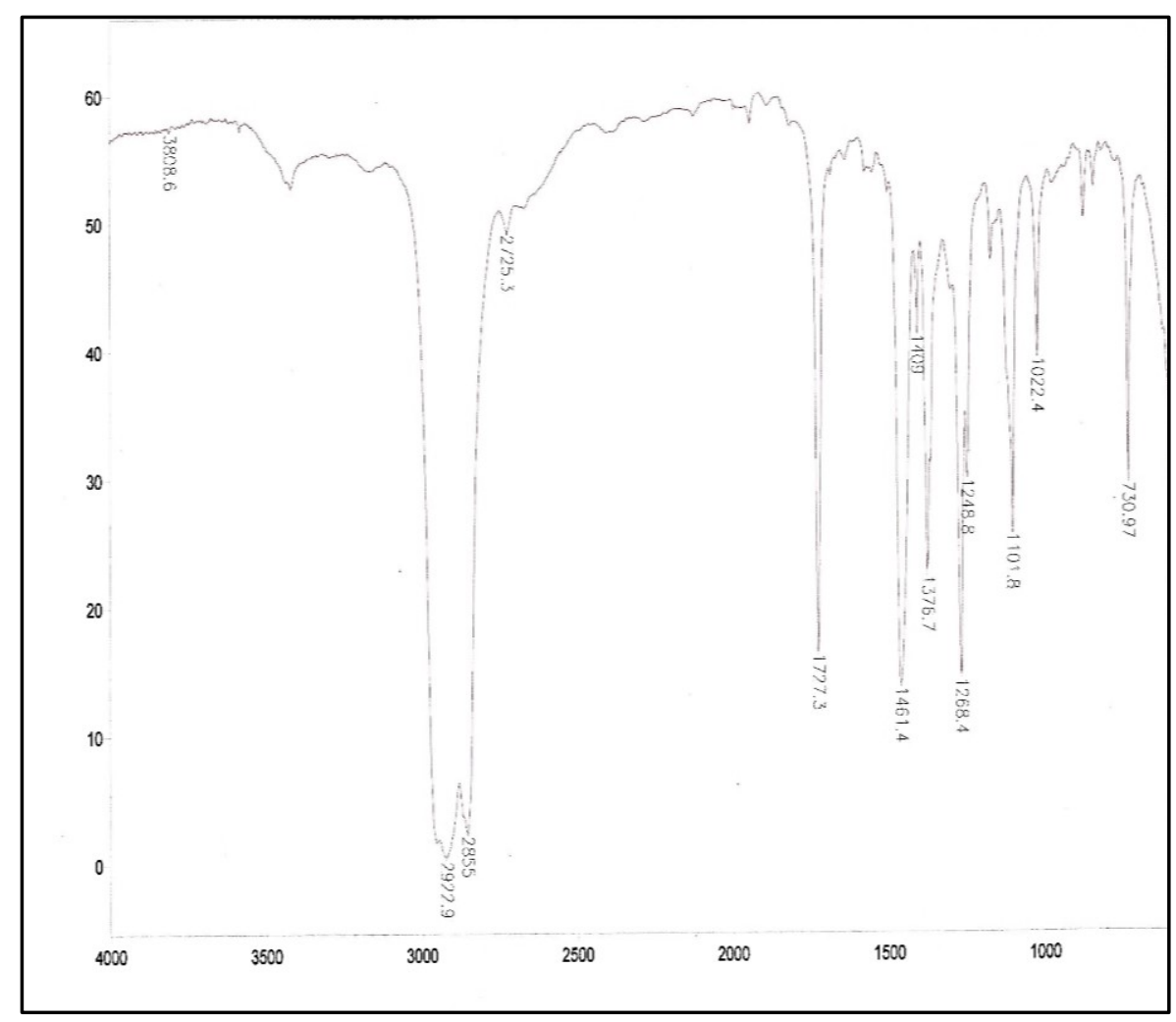

Figure II.1. IR spectrum of compound $\mathbf{1}$.

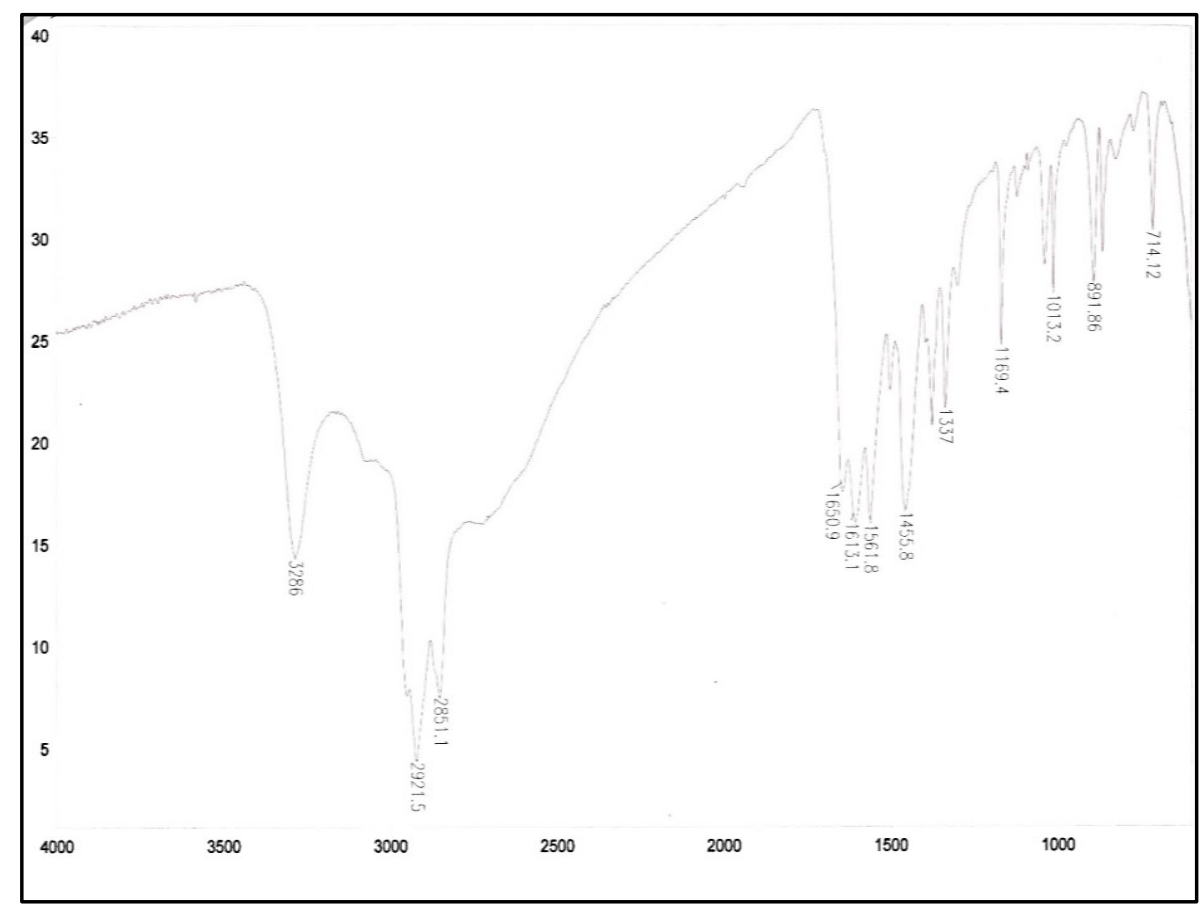

Figure II.2. IR spectrum of compound 2. 
After the isolation of compound 2, ${ }^{1} \mathrm{H}$ NMR was taken and compared with that of the starting material, compound $\mathbf{1}$.

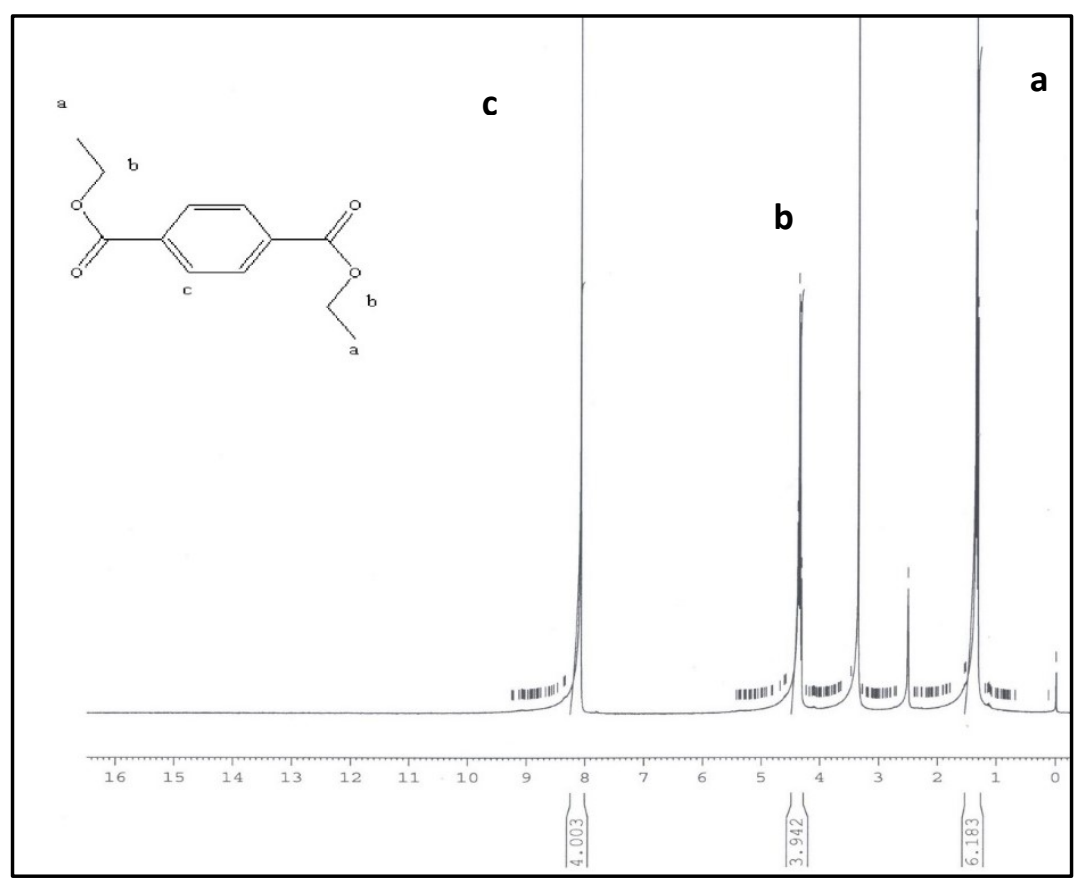

Figure II.3. ${ }^{1} \mathrm{H}$ NMR spectrum of compound 1 


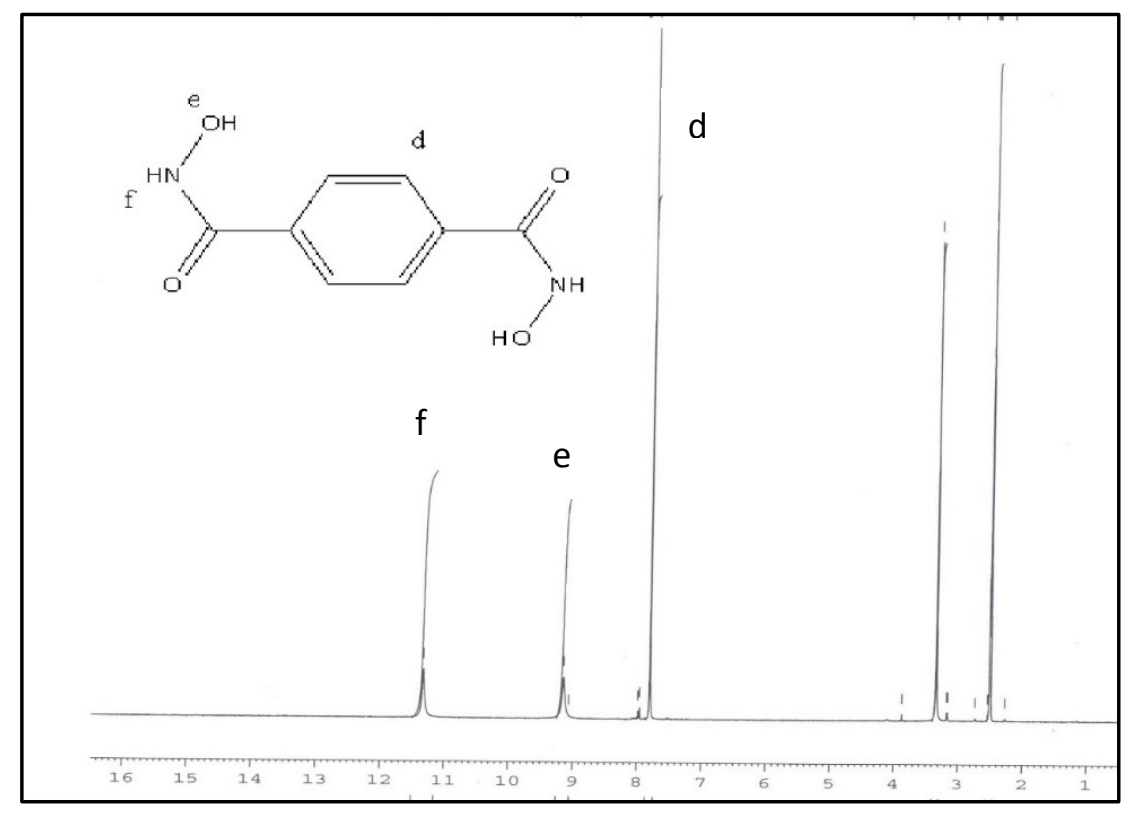

Figure II.4. ${ }^{1} \mathrm{H}$ NMR Spectrum of Compound 2.

Upon comparing the two NMR spectra, we notice the disappearance of two singlets at 1.40 and 4.60 ppm corresponding to $\mathrm{CH}_{3}$ - and $\mathrm{CH}_{2}$ - protons (Figure II.3), the appearance of labile protons at 9.10 and $11.30 \mathrm{ppm}$ corresponding to NH- and $\mathrm{OH}-$ protons (Figure II.4).

The parent molecular ion peak of compound 2 was at $\mathrm{m} / \mathrm{z} 195$, which confirms the structure of the desired compound. 


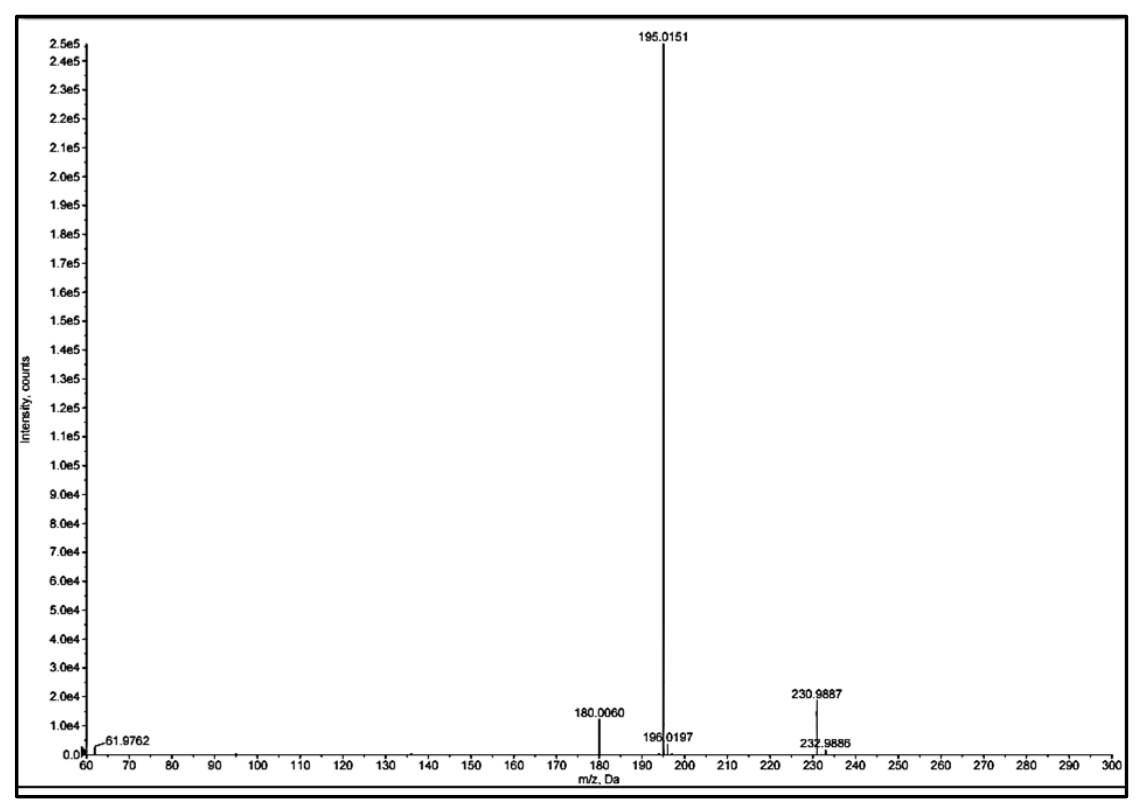

Figure II.5. Mass spectrum of compound 2.

Hydroxamic acid (compound 2) does not melt but undergoes decomposition. Thus, TGA was done in order to study the weight loss of the compound upon heating.

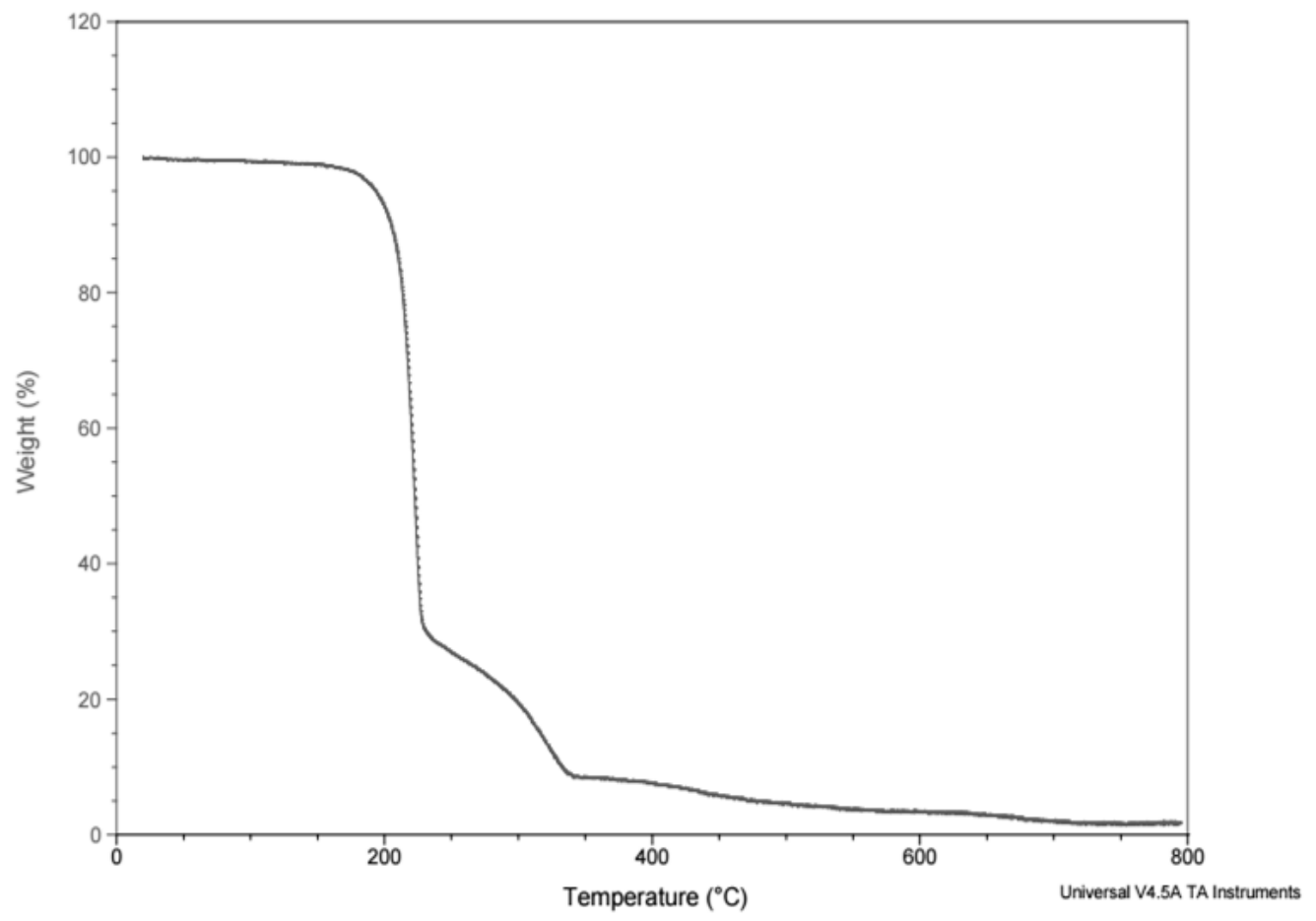

Figure II.6. Thermogravimetric analysis of compound $\mathbf{2}$ 
Around $200{ }^{\circ} \mathrm{C}$, the hydroxamic acid loses $70 \%$ of its weight. Upon performing DSC for the aromatic hydroxamic acid, we found out that when we heat the sample above $190-200{ }^{\circ} \mathrm{C}$, the sample decomposes, thus the cooling cycle is different than the heating cycle. The information given by DSC confirm the data obtained by TGA.

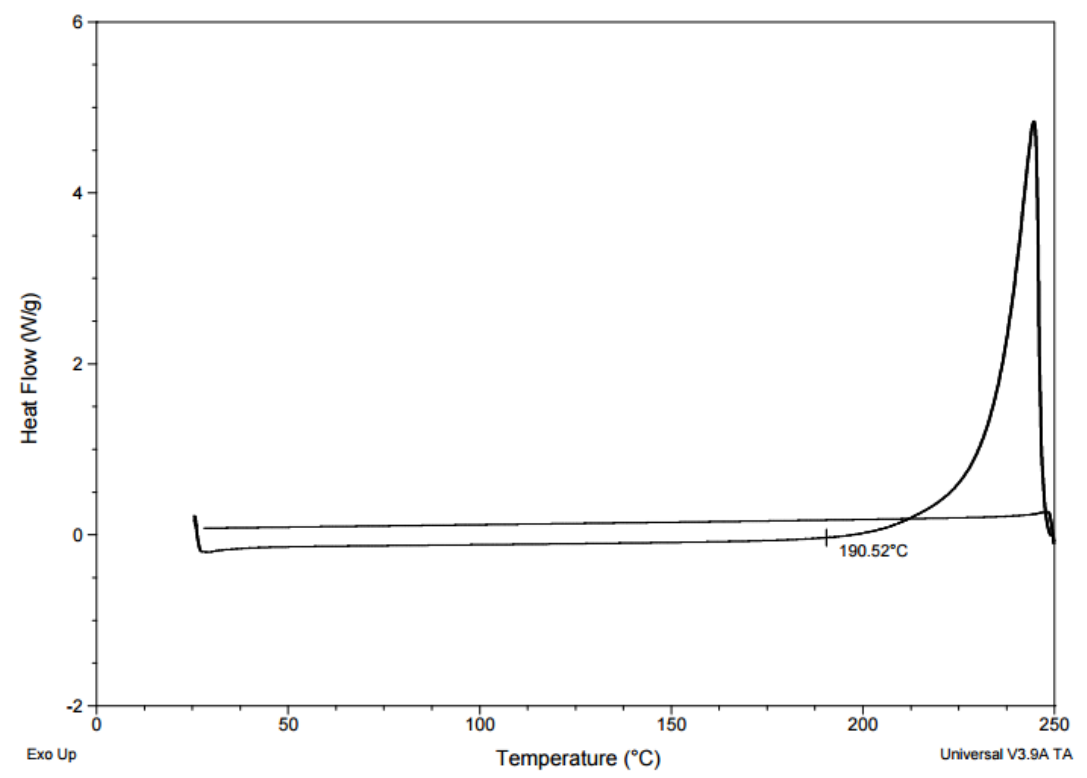

Figure II.7. DSC of compound 2 up to $250{ }^{\circ} \mathrm{C}$.

Thus, DSC was repeated but up to a lower temperature of $220{ }^{\circ} \mathrm{C}$ to see if there is any difference. According to DSC data (Figure II.8), compound 2 shows no melting point but decomposes. 


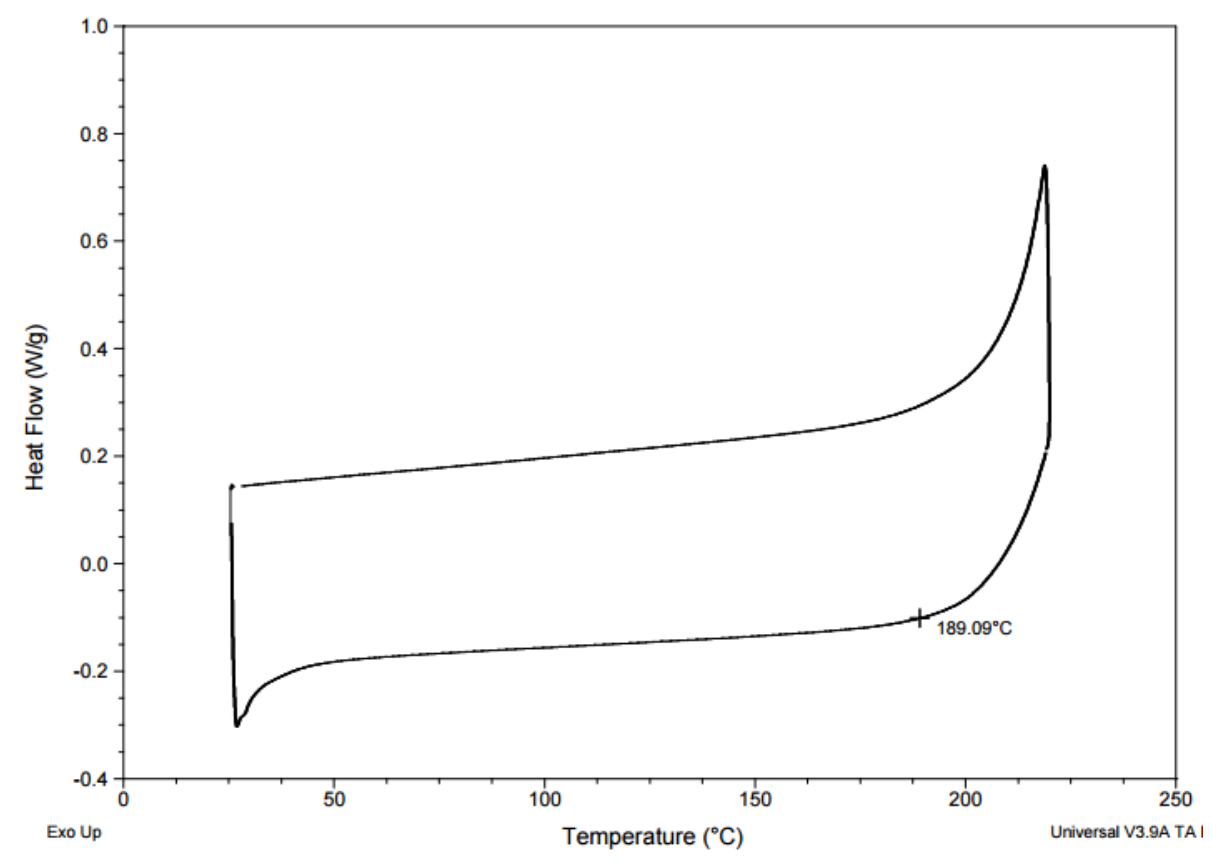

Figure II.8. DSC of compound 2 up to $220{ }^{\circ} \mathrm{C}$.

\section{1,4-Terephthalohydroxamic Diacetate (Aromatic HA Acetate)}

The reaction of compound 2 with AAN through both methods ( 1 and 2) was monitored by observing the peaks changing in IR spectra. The three characteristic peaks of compound $\mathbf{2}$ at 1613.4 and $1561.8 \mathrm{~cm}^{-1}$ were decreasing (Figure II.9) and a new ester sharp peak was forming at $1789.1 \mathrm{~cm}^{-1}$ corresponding to the aromatic HA acetate, compound $\mathbf{3}$ (Figure II.10). The reaction was stopped when the characteristic peak of compound $\mathbf{2}$ disappeared and a strong sharp peak of the ester at $1789 \mathrm{~cm}^{-1}$ was formed. 


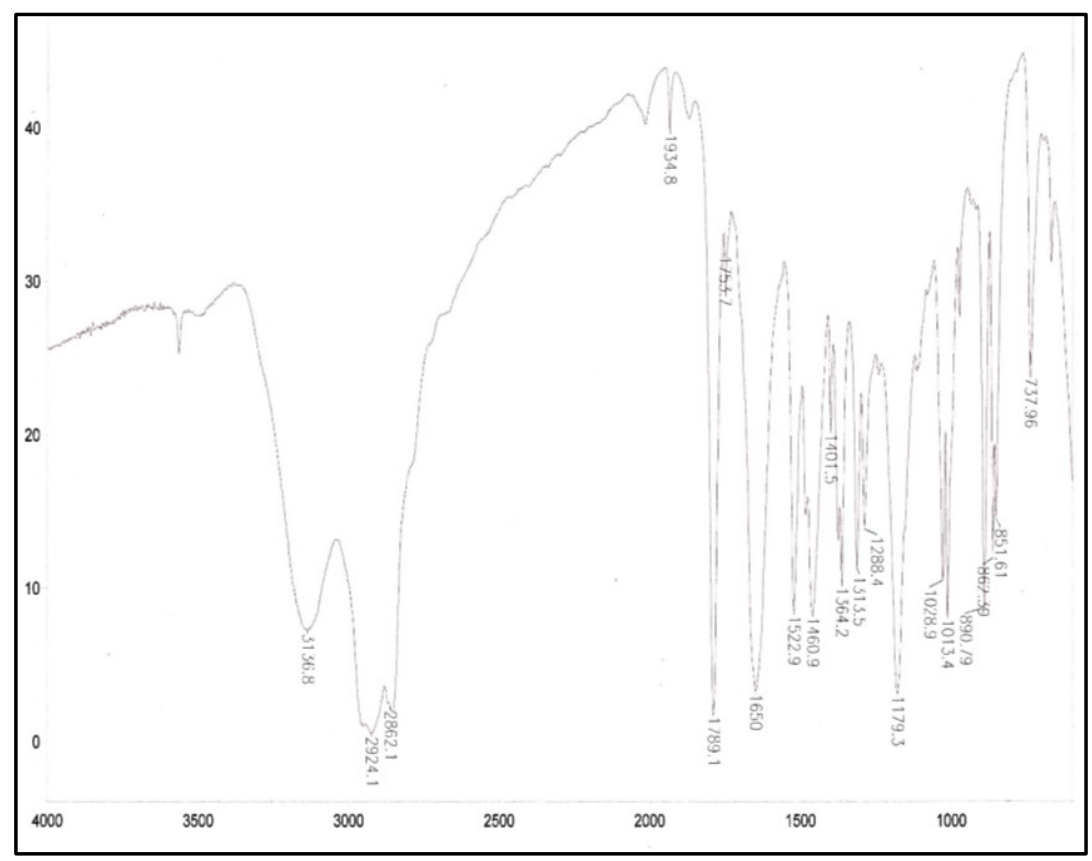

Figure II.9. IR spectrum of compound $\mathbf{3}$ (Method 1)

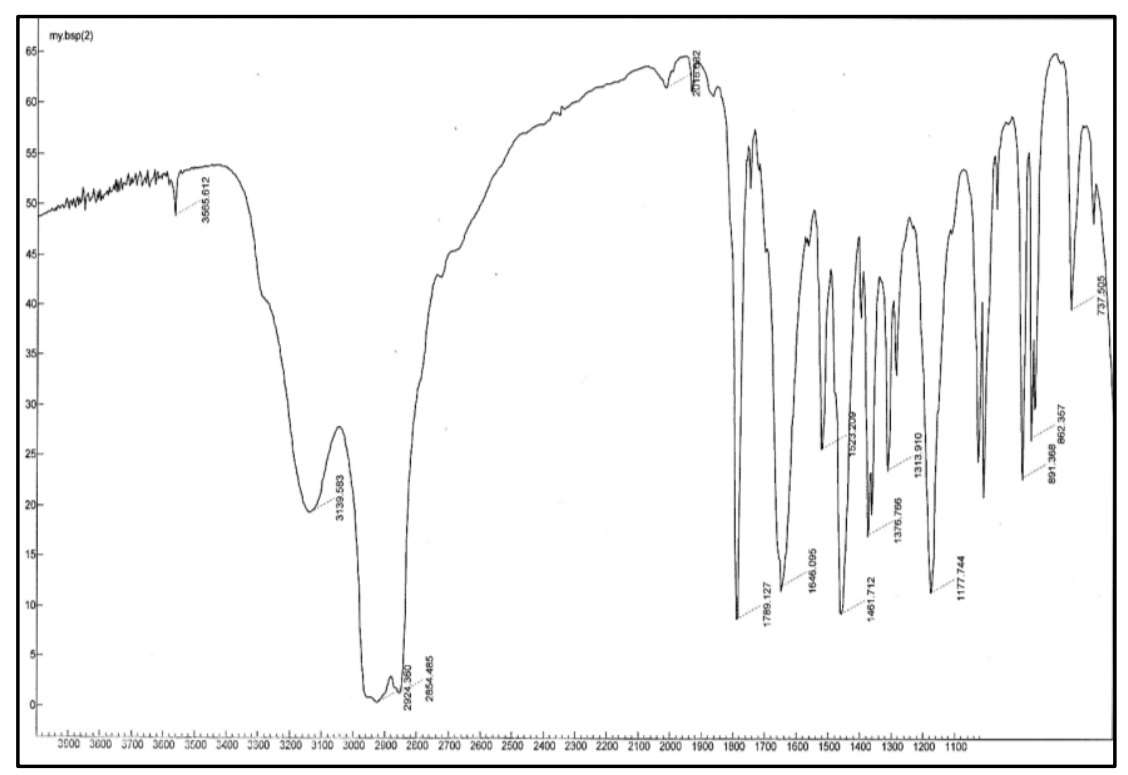

Figure II.10. IR spectrum of compound 3 (Method 2)

Also, proton NMR was done for compound 3, after its isolation which in return confirmed its structure. 


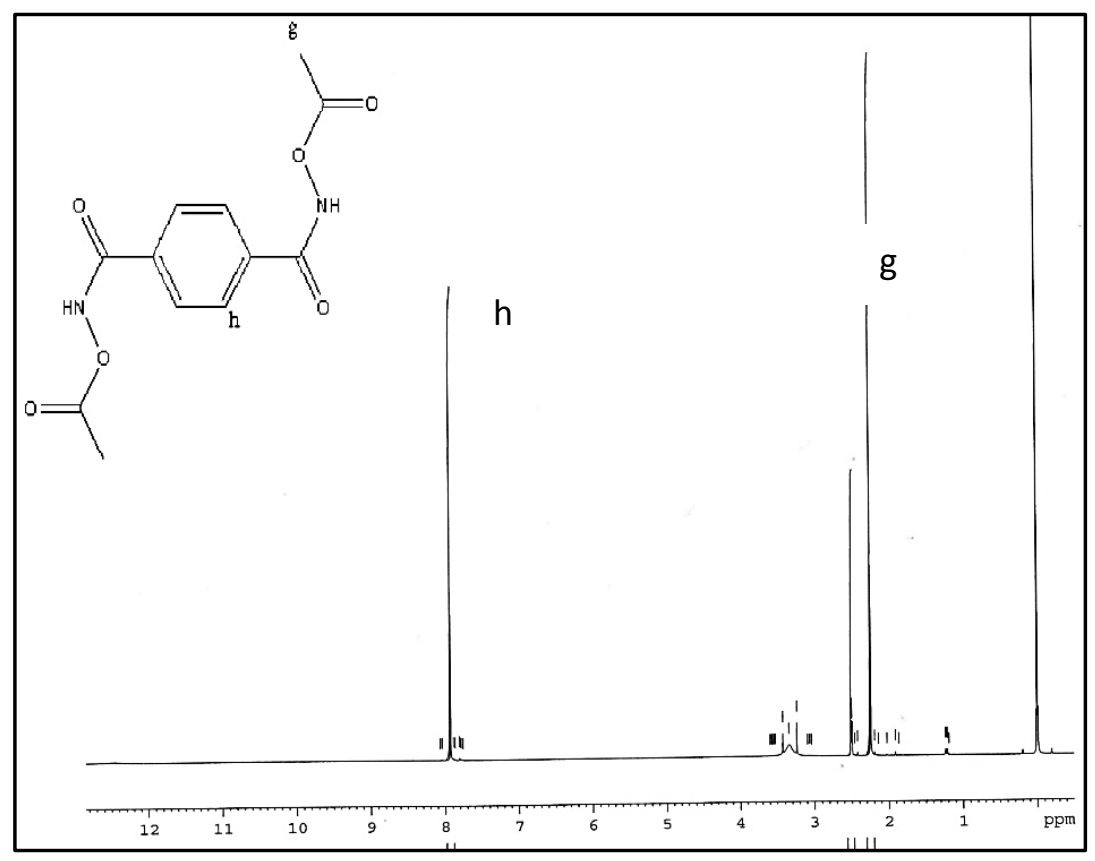

Figure II.11. ${ }^{1} \mathrm{H}$ NMR spectrum of compound 3 (Method 1).

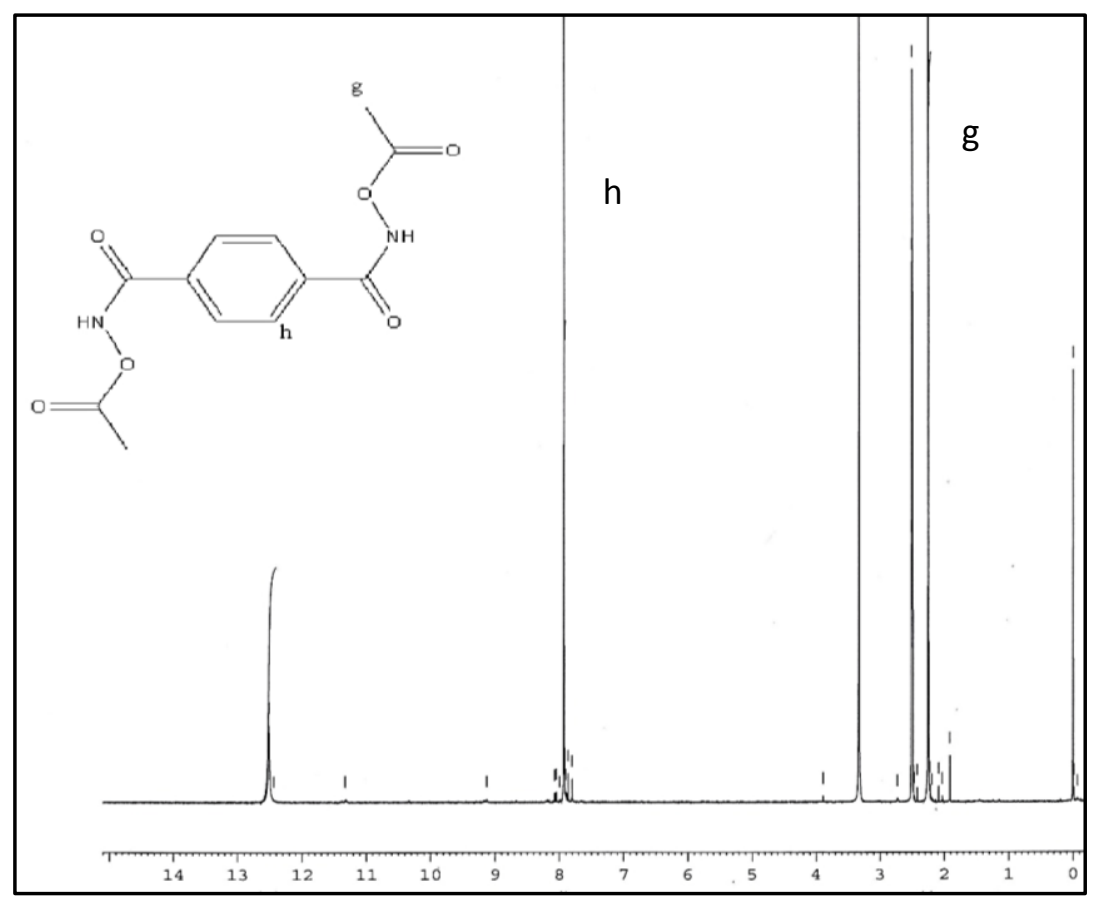

Figure II.12. ${ }^{1} \mathrm{H}$ NMR spectrum of compound 3 (Method 2) 
The ${ }^{1} \mathrm{H}$ NMR spectrum, in both methods, shows that the singlet at $7.95 \mathrm{ppm}$ corresponding to compound 2 (Figure II.11) was shifted to the right to become $7.90 \mathrm{ppm}$ (Figure II.12), also a new singlet is formed in the NMR spectra of compound $\mathbf{3}$, which corresponds to the protons of the aliphatic chain $-\mathrm{COCH}_{3}$, at $2.21 \mathrm{ppm}$.

Method 2 is more efficient to be applied industrially since there is no use of amine base and no use of DME as a solvent. In addition, the reaction runs at room temperature, which is a good factor to save energy when implemented in industry.

The yield, appearance of the final product, and spectra in both methods are very similar. The mass spectrum of the acetate compound confirmed the structure of the compound and its purity, the molecular ion peak $\mathrm{m} / \mathrm{z}$ was found at 279.0343 .

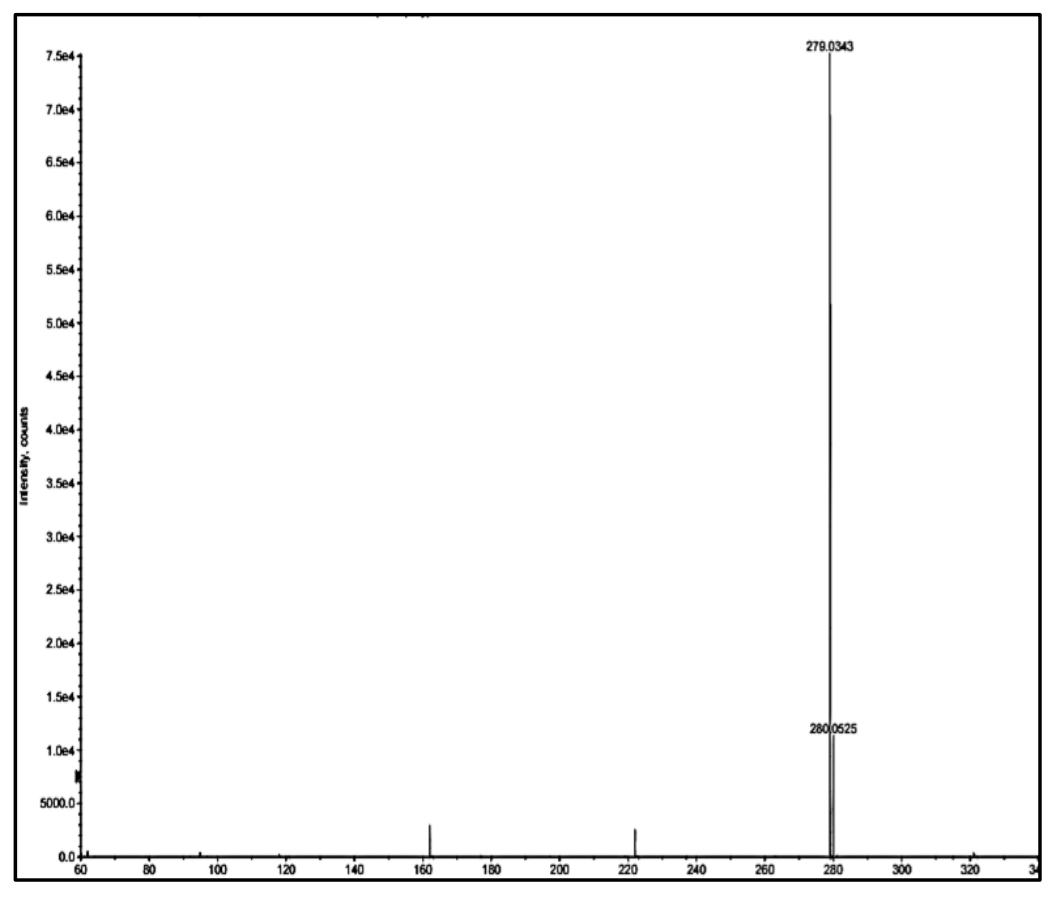

Figure II.13. Mass spectrum of compound 3. 
The TGA analysis of the acetate compound confirmed the temperature at which the decomposition of the acetate occurs to give PPDI (compound 4).

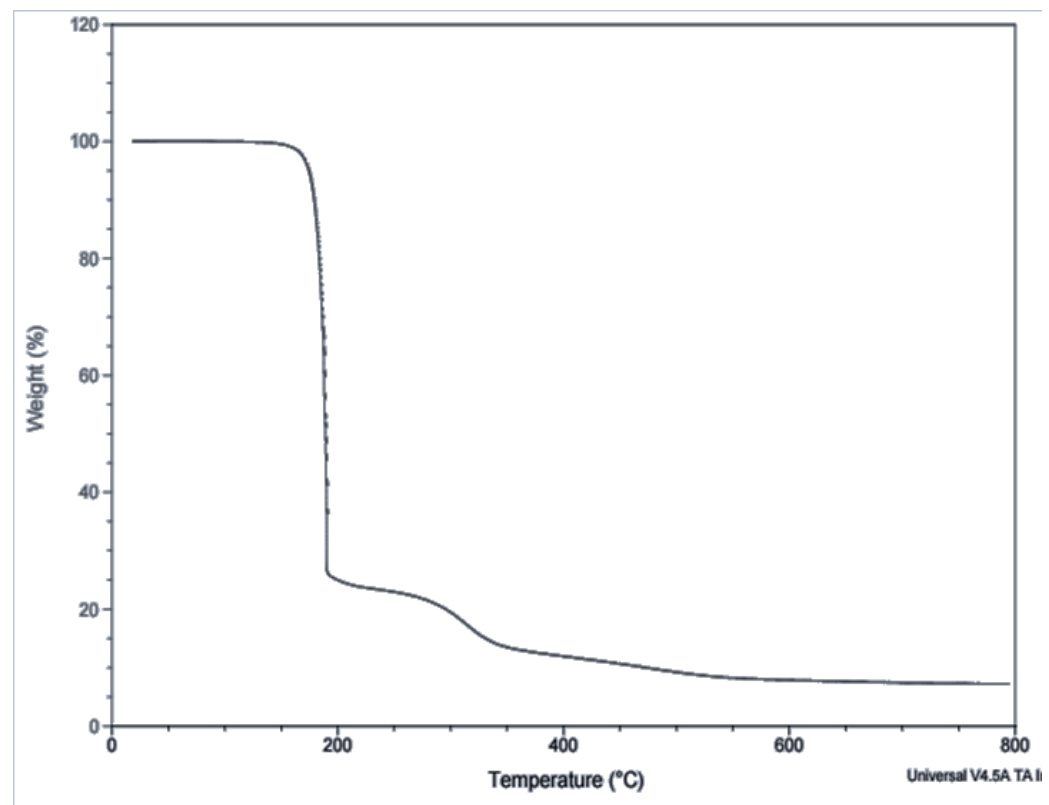

Figure II.14. Thermogravimetric analysis of compound $\mathbf{3}$

DSC was done for compound $\mathbf{3}$, at $200{ }^{\circ} \mathrm{C}$ the compound shows only decomposition peak. DSC was repeated at $160{ }^{\circ} \mathrm{C}$, and no change occurred. Compound 3 shows no melting point, only decomposition peak is found in DSC. 


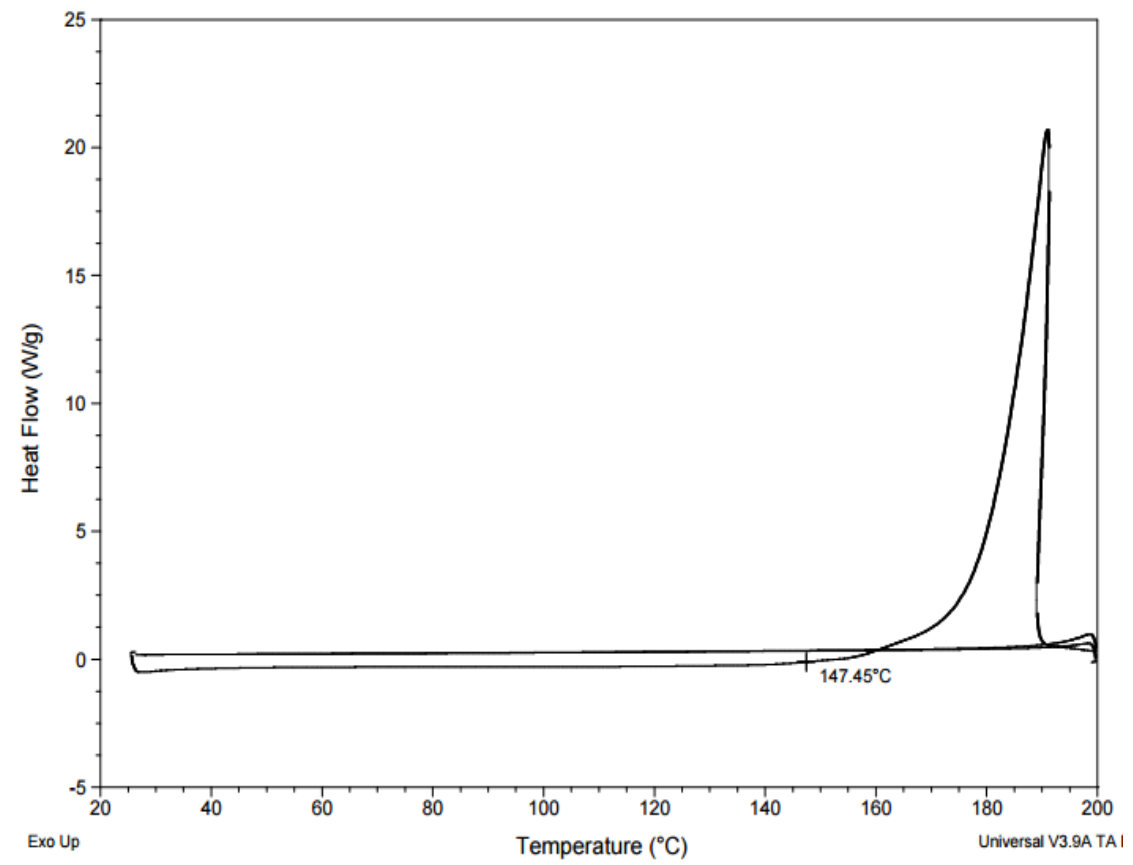

Figure II.15. DSC of compound 3 up to $200{ }^{\circ} \mathrm{C}$.

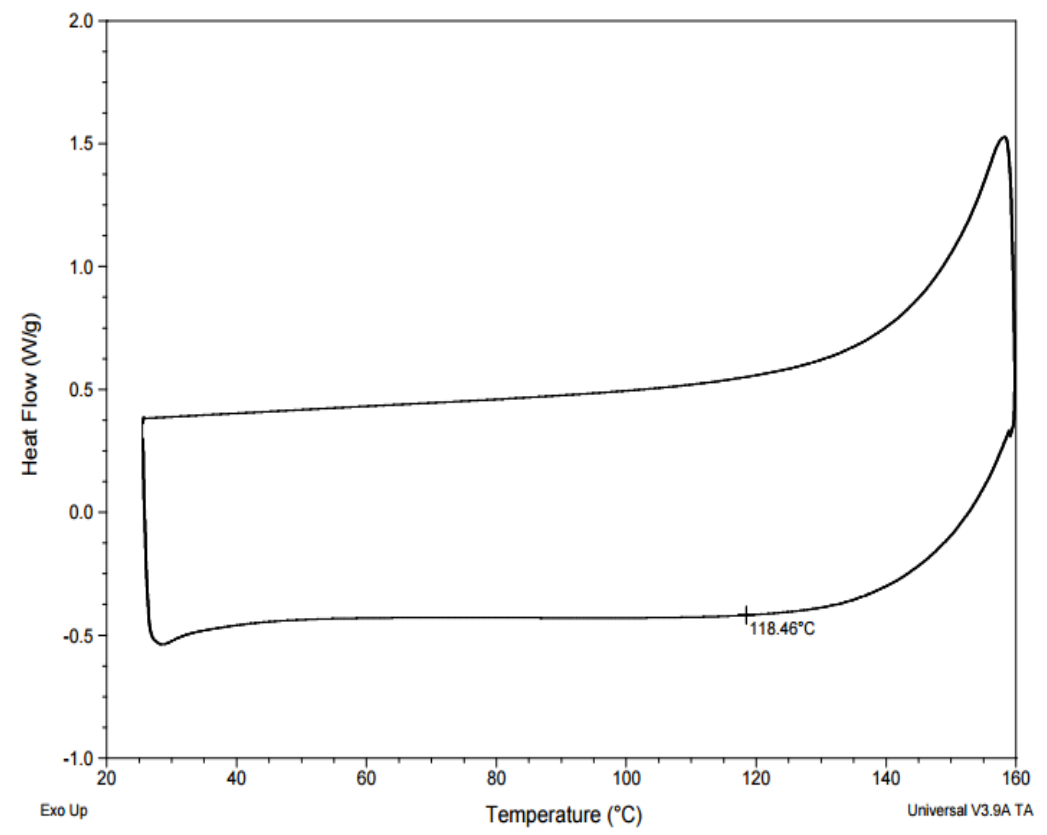

Figure II.16. DSC of compound 3 up to $160{ }^{\circ} \mathrm{C}$. 


\section{P-Phenylene Diisocyanate PPDI}

The decomposition of the acetate (compound 3) into PPDI (compound 4) was not

monitored using IR spectra since it was done under vacuum and due to the moisture sensitivity of the isocyanate. Thus, the reaction was done, once the amount of the acetate remains constant and changes in color from creamy white into deep yellow-brownish color. IR was taken for PPDI, NCO peak was found around $2288.4 \mathrm{~cm}^{-1}$ (Figure II.17).

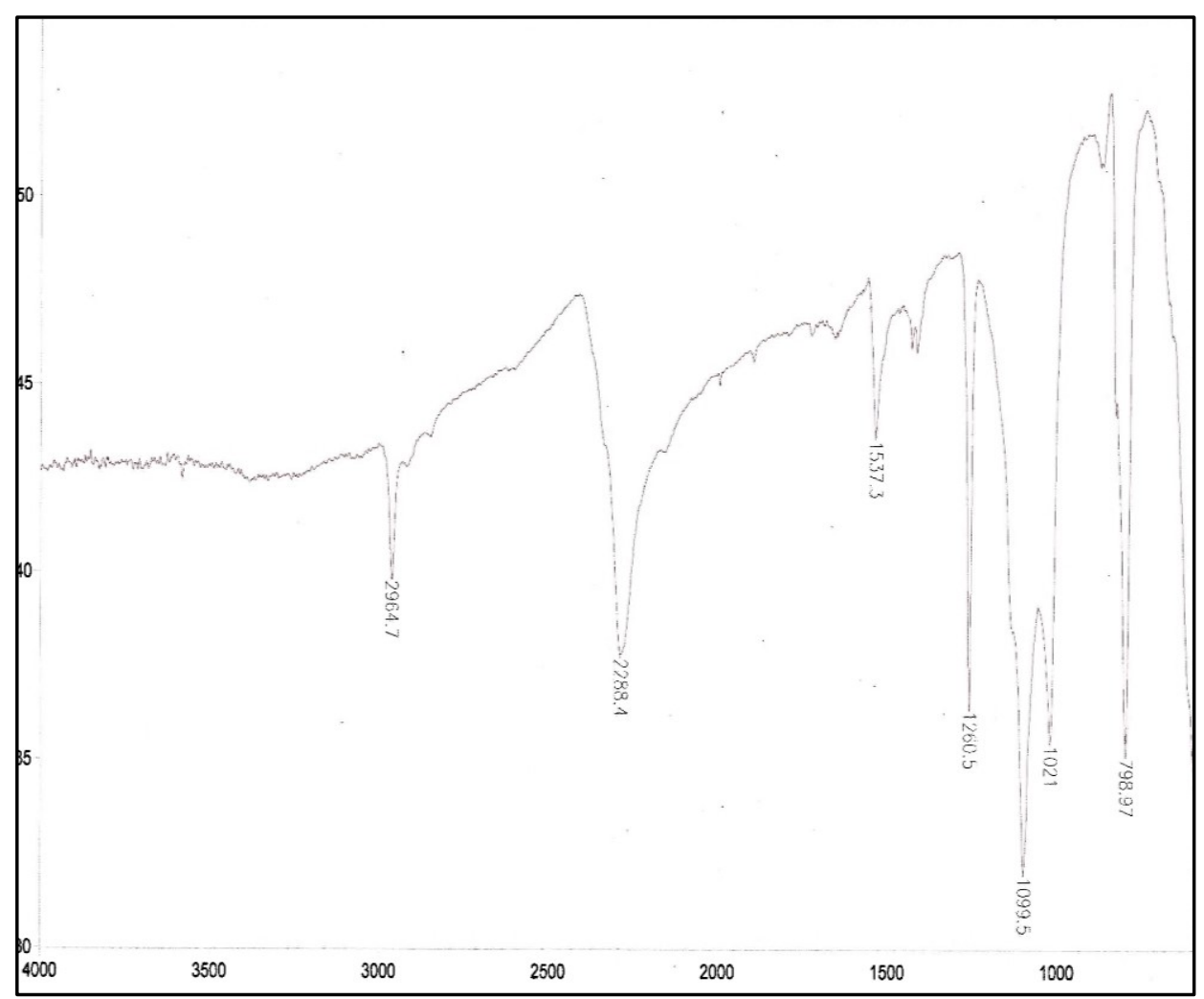

Figure II.17. IR spectrum of compound 4. 


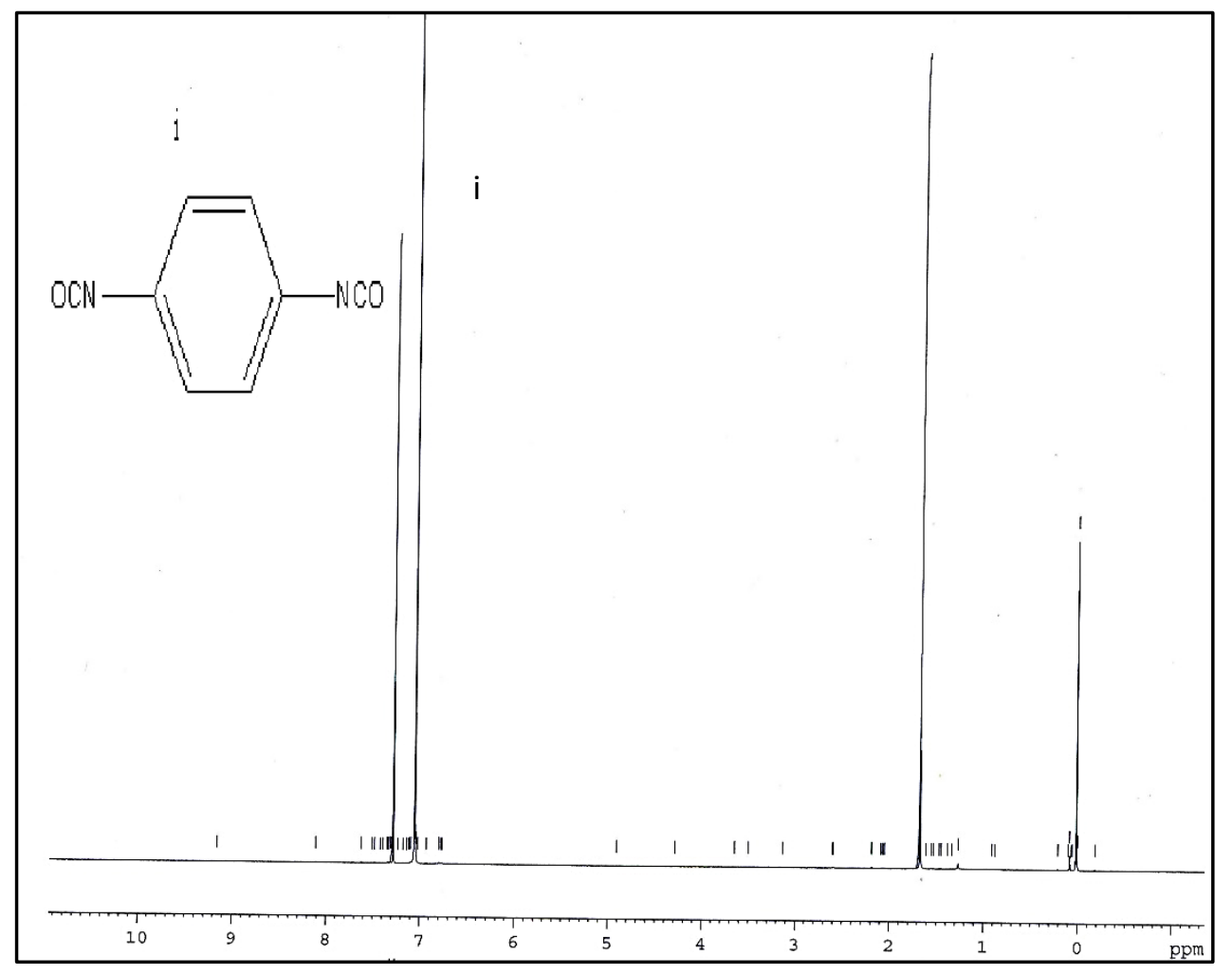

Figure II. 18. ${ }^{1} \mathrm{H}$ NMR spectrum of compound 4

\section{II.5. Conclusion}

A new route was developed for Lossen rearrangement for the synthesis of pure PPDI, starting from diethyl terephthalate that can be derived from biomass. The route included the least amount of toxic chemicals and alternative route was also developed without the use of amine base and organic solvent for the synthesis of the acetate form.

The decomposition reaction of the acetate into the isocyanate occurs at $180{ }^{\circ} \mathrm{C}$, thus for future work we need to find a way to lower the temperature of the reaction such as by using a catalyst. Thus, turning this method into an efficient, most economic and green way to synthesize PPDI and other aromatic isocyanates. 


\section{II.6. References}

1- Tianming, N.; Bing, Y. CN 1687022 A, 2005.

2- Butler, D.; Alper, H. Chem. Commun. 1998, 2575-2576.

3- Waldman, T.; McGhee, W. J. Chem. Soc., Chem. Commun. 1994, 957-958.

4- Masuno, M.; Cannon, D.; Bissell, J.; Smith, R.; Foster, M.; Wood, A.; Smith, P.; Hucul, D. WO 2013040514 A1, 2013.

5- Tachibana, Y.; Kimura, S.; Kasuya, K. Sci. Rep. 2015, 5, 8249.

6- Pang, J.; Zheng, M.; Sun, R.; Wang, A.; Wang, X.; Zhang, T. Green Chem. 2016, 18, 342359. 


\section{CHAPTER III}

Synthesis and Characterization of 1,4-Diisocyanatobutane BDI 


\section{III.1. Overview on BDI synthesis}

1,4-Diisocyanatobutane (BDI) is a diisocyanate with aliphatic chain made of four carbons and two NCO groups on both ends. BDI is mainly used in the synthesis of biomedical polyurethanes.

Unlike aromatic polyurethanes, those made from aliphatic isocyanates are more favourable in the medical field. BDI potentially degrade into non-toxic products such as amino acid lysine and diamine putrescine which are already found in the human body. ${ }^{1}$ Conventionally, BDI is synthesized using phosgene and diamine.

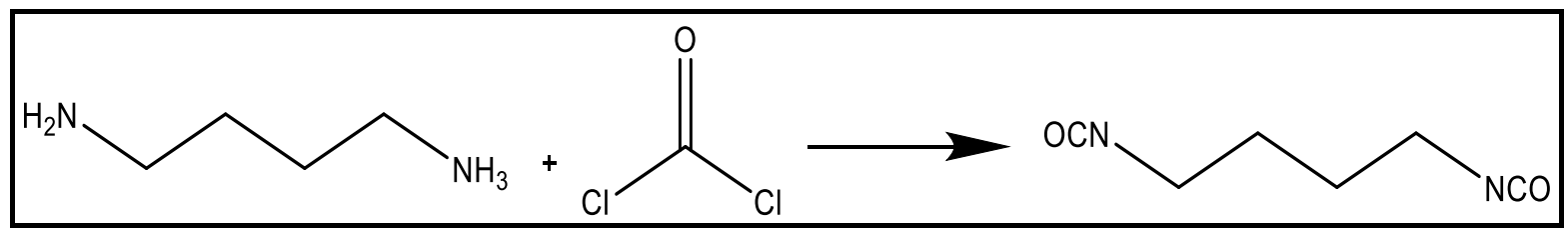

Scheme III.1. BDI by phosgenation of tetramtheylene diamine ${ }^{2}$

However, BDI is obtained in moderate yields which is not considered for application in industrial scale. Another route was also done for the synthesis of BDI by thermal decomposition of diurethane.

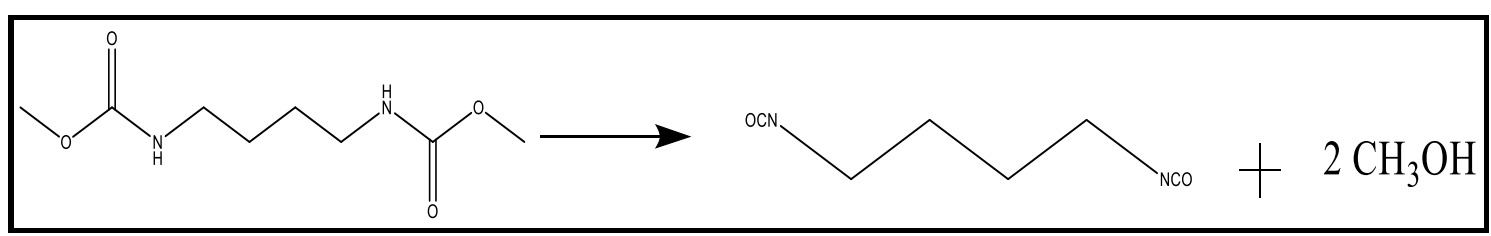

Scheme III.2. Thermal decomposition of diurethanes into BDI ${ }^{2}$ 
The diurethanes was obtained by the reaction of carbonic acid derivative (dialkyl carbonates) and aliphatic diamines. ${ }^{2}$

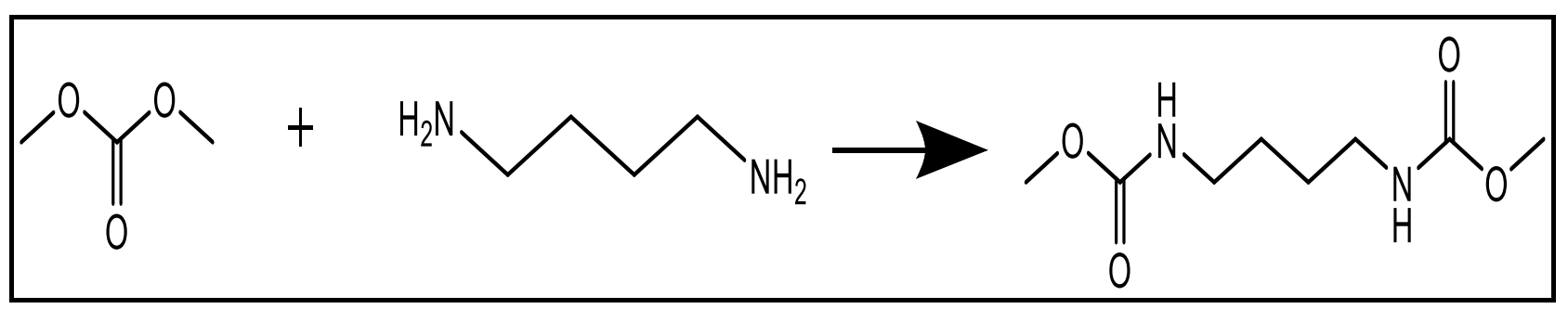

Scheme III.3. Synthesis of diurethanes ${ }^{2}$

All the mentioned were successful in synthesizing BDI and other aliphatic isocyanates. However, they relied on the use of toxic materials such as phosgene. We in our research have modified the synthesis of BDI and simplified it based on bio-based material such methyl adipate that we used to make hydroxamic acid. Then, we transferred the hydroxamic acid into its acetate form. The latter was decomposed by heating to give BDI.

\section{III.2. Synthesis of Bio-based Adipic Acid}

Adipic acid is used as a monomer for the synthesis of nylon, and as a starting material for the synthesis of monomers such as isocyanate, that is used in polyurethane production. Industrially, adipic acid is derived from petrochemicals such as cyclohexane and cyclohexanol. The commercial synthesis of adipic acid is based on the oxidation of cyclohexanol, which is derived from benzene. However, benzene is considered as non-renewable resource, and this route leads to the production of toxic by-products, and requires high energy input.

Thus, great work was done in order to find alternative routes for the synthesis of bio-based adipic acid. One method was developed, that consisted of converting biomass such as paper, 
wood, or any other low-cost bio-based renewable material into 1,6-hexanediol, then oxidizing the diol into adipic acid using Gluconobacter Oxidans.

\begin{tabular}{|c|c|c|c|c|c|c|c|}
\hline \multirow{2}{*}{ Biomass } & \multirow{2}{*}{$\underset{\text { hydrolysis }}{\stackrel{\text { acid }}{\longrightarrow}}$} & \multirow{2}{*}{ Glucose } & \multirow{2}{*}{ Dehydration } & \multirow{2}{*}{\multicolumn{2}{|c|}{$\begin{array}{l}\text { 5-Hydroxymethylfurfural } \\
\text { (5HMF) }\end{array}$}} & \multicolumn{2}{|c|}{ Raney Ni } \\
\hline & & & & & & & \\
\hline \multirow{2}{*}{\multicolumn{3}{|c|}{ 2,5-Tetrahydrofurandiomethanol }} & $\left(\mathrm{Cu}_{2} \mathrm{Cr}\right) \mathrm{O}$ & \multirow{2}{*}{ 1,6-Hexandiol } & \multicolumn{3}{|c|}{ Gluconobacter } \\
\hline & & & & & $\overrightarrow{\text { oxydants }}$ & & Acid \\
\hline
\end{tabular}

Scheme III.4. Transforming biomass into adipic acid ${ }^{3}$

However, performing this reaction at this elevated temperature could be considered as a limitation to be applied industrially.

Another trial was done using benzoate, which was fermented into muconoic acid and glucaric acid. This route doesn't eliminate the use of petroleum based starting material, hence it doesn't fall into desired development. 


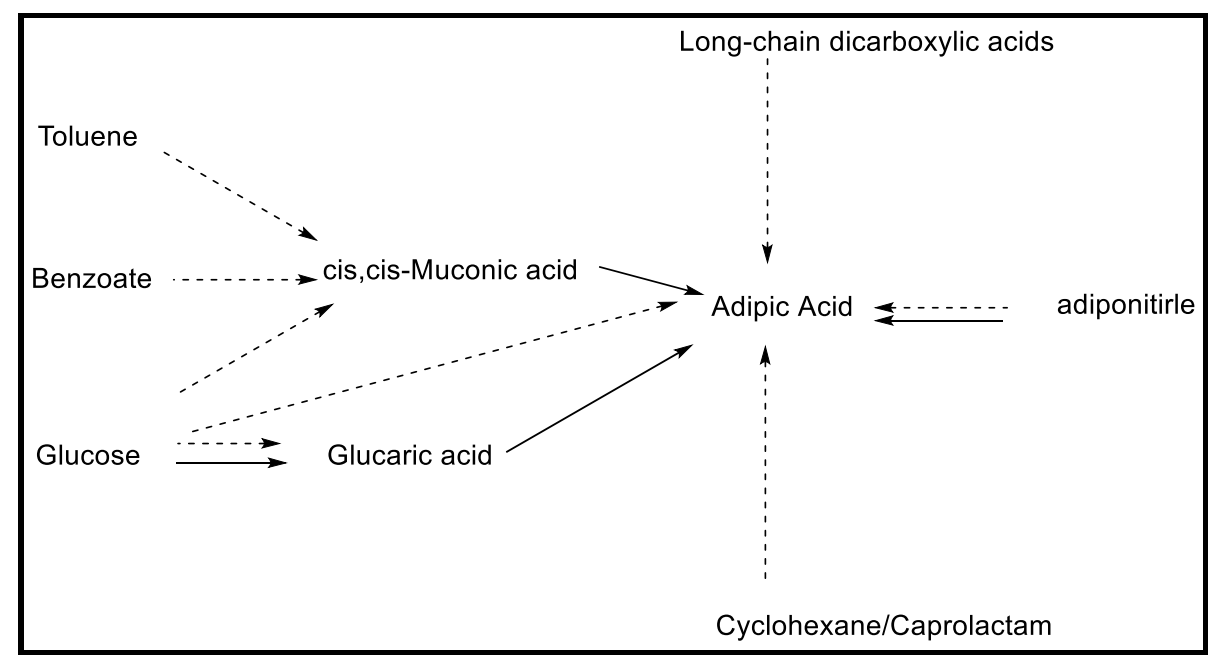

Scheme III.5. Transforming benzoate into muconic acid for synthesis of adipic acid ${ }^{3}$

A route was also introduced by Frost and Draths, that was based on converting Dglucose, which is considered as a renewable source, into adipic acid through many steps using enzymes and bacteria, such as E. Coli. However, this method gave low yield of adipic acid and required oxygen supply to the reaction system due to the use of dioxygenase.

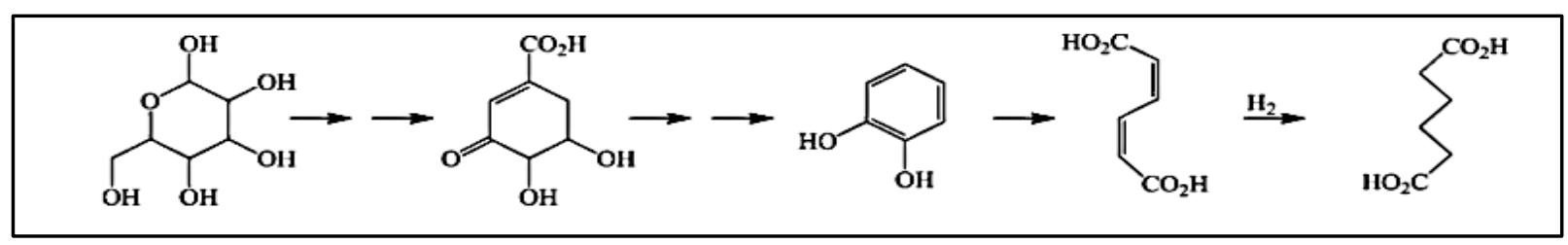

Scheme III.6. Adipic acid derived from D-glucose ${ }^{3}$

All the routes that are being developed, show great potential to replace the traditional petrochemcial synthesis of adipic acid. This replacement will need time inorder to be industrially 
applied. Studies show that the bio-based routes will have many advantages that will increase by $25 \%$ in the future. ${ }^{3}$

\section{III.3. Synthesis of BDI by Lossen Rearrangement Reaction}

Similar to aromatic diisocyanate PPDI, the synthesis of BDI was done using Lossen rearrangement reaction in order to eliminate the use of phosgene and avoid the production of corrosive $\mathrm{HCl}$. We started with dimethyl adipate and after multistep process we obtained BDI. The overall reaction can be summarized in scheme III.7.

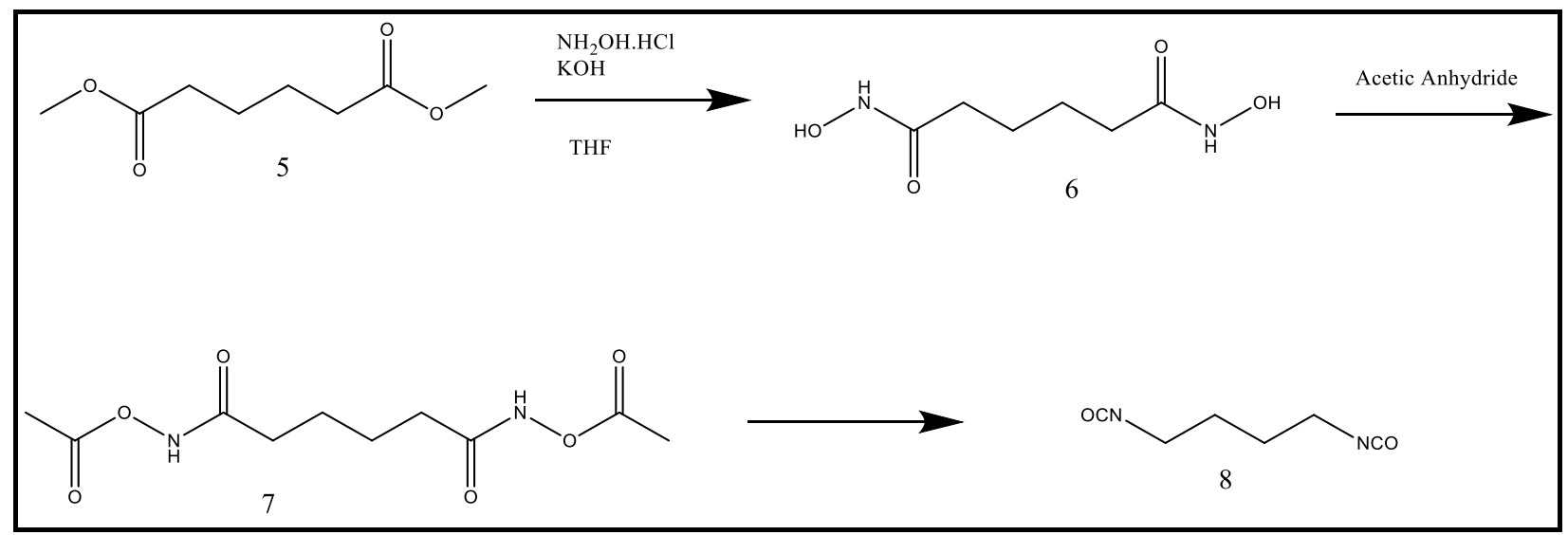

Scheme III.7. Overall synthesis of BDI

BDI is formed by the decomposition of the hydroxamate (compound 7) with a proposed reaction mechanism presented in Scheme III.8. 


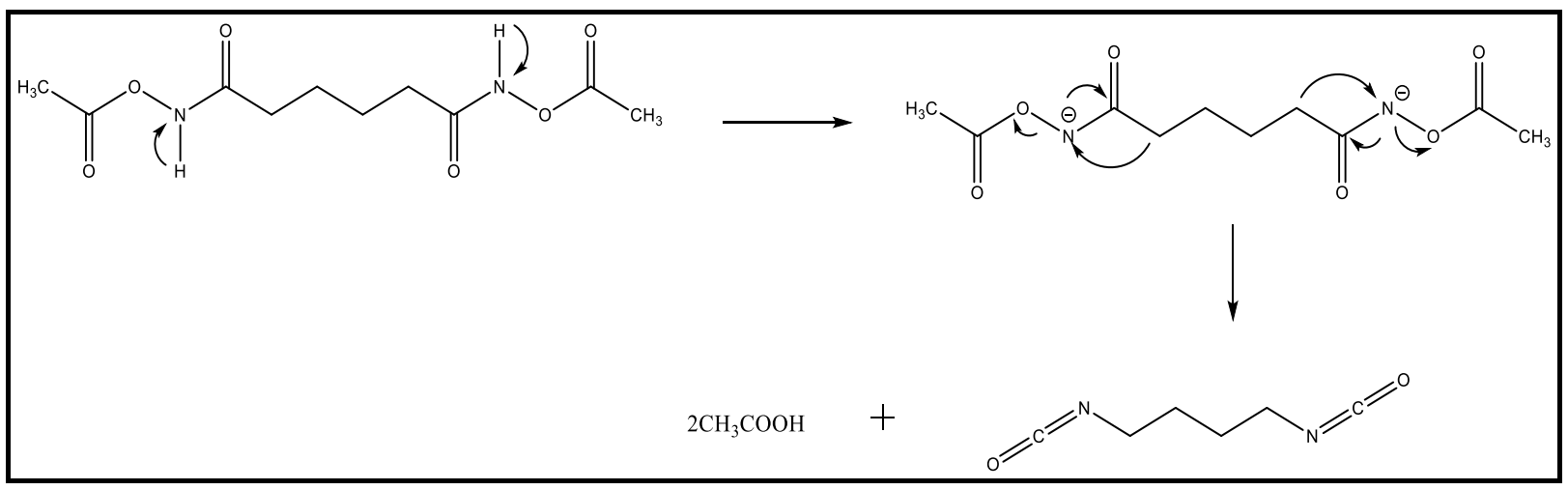

Scheme III.8. Proposed reaction mechanism for BDI formation by Lossen rearrangement

\section{III.4. Experimental Section}

\section{III.4.1. Materials}

Dimethyl adipate, hydroxylamine hydrochloride, Acetic Anhydride (AAN), and N,Ndiisopropylethylamine were purchased from Sigma Aldrich, potassium hydroxide was purchased from Carleton Laboratories, hydrochloric acid was purchased from Anachemia, methanol was purchased from $\mathrm{BDH}$, and dimethoxyethane (DME) was purchased from ACP chemicals, tetrahydrofuran (THF) was purchased from Caledon Laboratories.

All the chemicals were used as received, except for AAN, THF and DME were distilled and dried. Molecular sieve 4A were purchased from Sigma Aldrich and were oven dried over night before using.

\section{Distilling and Drying of Solvents}

The process of drying of solvents AAN and DME is described in Chapter 2 on page 5.

THF was refluxed with sodium and benzophenone then distilled. 


\section{III.4.2. General Characterization}

See Chapter 2.

\section{III.4.3 Synthesis}

\section{Synthesis of 1,6-Dihydroxyhexanediamide (Aliphatic HA)}

Dimethyl adipate (compound 5) (30.0 g, $0.20 \mathrm{~mol}$ ), was dissolved in $90 \mathrm{~mL}$ of THF in a $500 \mathrm{~mL}$ three-neck-round-bottom flask at room temperature. Potassium hydroxide (38.6 g, 0.70 mol) was dissolved in $60 \mathrm{~mL}$ distilled water in a $200 \mathrm{~mL}$ conical flask, and hydroxylamine hydrochloride $(28.7 \mathrm{~g}, 0.50 \mathrm{~mol})$ was dissolved in $60 \mathrm{~mL}$ distilled water. The two basic solutions were mixed together, and then poured in a dropping funnel placed on top of the flask of adipate solution. The basic solution was added dropwise to the adipate solution at $0^{\circ} \mathrm{C}$. Then, the mixture was stirred for one day at room temperature under nitrogen. Afterwards, the mixture was acidified with $400 \mathrm{~mL}(5 \% \mathrm{HCl})$ distilled water till $\mathrm{pH}$ was decreased to a value of 6-7. The mixture was stirred until a white precipitate appears at the bottom of the flask. The solid was isolated by filtration and washed with distilled water. Then it was stirred in methanol (400 $\mathrm{mL})$ for 20 minutes. Then, the mixture was filtered and the aliphatic HA, compound $\mathbf{6}$, was obtained as a white solid (10.5 g, 34.4\% yield) it was soluble in DMSO and partially soluble in water and methanol.

IR (Nujol, $\mathrm{cm}^{-1}$ ) 1566.3 N-C, 1619.6 HN-C=O, $1664 \mathrm{HN}-\mathrm{C}=\mathrm{O}$

${ }^{1} \mathrm{H}-\mathrm{NMR}$ (300 MHz, DMSO-d 6 , ppm): $\delta 10.38$ (2H s), 8.68 (2H s), 1.93 (4H m), 1.45 (4H m) 


\section{Synthesis of 1,6- Adipohydroxamic Diacetate (Aliphatic HA Acetate)}

Method 1: Aliphatic hydroxamic acid (compound 6) (7.0 g, $0.04 \mathrm{~mol}$ ), was mixed with dry AAN (10.2 g, $0.10 \mathrm{~mol})$ and N,N-diisopropylethylamine $(15.4 \mathrm{~g}, 0.12 \mathrm{~mol})$ in $40 \mathrm{~mL}$ of dry DME, in a $250 \mathrm{~mL}$ three-neck-round-bottom-flask connected with a condenser. The mixture was stirred for two hours at $70{ }^{\circ} \mathrm{C}$ under nitrogen. Then, the reaction mixture was filtered and the solid residue was washed with chloroform. Aliphatic HA acetate (compound 7), was obtained as a creamy white solid (4.8 g, $45.9 \%$ yield). It was soluble in DMSO and insoluble in methanol, chloroform, and water.

IR (Nujol, $\left.\mathrm{cm}^{-1}\right)$ 1794.1 OC $=\mathrm{O}$

${ }^{1} \mathrm{H}-\mathrm{NMR}$ (300 MHz, DMSO-d6, ppm): $\delta 11.47$ (2H s), 2.14 (10H s), 1.52 (4H s)

Method 2: Aliphatic HA (compound 6) (0.1 g, 0.0003 mol) was mixed with AAN (0.5 g, $0.005 \mathrm{~mol}$ ) in a $15 \mathrm{~mL}$ round-bottom flask. The mixture was stirred for two days at room temperature under nitrogen. Then, after the reaction was done the reaction mixture was filtered and the HA acetate $(0.01 \mathrm{~g}$, yield $14.9 \%)$.

IR (Nujol, $\left.\mathrm{cm}^{-1}\right)$ 1793.0 OC $=\mathrm{O}$

${ }^{1} \mathrm{H}-\mathrm{NMR}\left(300 \mathrm{MHz}, \mathrm{DMSO}-\mathrm{d}_{6}, \mathrm{ppm}\right): \delta 11.47$ (2H s), $2.14(10 \mathrm{H} \mathrm{s}), 1.52$ (4H s)

\section{Synthesis of 1,4-Butanediisocyanate (Compound 8)}

Aliphatic HA acetate (compound 7) $(24.8 \mathrm{mg}, 0.96 \mathrm{mmol})$, was placed inside a round bottom flask $(5 \mathrm{~mL})$ with stirring bar, connected to another receiving flask and vacuum adapter by a bridge. The acetate was heated till $180{ }^{\circ} \mathrm{C}$ under vacuum. The reaction was stopped after all 
HA acetate was decomposed and the remaining changed into brownish color. BDI, compound $\mathbf{8}$, along with other products was formed as small droplets on the bridge. BDI was only soluble in chloroform.

${ }^{1} \mathrm{H}-\mathrm{NMR}\left(300 \mathrm{MHz}, \mathrm{CDCl}_{3}, \mathrm{ppm}\right): 3.36(4 \mathrm{H}, \mathrm{m}), 1.68$ (4H, m);

$\operatorname{IR}\left(\mathrm{cm}^{-1}\right): 2273.1 \mathrm{NCO}$

\section{III.4.4. Discussion}

\section{1,6-Dihydroxyhexanediamide (Aliphatic HA)}

During the synthesis of aliphatic HA, compound $\mathbf{6}$, the reaction was monitored through taking IR samples at different intervals of time. The ester peak of starting material, compound $\mathbf{5}$, at $1736.9 \mathrm{~cm}^{-1}$ decreased as the reaction proceeded, and the three characterizing peaks at 1664.0, 1619.6, and $1566.3 \mathrm{~cm}^{-1}$ of compound 6 increased. 


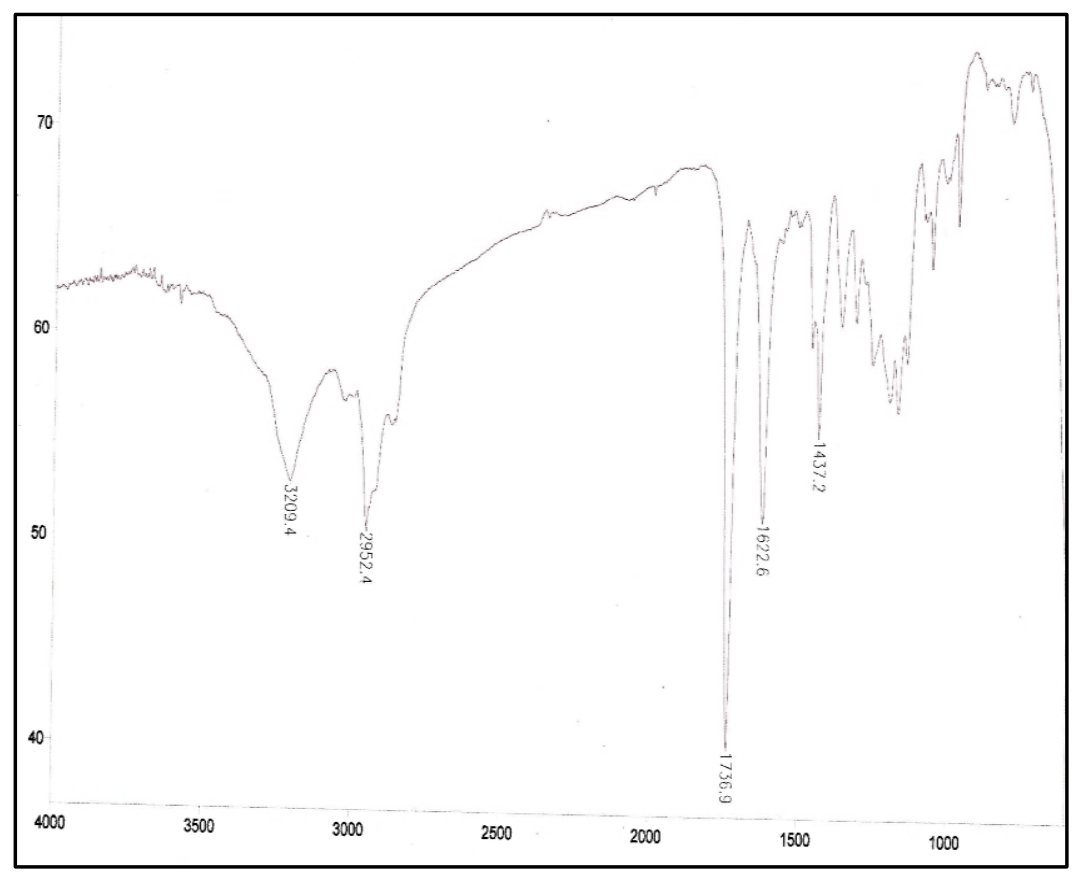

Figure III.1. IR spectrum of compound $\mathbf{5}$.

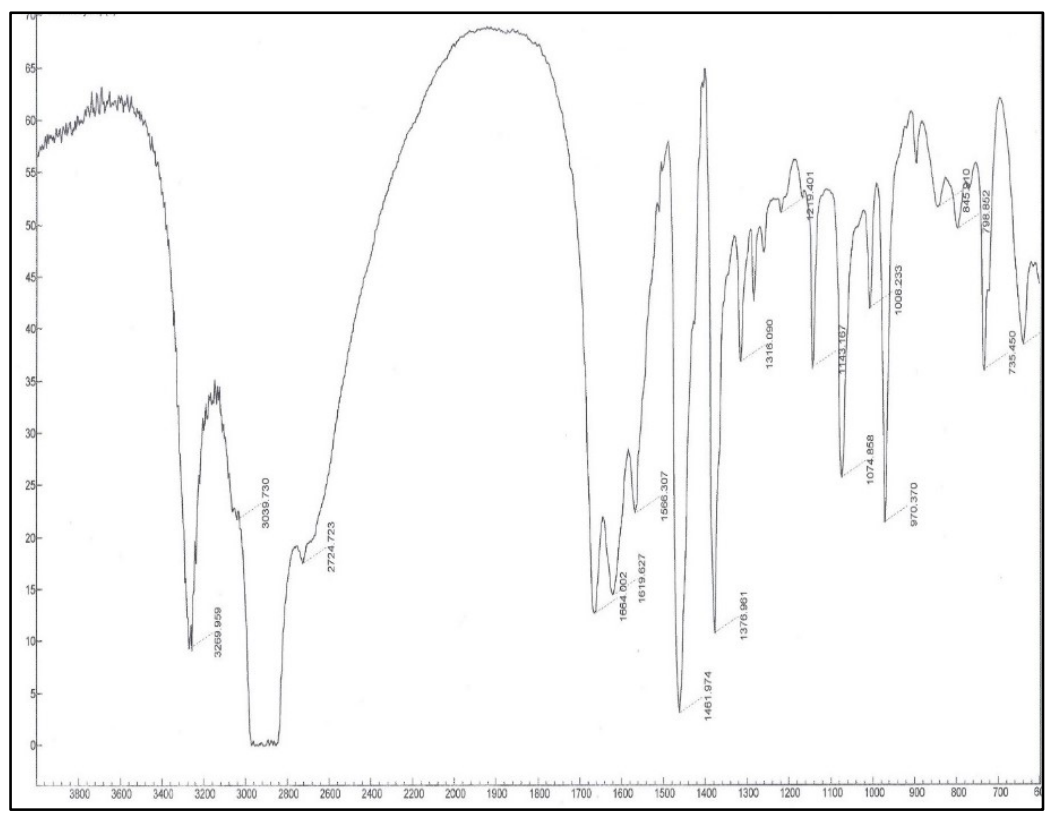

Figure III.2. IR spectrum of compound $\mathbf{6}$. 
After the work up for the purification of the aliphatic HA, compound $\mathbf{6},{ }^{1} \mathrm{H}$ NMR was done in DMSO and compared with that of the starting material.

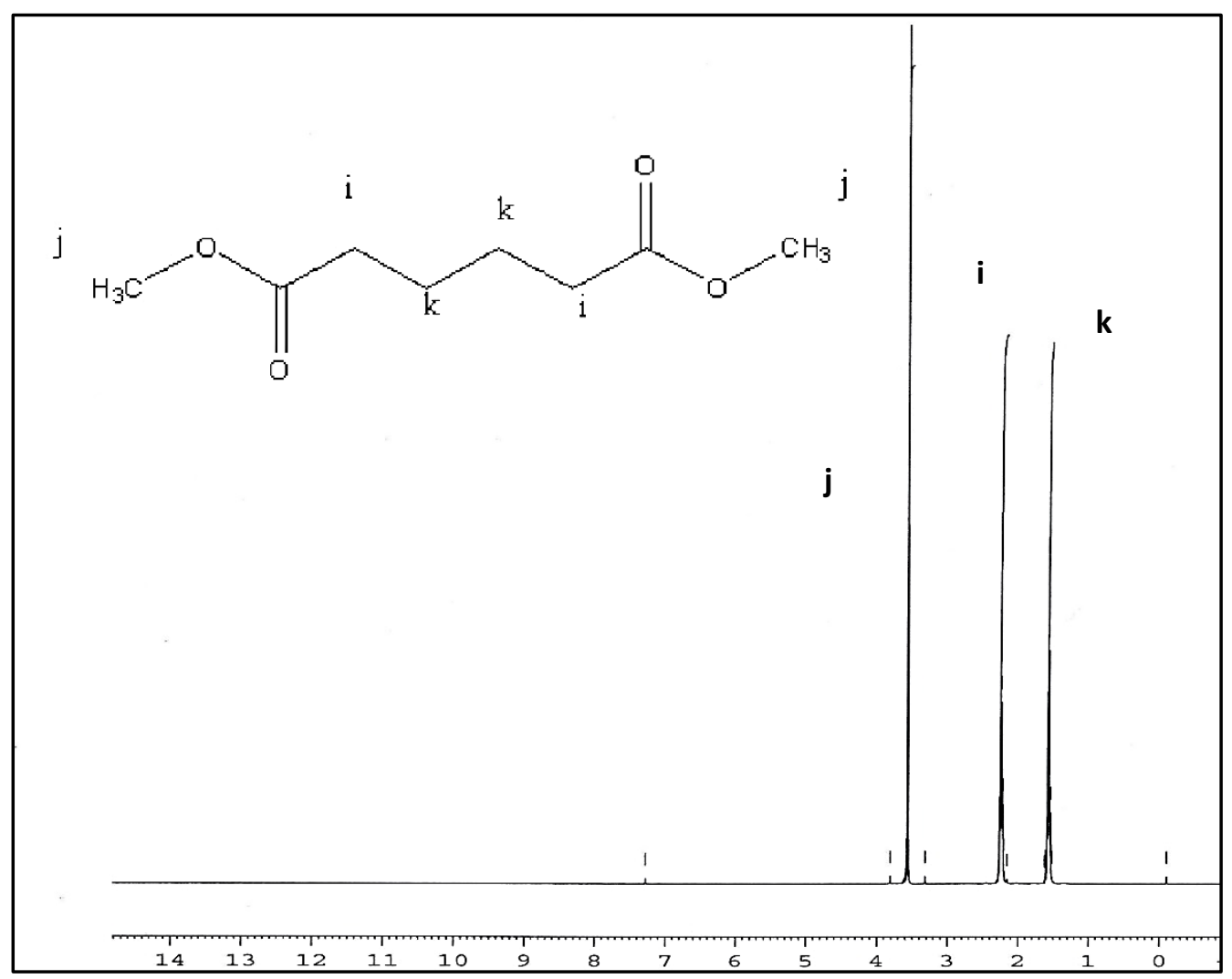

Figure III.3. ${ }^{1} \mathrm{HNMR}$ spectrum of compound $\mathbf{5}$. 


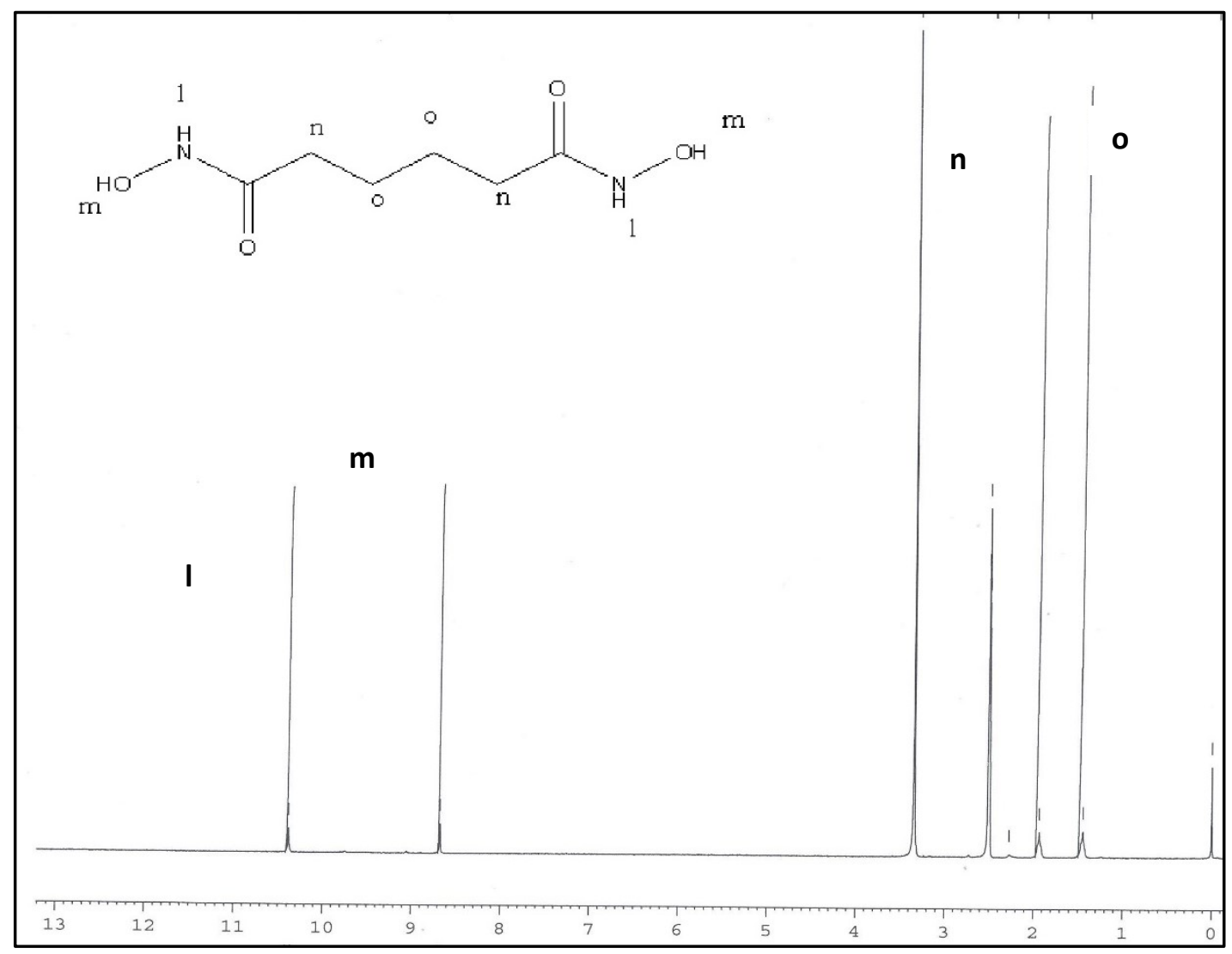

Figure III.4. ${ }^{1}$ HNMR spectrum of compound 6

By comparing the two proton NMR spectra of both compounds 5 (Figure III.5) and 6 (Figure III.6), we noticed the disappearance of singlet at $3.57 \mathrm{ppm}$ which corresponds to the methyl groups of the ester, and the appearance of $\mathrm{NH}$ and $\mathrm{OH}$ singlets at 10.38 and at $8.68 \mathrm{ppm}$ respectively.

The structure of the aliphatic hydroxamic acid and purity were confirmed using mass spectrometry. The major molecular ion peak m/z was found to be at 175.0. 


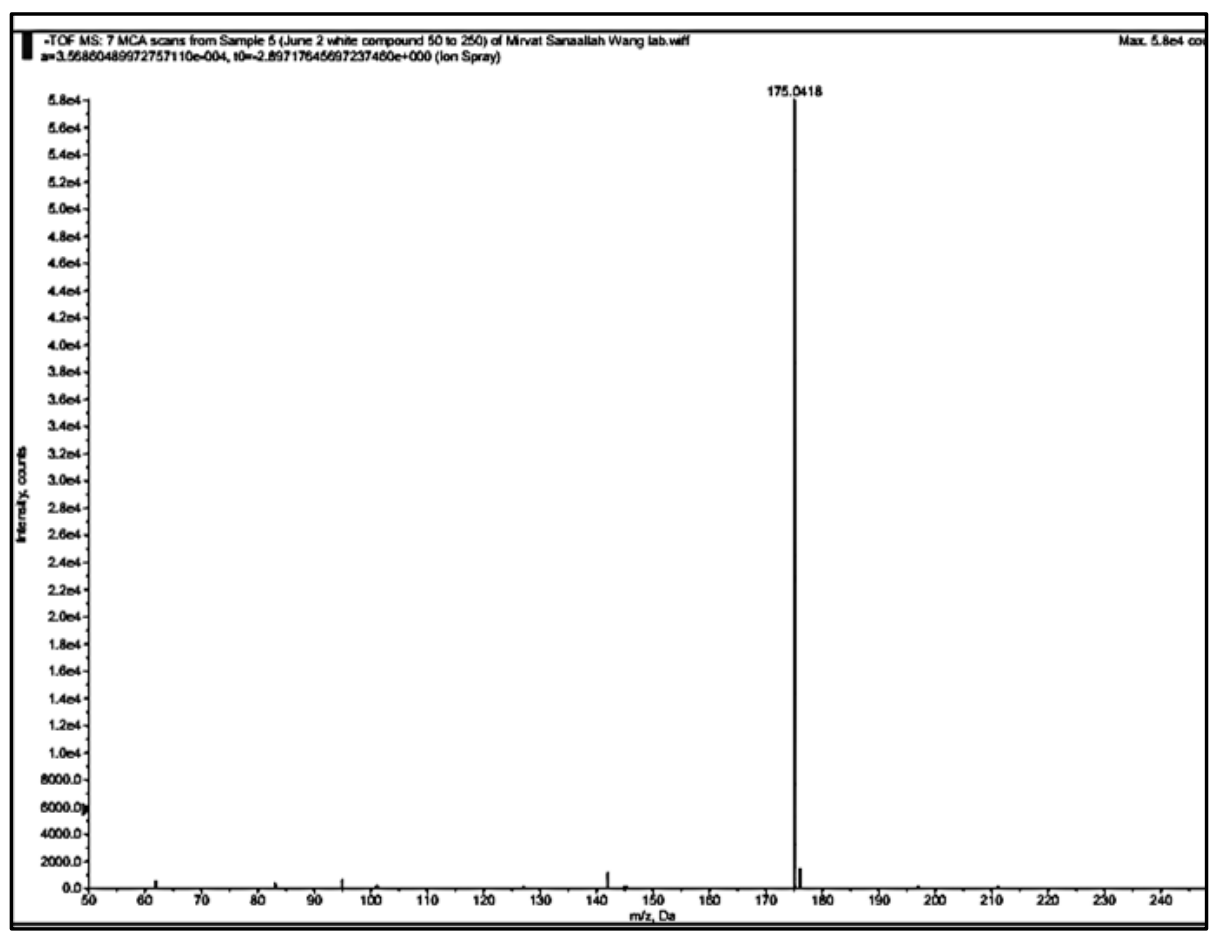

Figure III.5. Mass spectrum of compound 6

TGA was done for the aliphatic hydroxamic acid to test the stability of the compound versus heating. 


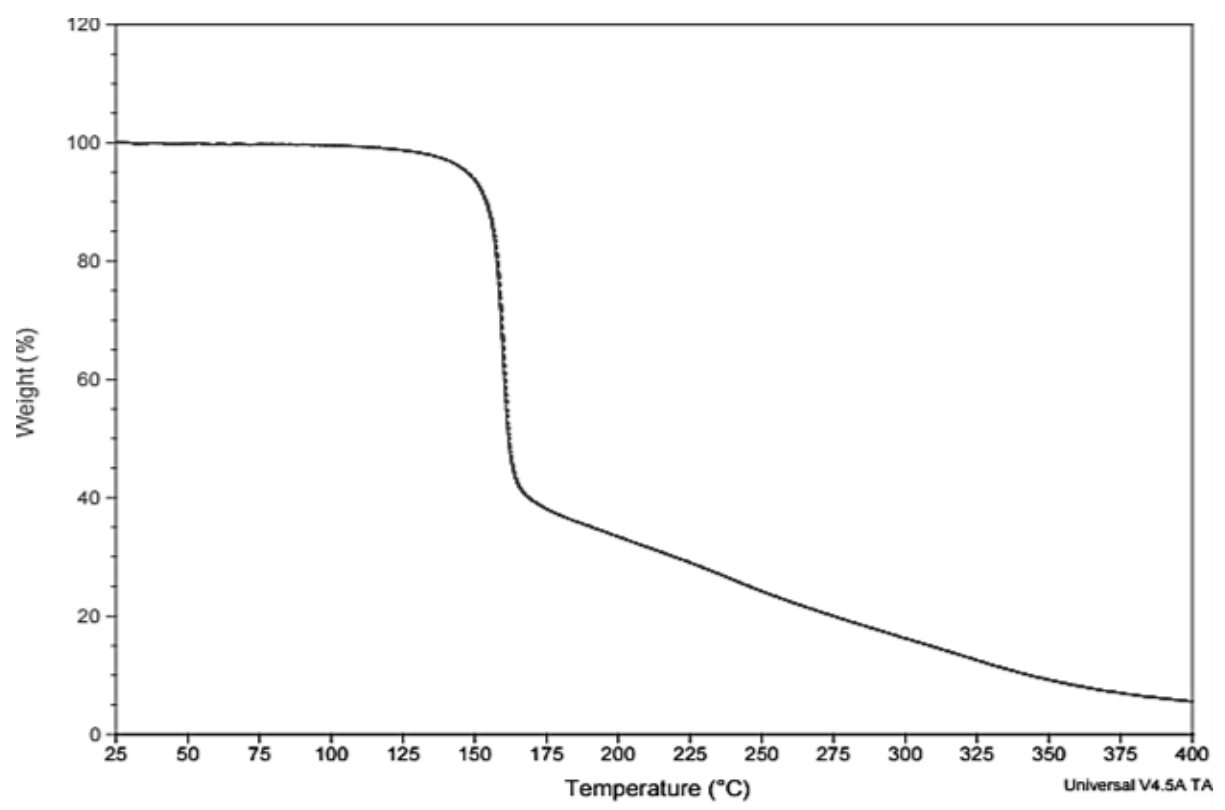

Figure III.6.Thermogravimetric analysis of compound 6.

The compound was found to be stable till a temperature around $130-140^{\circ} \mathrm{C}$, then the weight of the compound drops by $65 \%$. Upon taking DSC of the compound, we notice only decomposition peak at $200{ }^{\circ} \mathrm{C}$. 


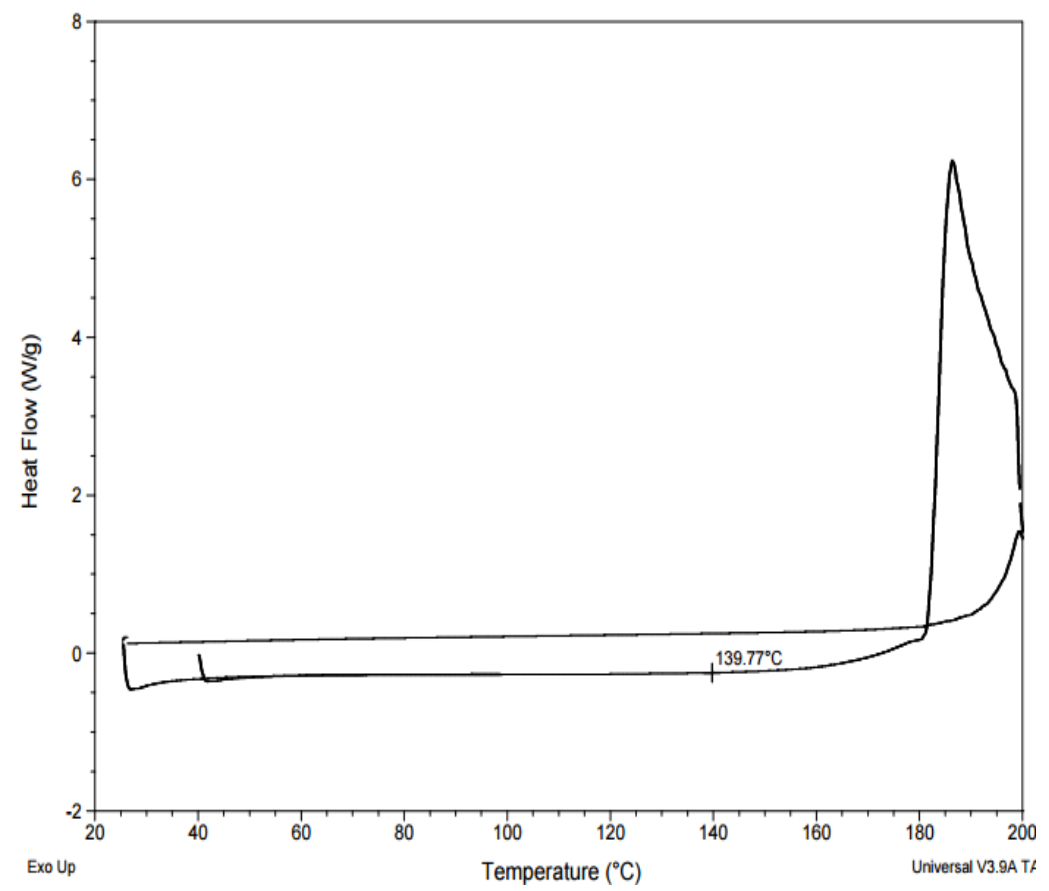

Figure III.7. DSC of compound 6 up to $200{ }^{\circ} \mathrm{C}$

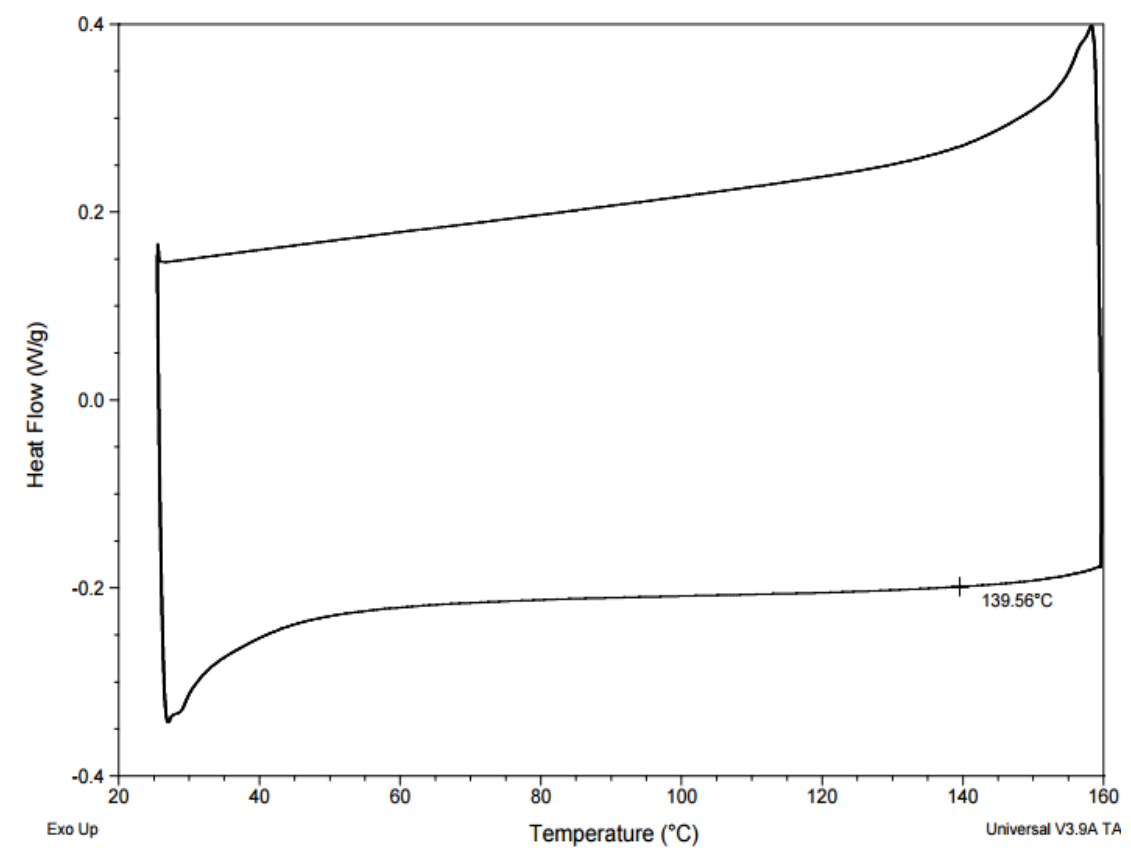

Figure III.8. DSC of compound 6 up to $160{ }^{\circ} \mathrm{C}$ 
DSC was repeated and the sample was heated till $160^{\circ} \mathrm{C}$, the compound doesn't show any melting peak, thus no change occurs to the compound upon heating, it only undergo decomposition.

\section{6- Adipohydroxamic Diacetate (Aliphatic HA Acetate)}

For the synthesis of the aliphatic HA acetate compound 7 through both routes, the reaction was monitored using IR. A sharp peak will start to appear at $1794.0 \mathrm{~cm}^{-1}$ which corresponds to the formation of the ester bond of the acetate. On the other side, the three characteristic peaks of the hydroxamic acid start disappearing.

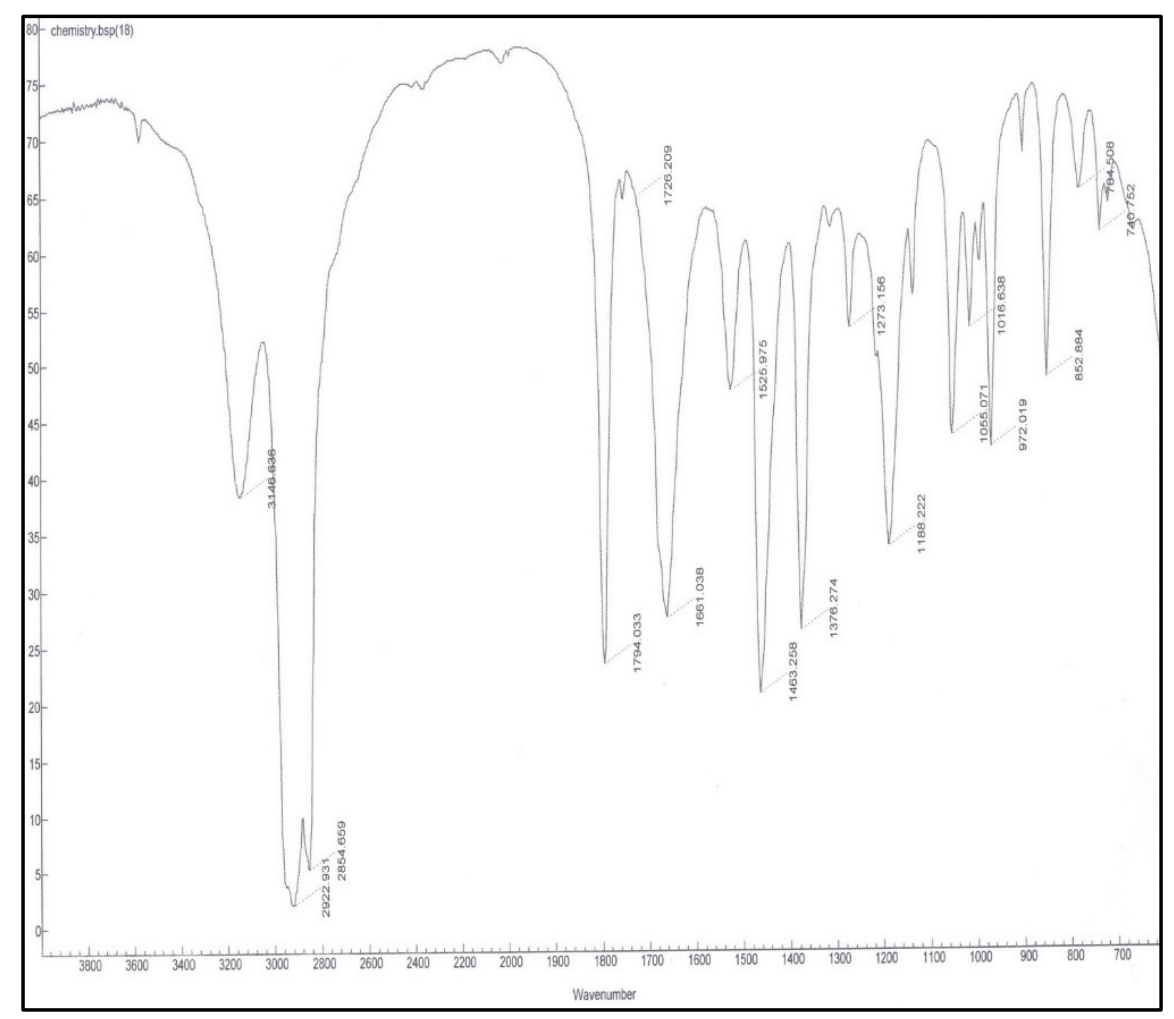

Figure III.9. IR spectrum of compound 7 (Method 1) 


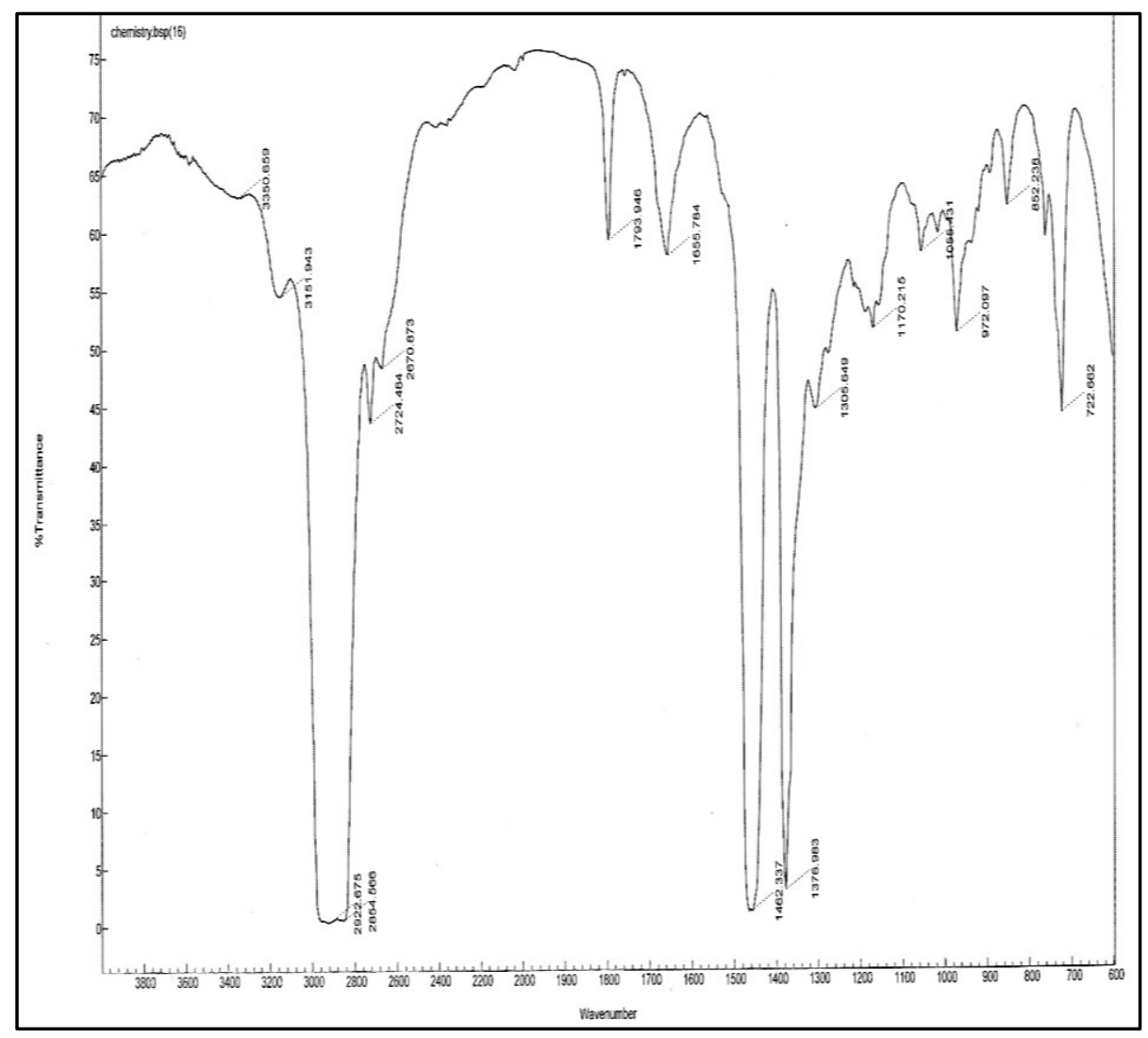

Figure III.10. IR spectrum of compound 7 (Method 2).

Once the aliphatic HA acetate was isolated, and ${ }^{1} \mathrm{H}$ NMR spectrum was done to confirm its structure. 


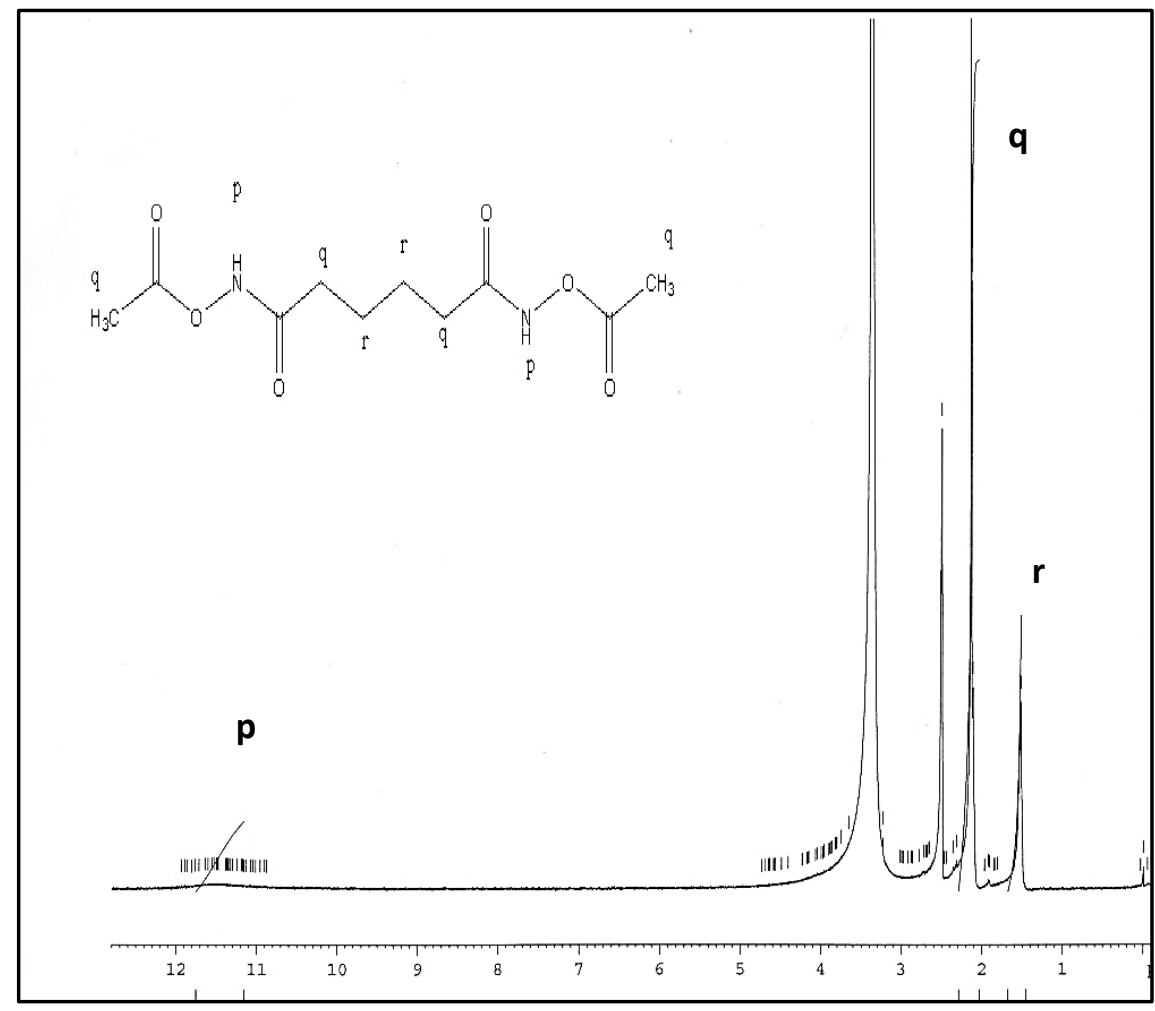

Figure III.11. ${ }^{1}$ HNMR spectrum of compound 7 (Method 1)

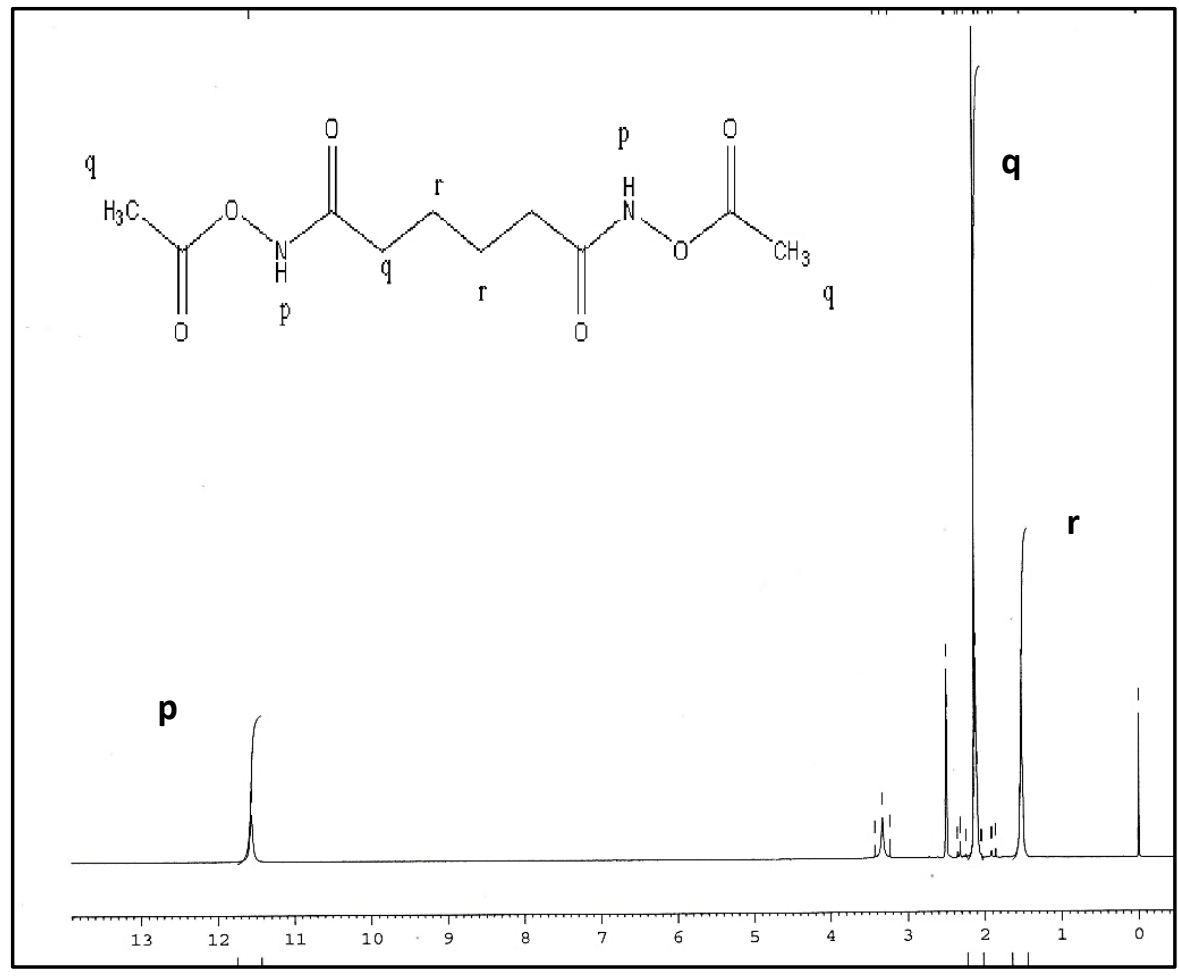

Figure III.12. ${ }^{1} \mathrm{H}$ NMR spectrum of compound 7 (Method 2) 
The NMR (Figures III.11 and III.12) in both methods shows the disappearance of the singlet at $8.7 \mathrm{ppm}$ which corresponds to the $\mathrm{OH}$ protons. In addition to the appearance of more protons around $2.12 \mathrm{ppm}$ that correspond to $\mathrm{CH}_{3}$ - protons, thus confirming the formation of the acetate bond.

Both methods have low yield, same spectra and final product appearance. However, the second method is more favoured since there is no amine base and no organic solvent used. To further prove the structure and purity of the sample we took Mass Spectrometry.

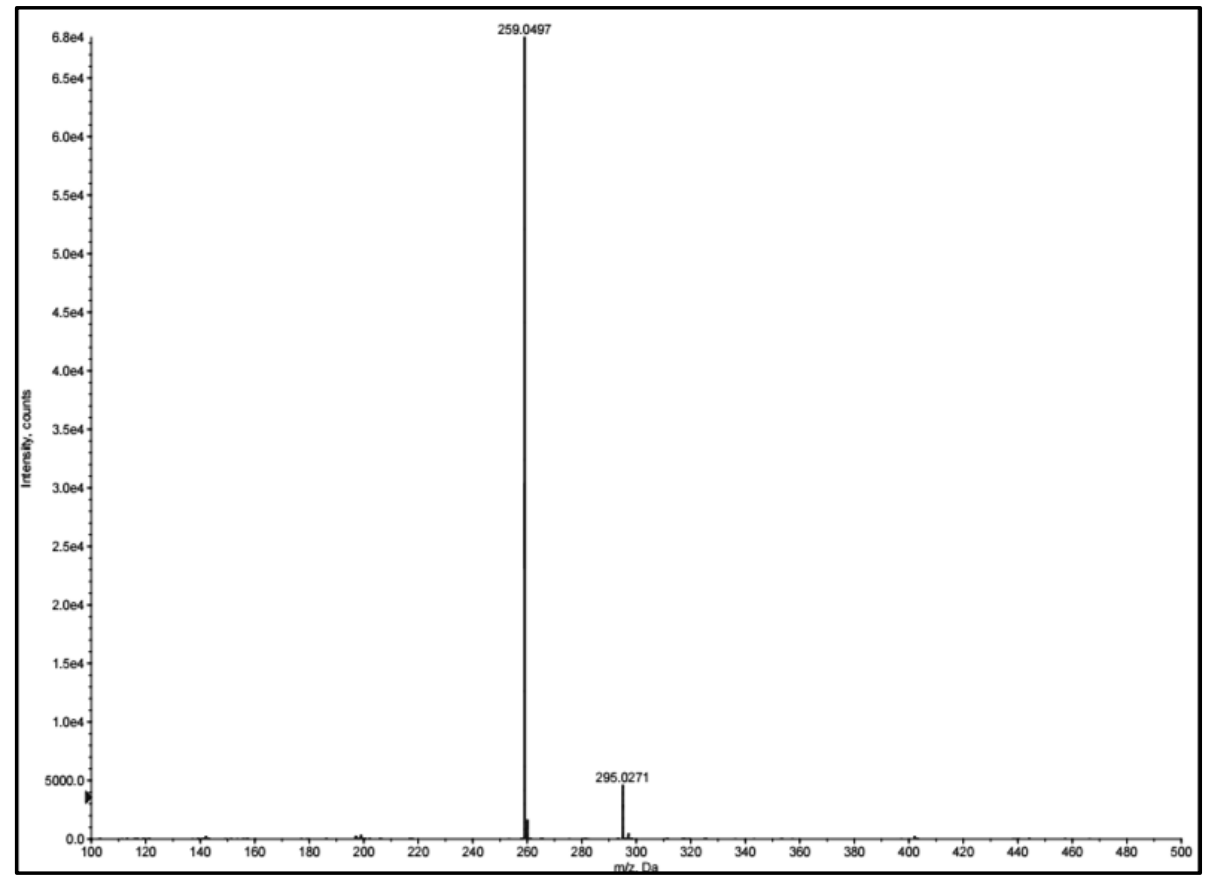

Figure III.13. Mass spectrum of compound 7

TGA was also done and DSC to confirm the temperature at which this compound decompose. We noticed around $160{ }^{\circ} \mathrm{C}$ the weight of the aliphatic acetate drops by almost $70 \%$. Upon heating the sample for DSC till $160{ }^{\circ} \mathrm{C}$, the curve shows no change happen to the sample. DSC was repeated again by heating till $200{ }^{\circ} \mathrm{C}$, the curve shows only decomposition. 


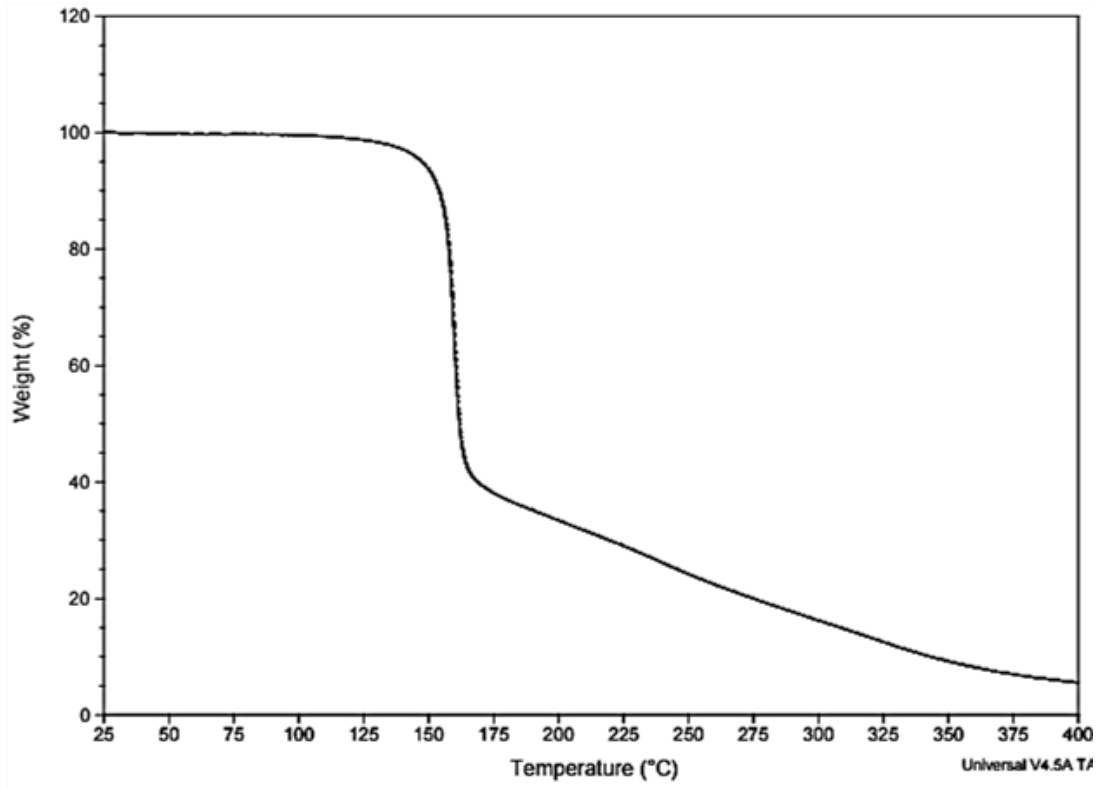

Figure III.14. Thermogravimetric analysis of compound 7.

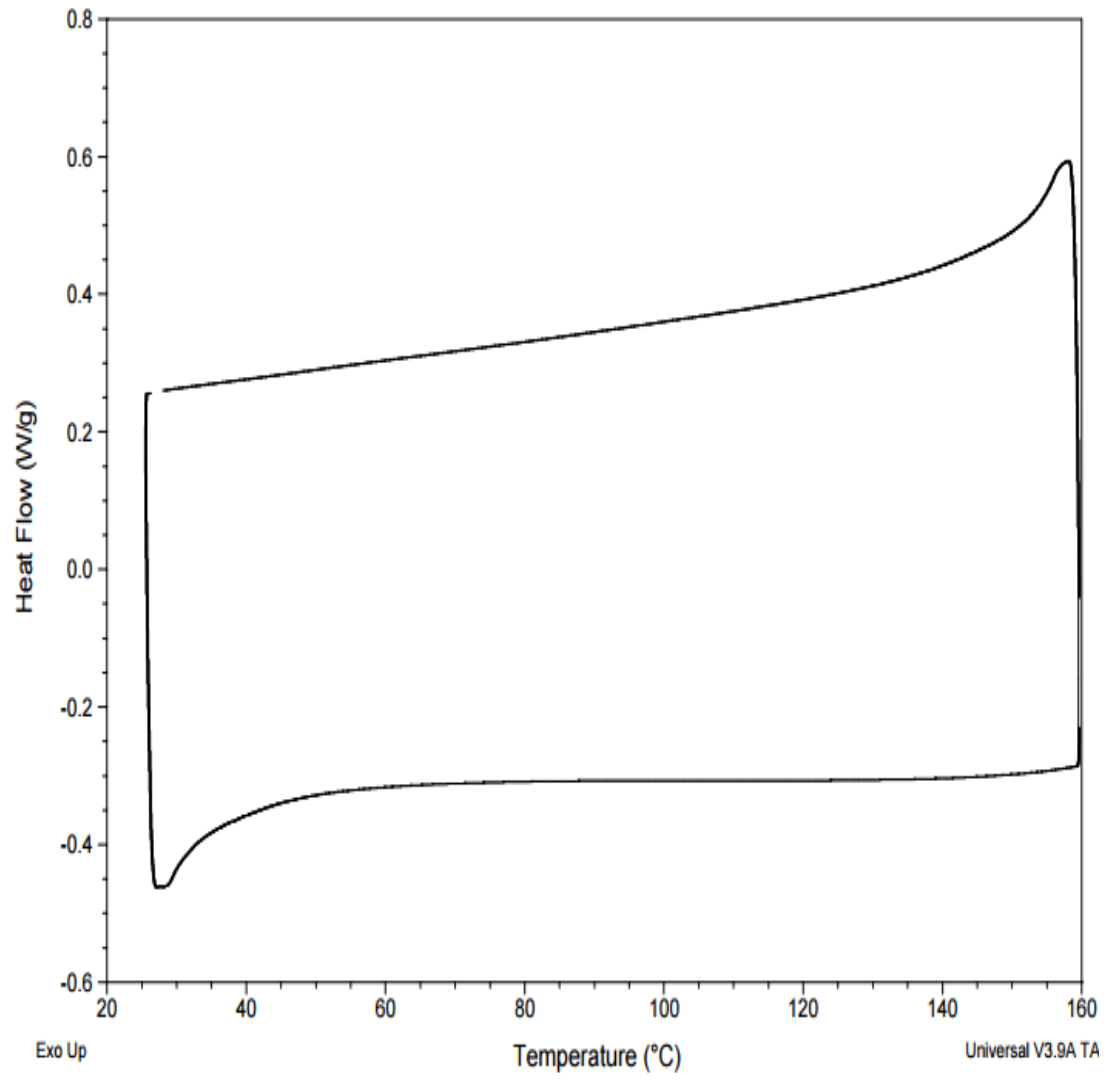

Figure III.15. DSC of compound 7 up to $180{ }^{\circ} \mathrm{C}$. 


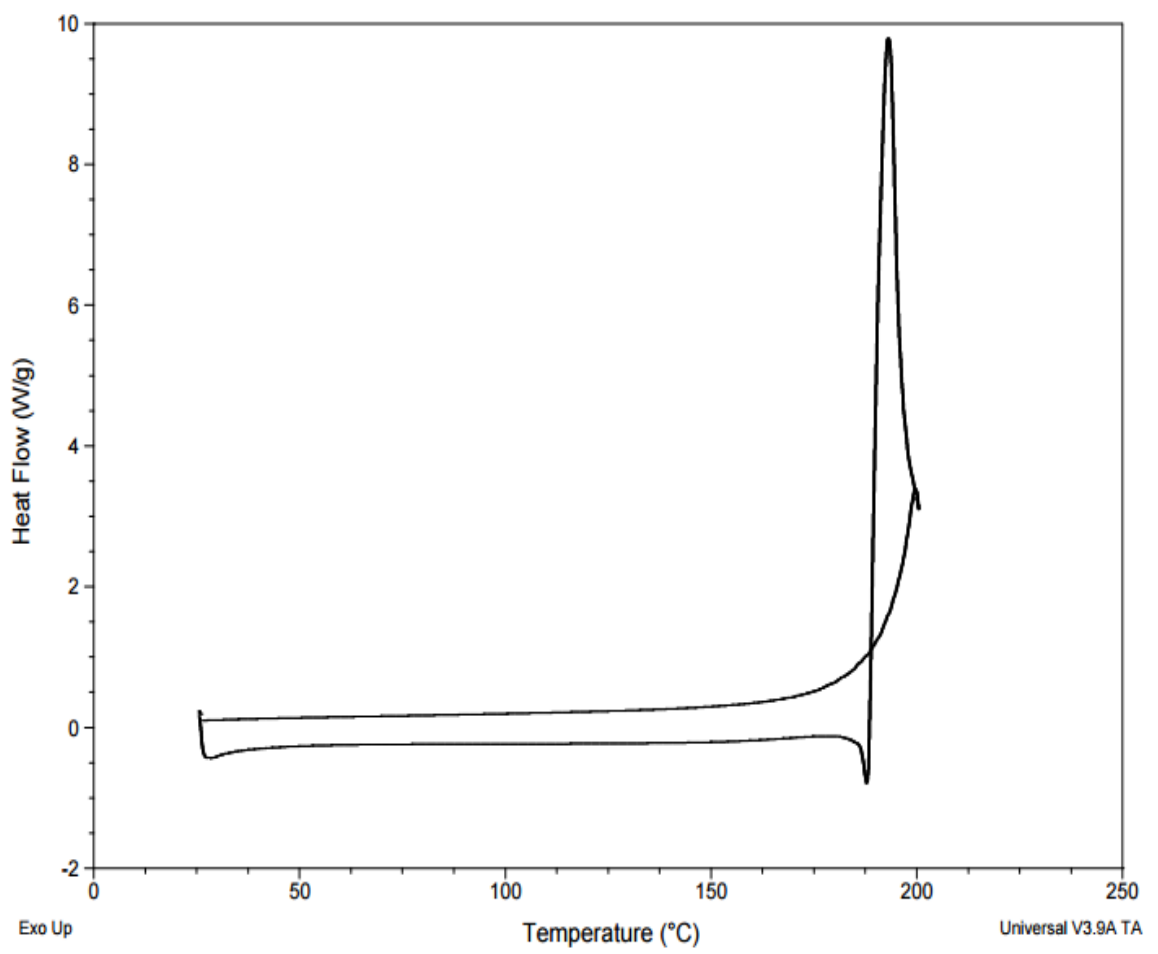

Figure III.16. DSC of compound 7 up to $200{ }^{\circ} \mathrm{C}$

\section{1,4-Butylene Diisocyanate}

The reaction of decomposition of compound $\mathbf{7}$ was allowed to run until most of the acetate was decomposed and the remaining in the main flask was turned into a brown sticky solid. BDI, acetic acid and some of the starting material were condensed on the bridge connecting the main flask to the receiving flask. IR was taken (Figure III.18) and it was found that a strong peak at $2273.1 \mathrm{~cm}^{-1}$ corresponding to NCO peak of BDI. Another two peaks at 1782.3 and $1736.8 \mathrm{~cm}^{-1}$ corresponding to $\mathrm{C}=\mathrm{O}$ of $\mathrm{HA}$ acetate (starting material) and acetic acid (by-product). 


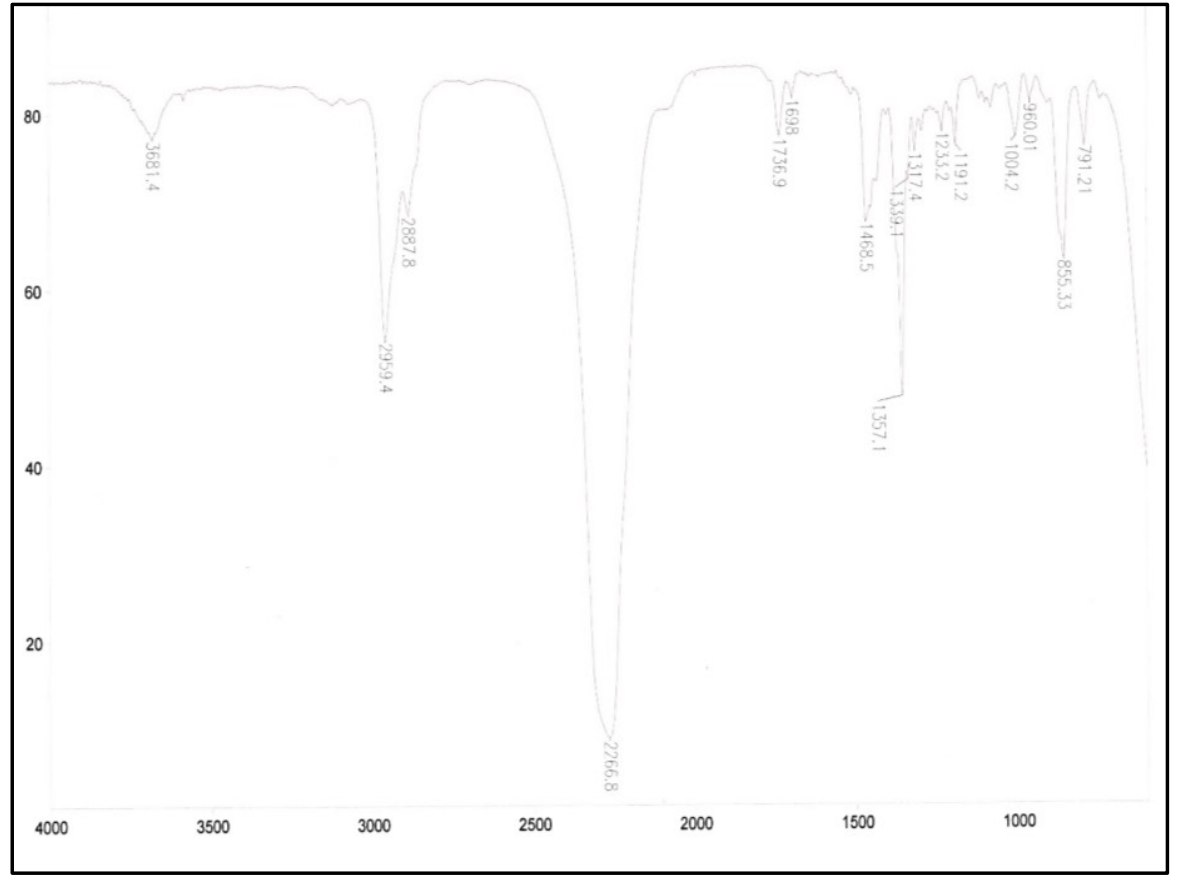

Figure III.17. IR spectrum of pure BDI compound $\mathbf{8}$ 


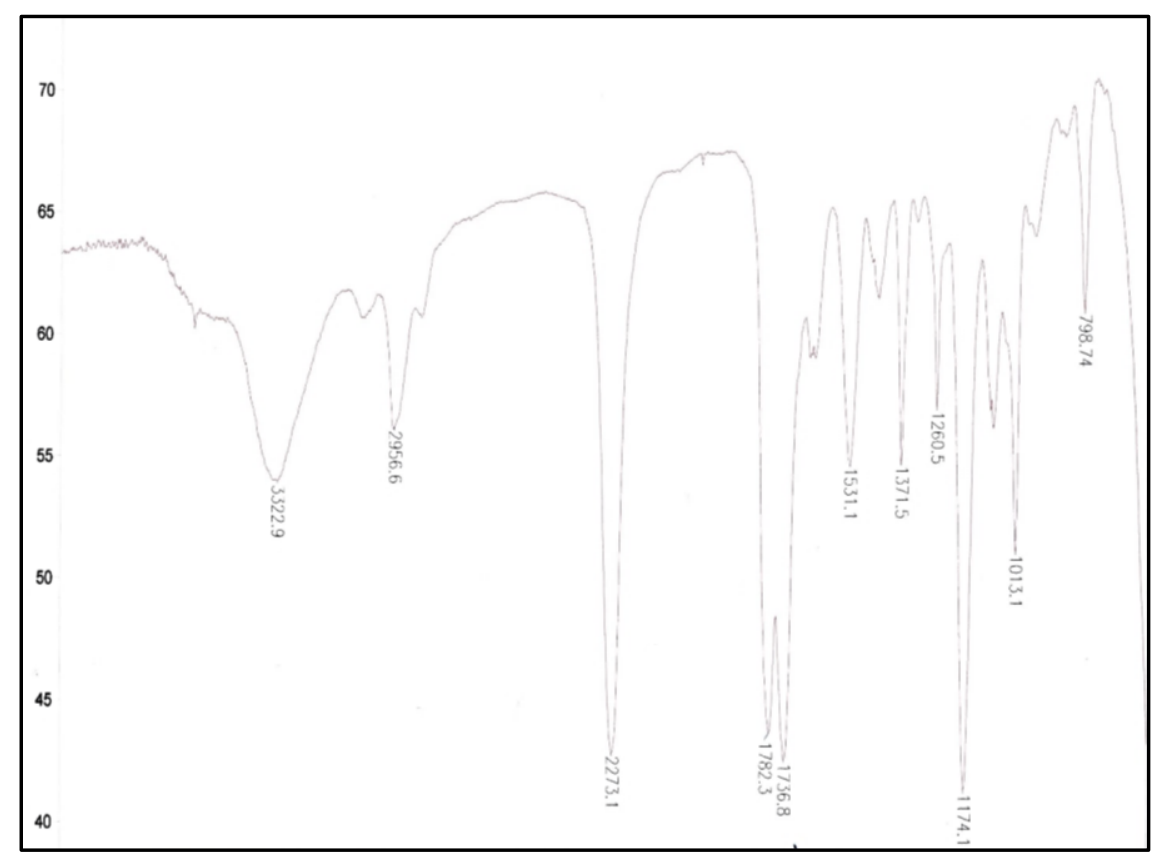

Figure III.18. IR spectrum of BDI mixture

The IR spectrum of the mixture obtained from the decomposition reaction was compared to that of BDI purchased from a commercial source.

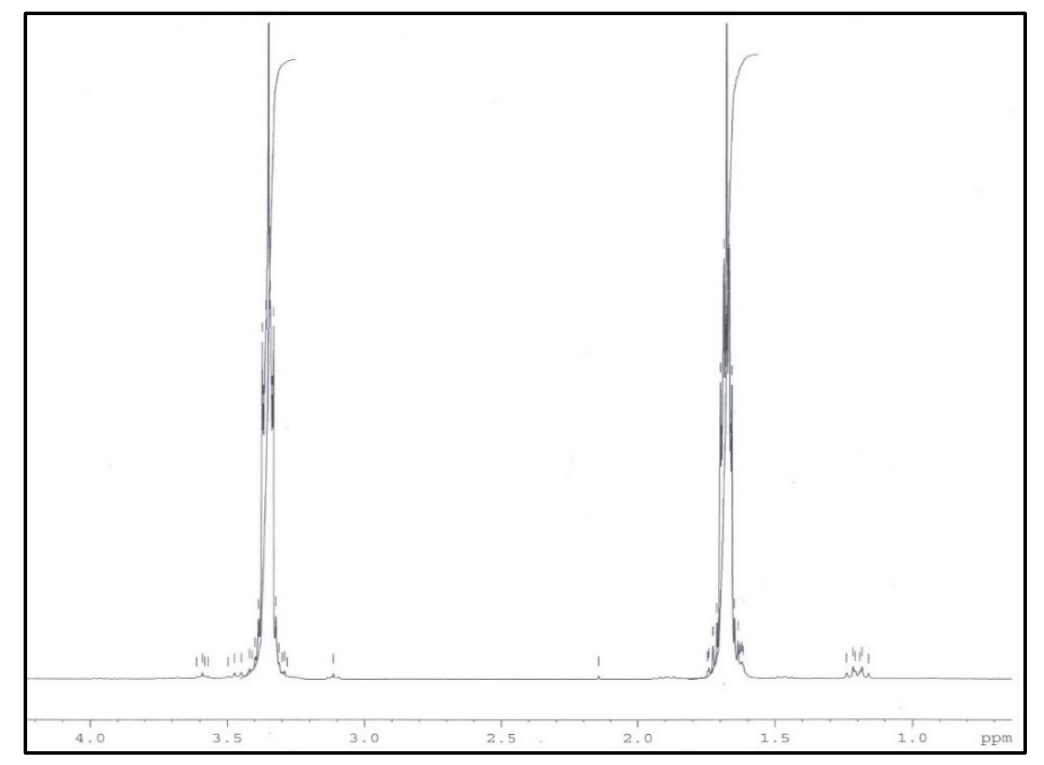

Figure III.19. ${ }^{1} \mathrm{H}$ NMR spectrum of pure BDI 


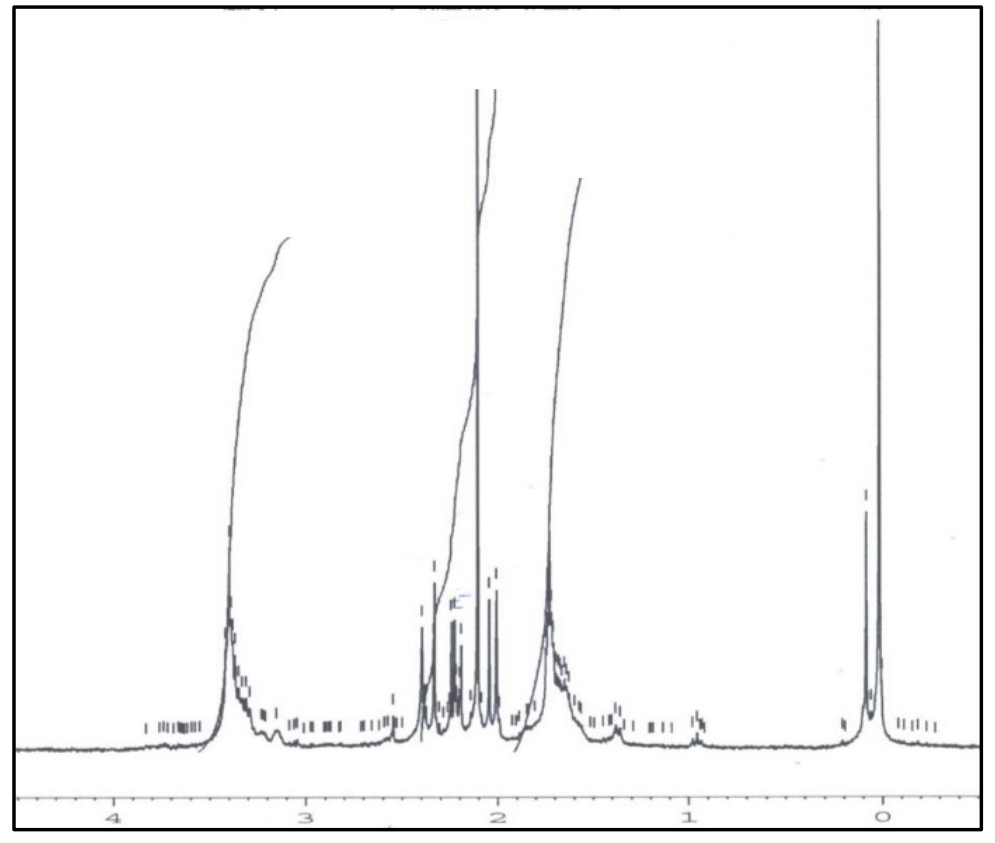

Figure III.20. ${ }^{1} \mathrm{H}$ NMR spectrum of BDI mixture

By comparing the proton NMR of pure BDI to the BDI mixture obtained through the decomposition reaction we notice the presence of two quintets at 3.36 and $1.68 \mathrm{ppm}$ (Figure III.20) each corresponding to 4 protons ( $\left.2 \mathrm{CH}_{2}-\right)$. Since the NMR was taken using chloroform-d, thus we were not able to detect the presence of the starting material (HA acetate) since it's soluble in strong polar solvents such as DMSO.

\section{III.5. Conclusion}

Unlike PPDI, following the same developed Lossen rearrangement gave low yield of aliphatic HA, aliphatic HA acetate and aliphatic isocyanate BDI. BDI was obtained through decomposition of aliphatic acetate, in a mixture along with acetic acid and some starting material (acetate). This mixture can be separated into its individual components through further 
distillation of larger scale. Pure BDI was not obtained on its own due to the condensation of the acetic acid in the same time. In addition, for future modification, the temperature of the decomposition reaction to form BDI also needs to be lowered in order to be applicable in the industry. 


\section{III.6. References}

1- Guelcher, S.; Gallagher, K.; Didier, J.; Klinedinst, D.; Doctor, J.; Goldstein, A.; Wilkes, G.; Beckman, E.; Hollinger, J. Acta Biomaterialia,2005, 1, 471-484.

2- Harald, M.; Oswald, W.; Klaus, N.; Juergen, D.; Juergen, M. DE 4413580 A1, 1995.

3- Bart, J.Cavallaro, S. Industrial \& Engineering Chemistry Research, 2015, 54, 567-576. 